University of Louisville ThinkIR: The University of Louisville's Institutional Repository

Electronic Theses and Dissertations

$5-2019$

\title{
Creating a college-going culture : accountability models and measuring institutional rigor in secondary schools.
}

Roland O'Daniel

University of Louisville

Follow this and additional works at: https://ir.library.louisville.edu/etd

Part of the Curriculum and Instruction Commons

\section{Recommended Citation}

O'Daniel, Roland, "Creating a college-going culture : accountability models and measuring institutional rigor in secondary schools." (2019). Electronic Theses and Dissertations. Paper 3155.

https://doi.org/10.18297/etd/3155

This Doctoral Dissertation is brought to you for free and open access by ThinkIR: The University of Louisville's Institutional Repository. It has been accepted for inclusion in Electronic Theses and Dissertations by an authorized administrator of ThinkIR: The University of Louisville's Institutional Repository. This title appears here courtesy of the author, who has retained all other copyrights. For more information, please contact thinkir@louisville.edu. 


\title{
CREATING A COLLEGE-GOING CULTURE: ACCOUNTABILITY MODELS AND MEASURING INSTITUTIONAL RIGOR IN SECONDARY SCHOOLS
}

\author{
By \\ Roland O'Daniel \\ B.A., University of Louisville, 1989 \\ M.A.T. Spalding University, 1997
}

\begin{abstract}
A Dissertation
Submitted to the Faculty of the

College of Education and Human Development of the University of Louisville in Partial Fulfillment of the Requirements

for the Degree of

Doctor of Philosophy

in Curriculum and Instruction

Department of Middle and Secondary Education

University of Louisville Louisville, KY
\end{abstract}

May 2019 
Copyright 2018 by Roland L. O’Daniel

All Rights Reserved 



\title{
CREATING A COLLEGE-GOING CULTURE, ACCOUNTABILITY MODELS, AND
} MEASURING INSTITUTIONAL RIGOR IN SECONDARY SCHOOLS

\author{
By \\ Roland O’Daniel \\ B.A., University of Louisville, 1989 \\ M.A.T. Spalding University, 1997 \\ A Dissertation Approved on
}

August 14, 2018

by the following Dissertation Committee:

Dissertation Director

Dr. Tom Tretter

Dr. Jenny Bay-Williams

Dr. Jacob Gross

Dr. Maggie McGatha 


\section{DEDICATION}

This dissertation is dedicated to my wife, Tamalynn, my children, Jacquelynn, Tayler, Alexandria, and Kearstin, and my mother and father, Doris and Ray. They stuck by me during this process and their support never wavered. Even when I had doubts that I would be able to complete this, they encouraged me and put up with my hours without complaint. My wife is my greatest champion and I will need to work every day for the rest of my life to make up for the support she has given me during the writing of this dissertation. 


\section{ACKNOWLEDGEMENTS}

First I want to thank each member of my committee. Dr. Tom Tretter was indispensable in reviewing and refining the articles. Without his support, I would not have been able to navigate the formatting, or research analysis language that was needed to complete this process. Drs. Maggie McGatha and Jenny Bay-Williams stood by me and provided wisdom, support, and encouragement that was needed every step of the way. I still remember the KCTM meeting where Maggie told me to get back to work and then proceeded to help me do it, thank you! Their support is and will always be greatly appreciated. The faculty in the School of Education, who taught me to appreciate research, question results, push for more evidence, and sweat the details. Your efforts are noticed and appreciated.

Finally, I would like to thank Dr. Bill Bush who has been a mentor my entire career (even during the long gaps when we weren't in contact). He influenced my early teaching career and then when I came back to get this degree was my initial advisor. Thank you for your wisdom and dedication to mathematics instruction in Kentucky. 


\title{
ABSTRACT \\ CREATING A COLLEGE-GOING CULTURE, ACCOUNTABILITY MODELS, AND MEASURING INSTITUTIONAL RIGOR IN SECONDARY SCHOOLS
}

\author{
Roland O’Daniel
}

August 14, 2018

This dissertation is an examination of approaches Kentucky high schools have taken in an effort to prepare their graduates to be college and career ready. This dissertation consists of three separate articles. The first explores Kentucky college readiness reform efforts at the secondary school level since the passing of the No Child Left Behind Act of 2002. The need for an educated population is critical to a strong economy and citizenship. Creating that educated population has been a focus for centuries but in the recent history the United States has taken a different approach. Since 2002, No Child Left Behind has directed how and on what schools have focused through high stakes accountability. As the United States moves into the next version of highstakes accountabilities there are opportunities for schools in the state to learn from previous successes and mistakes.

Kentucky has a history of reform since the 1990's and has been working to improve the level of education for its citizens. Beginning in 1990 with the Kentucky Education Reform Act and all the way through the 2015 Every Student Succeeds Act, Kentucky has striven for a well-educated workforce. The progress has been slow and often times short sighted. The first article of this dissertation will explore the changes that 
have been adopted in the education system of Kentucky and look to illustrate the impacts these decisions have had on teaching and learning in the state, with specific focus on high schools' efforts to support their students' being college and career ready..

The second article in this dissertation will examine a walkthrough process implemented in twenty-one high poverty Kentucky high schools that were part of the GEAR UP Kentucky project. The process was designed to provide feedback to schools on how they were doing in preparing their students for postsecondary as well as building a stronger college-going culture. The process contained two parts the walkthrough itself and a self-analysis all schools did to reflect on practices and policies that support rigorous instruction and expectations for all students. The results of the study indicated that school rigorous instruction ratings developed from the process correlated moderately with measures of college readiness and college success, indicating that rigor may be able to be measured in a manner feasible within the complex everyday tasks of school administrators.

The last article explores the opportunities that Kentucky schools have beginning in 2018 as the new Every Student Succeeds Act accountability system is implemented. The new policies at the federal level provide more flexibility for states define college and career readiness. Kentucky's response has been approved and provides schools and districts opportunity to create experiences for students to allow them to show what they know and are able to do, rather than just how well they do on standardized assessments. This article focuses on suggested policy recommendations for districts to consider based on the results from article 2 . 


\section{TABLE OF CONTENTS}

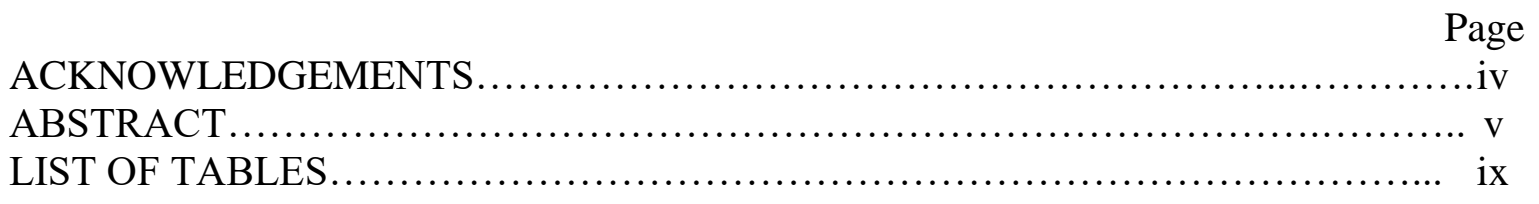

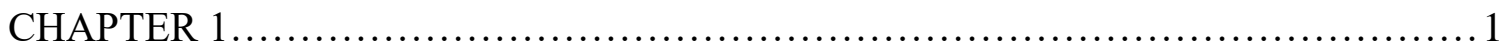

National Context............................................................. 1

Kentucky Context.......................................................... 1

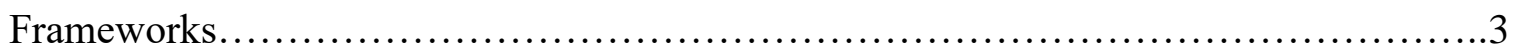

Outline of Three Articles.......................................................... 5

CHAPTER 2- INFLUENCES ON COLLEGE READINESS IN KENTUCKY AT THE BEGINNING OF THE $21^{\text {ST }}$ CENTURY ...................................... 11

Kentucky Educational Reform Act........................................... 11

No Child Left Behind........................................................... 13

Greater flexibility in allocating federal funds................................. 13

Increased options for parents...................................... 15

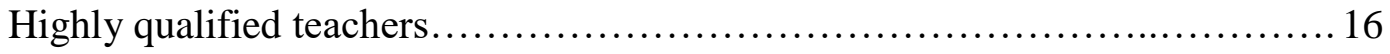

Research-based instruction................................................ 16

Need for College Readiness.............................................. 19

Recent history of education status in Kentucky.............................. 19

Education reform in Kentucky....................................... 24

College Readiness Frameworks................................................ 26

Impacts of Tightly Defined College Readiness in High-Stakes Accountability.............. 31 
Characteristics of rigorous instruction.................................. 36

Student engagement as an indicator of rigor............................ 38

Institutional indicators of college readiness .............................. 39

GEAR UP ......................................................... 45

Methods........................................................................ 46

Sample..........................................................46

Walkthrough process - classroom observations and school self-report....... 46

Input measures................................................. 48

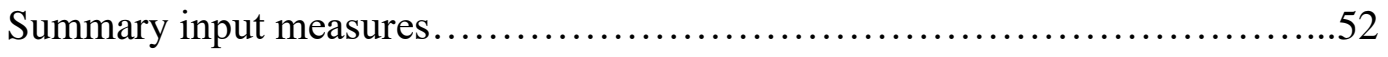

Moderator Variable.....................................................53

Outcome Measures.................................................... 54

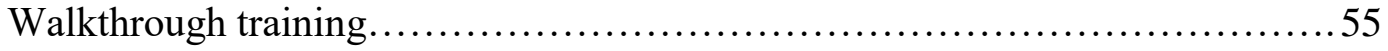

Analysis............................................................ 55

Norming item analysis............................................ 58

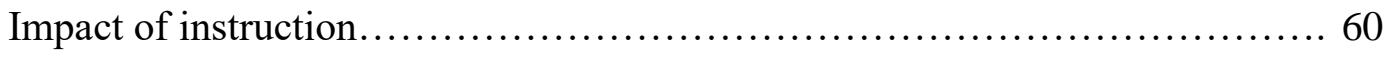

Results ...............................................................61

Establishing equivalence of reduced item and normed scales.................61

Inter-content analysis............................................ 65

Outcome Analysis.................................................. 68

Walkthrough data comparison with outcome measures.................... 70

Analysis of input data by content and content section....................... 71

Analysis of the school performance guide for a college-going culture...........73 


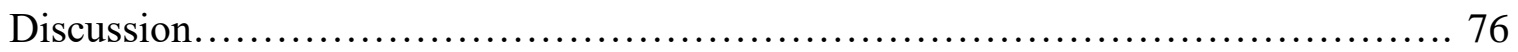

Implications for School Performance Guide Results.........................77

Implications from the Walkthrough Process...................................78

Overall Score Implications............................................. 80

CHAPTER 4- EVERY STUDENT SUCCEEDS IS MORE THAN AN ACT..............83

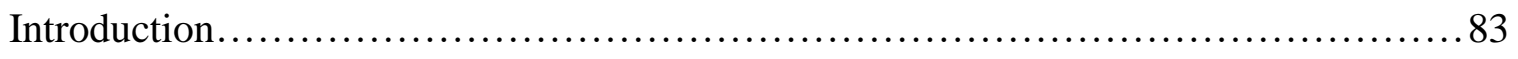

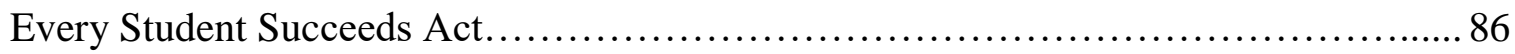

Assessing local standards.............................................. 91

Opportunities for dual enrollment........................................ 95

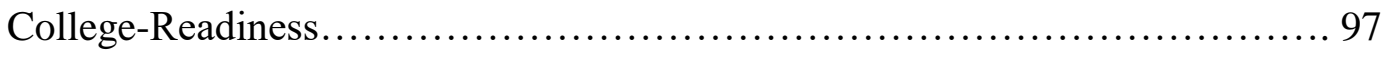

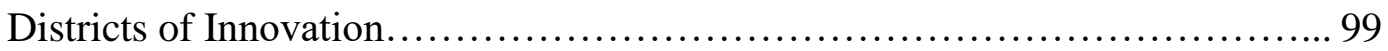

Alignment of Instructional Practice........................................ 101

Postsecondary skills development.................................. 103

Looking beyond math and reading................................ 107

Gifted education................................................ 107

Career-Readiness....................................................... 108

Low-Performing Schools............................................. 110

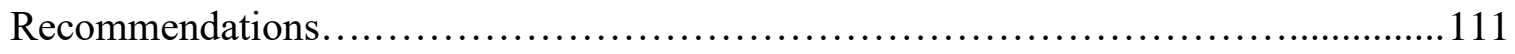

Systemic Approaches to Instruction.................................... 112

Rigor, Relevance, Differentiation Framework...............................112

Systemizing high expectations over longer time-frames............... 114

School Performance Guide.......................................... 115

Focus Beyond Data Analysis........................................... 115 
Models for Leaders

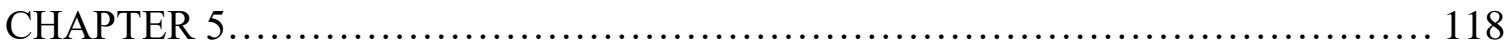

REFERENCES ......................................................... 124

APPENDIX A Walkthrough Observation Instruments............................ 145

APPENDIX B School Performance Guide for a College-going Culture................. 151

APPENDIX C Walkthrough Content Scores with Normalized Scores for each subsection (ACT Standards, Common Core Instructional Shifts, and Rigor, Relevance, and

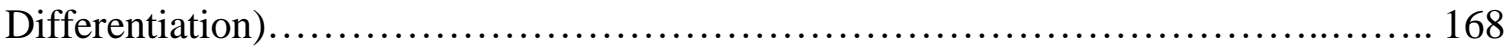

APPENDIX D Dictionary of Terms...................................... 174

CURRICULUM VITA...................................................... 177 


\section{LIST OF TABLES}

TABLE

PAGE

1. Kentucky benchmark scores on the ACT compared to national scores.................32

2. Percent of students making college readiness benchmarks in Kentucky...............32

3. Core components of high school reform models............................... 40

4. ACT college readiness standards for classroom instructions documented during classroom observation............................................... 49

5. Recommended common core instructional shifts documented during classroom

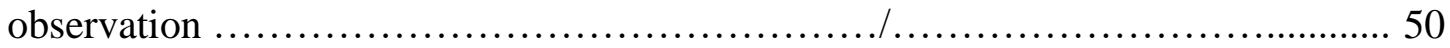

6. Rigor, relevance, and differentiation indicators documented during classroom

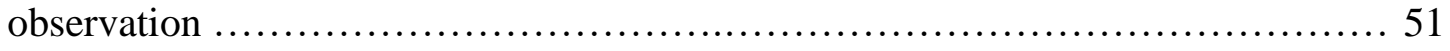

7. School performance guide indicators included in school self-report about college-

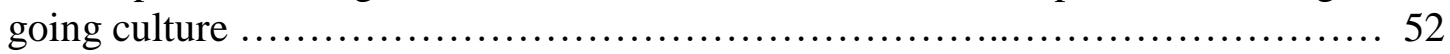

8. Summary of college-ready rigorous instruction input measures for this study........ 53

9. Outcome measures of postsecondary success............................. 54

10. Sample item score calculation for mathematics in one high school $\ldots \ldots \ldots \ldots \ldots \ldots . .56$

11. Walkthrough content and subscores with all indicators included $\ldots \ldots \ldots \ldots \ldots \ldots \ldots . \ldots 6$

12. Select classroom observation items with greater than $10 \%$ frequency and less than

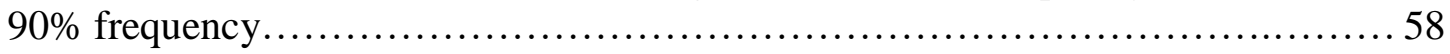

13. Sample unnormed scoring for all four content areas for a high school ...............59

14. Sample normed scoring for all four content areas for same high school in table $13 \ldots . .59$

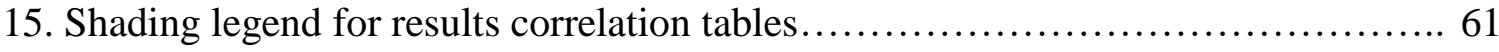


16. English normed section and overall English scores Pearson product-moment correlation coefficients

17. Social studies normed section and overall social studies scores Pearson productmoment correlation coefficients.

18. Science normed section and overall science scores Pearson product-moment correlation coefficients

19. Math normed section and overall math scores Pearson product-moment correlation coefficients

20. Walkthrough overall score analysis

21. Walkthrough content score inter-correlations

22. Walkthrough content act standards subscores with overall act standards score intercorrelations

23. Walkthrough content common core instructional shifts subscores with overall cc score inter-correlations

24. Walkthrough content rigor, relevance, and differentiation subscores with overall RRD score inter-correlations

25. Pearson product-moment correlation coefficients between the selected outcome measures

26. Input measures scores compared to outcome measures

27. Content subscore and content section Pearson product-moment correlation coefficients with outcome data....

28. School performance guide section correlation comparisons.

29. Normed school performance guide for a college-going culture Pearson productmoment correlation coefficients with outcome measures

30. Overall school performance guide without accountability subscore compared to outcome measures.

31. Walkthrough and spg scores combined for overall process score compared to outcome measures.

32. Grade 4 mathematics proficiency and below proficiency scores on NAEP and KPREP with ESSA projections for 2030 . 
33. Grade 8 mathematics proficiency and below proficiency scores on NAEP and KPREP

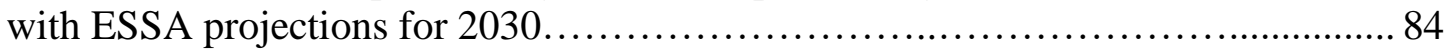

34. Grade 4 reading proficiency and below proficiency scores on NAEP and KPREP with ESSA projections for 2030

35. Grade 8 reading proficiency and below proficiency scores on NAEP and KPREP with

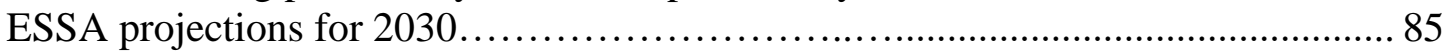

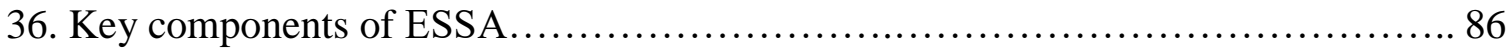

37. Kentucky's ESSA accountability system components............................ 89

38. Peer reviewer feedback on Kentucky's ESSA plan............................ 91

39. Comparison between quality core and common core algebra II standards............ 92

40. Pearson product-moment correlation coefficients between college readiness indicators and college success indicators in 21 high-poverty high schools................... 98

41. Conley's college readiness skills ......................................... 103

42. Kentucky's high school transition readiness indicators for career readiness........ 109

C1. Walkthrough content scores with normalized scores for each subsection (ACT standards, common core instructional shifts, and RRD)....................... 168

C2. Walkthrough content scores with scores for each analysis (TOT_**_all-all items, TOT_**_10-below 10\%/above 90\% removed, TOT_**_norm- subscale normed from

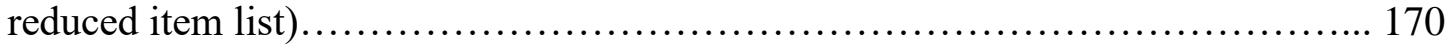

C3. Variable abbreviations, names, descriptions 


\section{LIST OF FIGURES}

TABLE

PAGE

1. Number of AP math, science, English qualifying score per 1,000 juniors and seniors ............................................................ 106 


\section{CHAPTER 1}

\section{National Context}

The regulations that accompanied the No Child Left Behind (NCLB) law that was passed in 2002 changed how the federal government regulated public education. The law increased efforts to hold schools accountable for educating all students with a multifaceted approach with standardized testing at the center of the approach. There were other significant changes that came with NCLB.

Current achievement data for American education continues to show stagnation or regression on international assessments like National Assessment of Education Progress (NAEP) and the Program for International Student Assessment (PISA) (Desilver, 2017). If the United States is going to continue to be a source of innovation and economic power, ensuring that all students have access to the kind of instruction that prepares them for postsecondary success is critical. Currently there is a large gap between students of means and students of poverty (Burney \& Beilke, 2008; Payne, 2005; Simon \& Johnson, 2015). If America is going to meet the challenges outlined in the American Innovation and Competitiveness Act ("AICA") (2017) then it is imperative that we address the growing gap in student learning.

\section{Kentucky Context}

As Kentucky entered the 21st Century, the population was not prepared for the shifting focus of an economy centered on information and not manufacturing. The call for 
increased college readiness to address the demands of future jobs pushed the education system into a new era. Along with changing expectations, came new federal demands to make sure that all students were prepared for success after graduation. At the time of Kentucky's initial foray into education reform in the early 1990's, Kentucky ranked at the bottom of having an educated workforce. In fact a decade after Gov. Paul Patton's 1995 call for increasing educational attainment for all of the commonwealth's citizens, Kentucky still ranked 49th for an adult population with a high school diploma.

The first article explores the premise of the NCLB law and reviews how implementation of the law impacted Kentucky students, teachers, and schools. Along with the changes in federal regulations came an increase in the expectations that more Kentuckians would be ready for and apply to and enter college. As Kentucky was implementing NCLB and tracking college readiness as part of the education accountability system, it was becoming obvious that many students who entered college did not have the skills necessary to be successful in attaining a degree.

With changing demands of the economy and jobs, it is imperative that students have the skills necessary to be able to obtain additional degrees and certification. Even manufacturing jobs come with demands to be able to operate in more complex factory settings (Carnevale, Rose, \& Cheah, 2013). In 1995 Kentucky's Economy ranked 41st in Gross State Product. Kentucky's high rural population was impacted even more because not only did these Kentuckians lack the training, they lacked any opportunity. In Forbe's 2014 rankings of America's fastest growing cities, they cite the presence of a highly educated workforce as one of the keys to attracting high paying technology companies (Carlyle, 2014). In order for Kentucky to remain competitive it was important that the 
workforce be prepared. Kentucky's 49th ranked adult education population was not going to lure the kinds of jobs Kentucky needed to change the dynamic. The high percentage of adults without an education contributed to a cycle of poverty, also known as generational poverty, and Kentucky's college-going population was more than 50\% first generation. Even with academic preparedness, this population of students faces dim chances of graduating with a college degree. All of this contributed to a large portion of Kentucky's population not being prepared for the rigors of the new economy.

It is a unique time for schools in Kentucky as lessons learned from our past can now inform the new systems that we put in place to create a population that is ready to lead Kentucky well into the $21^{\text {st }}$ century.

\section{Frameworks}

In addition to meeting new workforce demands, providing students an effective educational experience has been the target of study for centuries from Socrates to Dewey. Research continues to inform effective instructional practices (National Research Council [NRC], 2013a; [NRC], 2013b; Zierer and Hattie, 2017). These practices along with new Common Core National Standards provide expectations for learning as well as tested methods for teaching the content at the appropriate levels of learning. Identifying the different levels of learning has been a building process. Bloom (1956) identified his taxonomy of educational objectives. Webb furthered Bloom taxonomy by identifying the different depths of knowledge that content can be taught at (Webb, 2002). About the same time as Webb, Bill Daggett created the Rigor, Relevance Framework which also attempted to examine curriculum, instruction, and assessment along the two dimensions of higher standards and student achievement (2018). Each of these frameworks provide 
insights into expectations for students that teachers must consider when teaching a course. Finally, Charlotte Danielson created the Framework for Teaching (2017) that was adopted by Kentucky as part of the instructional expectations for teachers as part of the Professional Growth and Evaluation System (PGES). Even though PGES has evolved since its inception, Danielson's framework has provided guidance for teachers across the state.

The instruments designed for the GEAR UP Walkthrough Processes used college readiness framework research from David Conley, Bill Tierney, and ACT as foundational components. In addition the instruments used Kentucky's modified version of Charlotte Danielson's Framework for Teaching, instructional standards from the Kentucky Academic Standards, and Bill Daggett's Rigor/Relevance Framework to look at effective instruction. Because the project incorporated increased success on the ACT, presence of the ACT College Readiness standards were incorporated as part of the expectation that teachers engaged in standards-based instruction. The second instrument was the School Performance Guide for a College Going Culture Self-Assessment. It was written around the 5 Key Attributes of the GEAR UP State Project (Aspiration, Rigor, Expectations, Accountability, and Sustainability) integrating the characteristics of the college readiness research as well as research of effective schools. The second article will further discuss the development of this instrument as well as the design of the walkthrough process in order to establish both content and predictive validity.

The frameworks that influenced the School Performance Guide (SPG) provide a wide range of expectations for classroom instruction and school policies and procedures. The first framework is Conley's Four Key's to College Readiness: habits of mind, 
academic knowledge and skills, academic behaviors, and contextual knowledge. William Tierney's work takes the efforts into an analysis of existing frameworks and explores not just individual student preparedness for college but what states, districts, and schools can do to build a culture of college readiness, and in his work with Corwin (2007), he outlines specific school policies and characteristics that schools can implement to prepare the entire student population for college success. In 2014 ACT outlined ACT's multidimensional college readiness framework in an attempt to identify a more 'holistic' approach to college readiness (Mattern et al., 2014). This framework confirms and even builds on Conley's efforts.

It is important in this work to distinguish the connection between and difference between college readiness and college success. College readiness is measured prior to college enrollment and provides evidence that this student is prepared to enroll in and be successful in college level courses. College success on the other hand is the outcome of attending college and completing a program of study. Not all students who are college ready will be successful graduates and there will be students who graduate from college who were not deemed college ready upon graduating high school. When dealing with high schools, it is important to realize the goal is that all students who wish to go to college would be successful, but schools cannot know that when students graduate high school. Therefore it is important that schools do everything in their power to identify and define college readiness so they are providing students the most information possible.

\section{Outline of the Three Articles}

The set of three articles that comprise this dissertation target the current efforts and underlying pressures in which high schools are implementing to ensure their students 
are college and career ready (article 1), then empirically explores process and measurement tools that administrators could use to capture relevant aspects of their school in support of this effort (article 2), and finally offers policy recommendations and suggestions as we move into a new era of federal accountability (article 3).

The first article in this dissertation then explored different frameworks for college readiness and identified the different components that are necessary for students to persevere in attending college and receiving a degree. The article looks at multiple frameworks including David Conley's Four Dimensions, William Tierney's, ACT's, and NCLB. The article compares the frameworks for consistencies and discusses the issues facing Kentucky schools as they attempt to apply these components in a system geared toward test accountability.

The second article of this dissertation is an analysis of two processes coupled to provide context into how well schools are preparing students for college level learning. The first process, the walkthrough process, is designed to identify rigorous instruction that prepares students for postsecondary success. The second process is a self-report process designed to help schools identify if they have policies and practices in place to prepare all students for college success. The article describes the framework created to measure institutional rigor. The walkthrough gathered data on the intentional presence of ACT College Readiness Indicators in instruction. In addition observers gathered data on the instructional shifts that are part of the expectations of the Common Core Standards. The shifts are divided into two categories; the literacy anchor standards and the mathematical practice standards. These shifts provide guidance for actively engaging students with content through student-centered practices. The final component of the 
walkthrough process is the rigor and relevance of instruction. The indicators were designed using Bill Daggett's Rigor/Relevance Framework. They provided data about the level of thinking students were expected to perform as part of the lesson as well as data about the classroom expectations.

As part of the walkthrough process, schools used the SPG to perform a selfanalysis of school level practices identified as contributing to building a college-going school culture.

The article uses three types of measures to analyze college readiness/success at the school level. The process uses two types of measures of college readiness:

- Internal- high school grade point average, percent of students going to college

- External-ACT composite and content averages, Kentucky College Readiness Index

In addition two measures of college success are included in the outcome measures:

- Percent of students earning 30 hours and percent of students showing up for their sophomore year.

Both of these measures provide insights into how graduates are progressing towards graduation in a timely manner. Finally, the demographic measure (percent of students qualifying for free/reduced lunch status) was included to provide insights into how well schools are preparing all students for college success.

The study uses a Pearson product-moment correlational analysis of the walkthrough data and self-analysis and outcome measures. The article establishes theoretical and predictive validity. Outcome measures were identified through the Kentucky Center for Workforce Statistics and included school level: ACT percent 
making benchmark in each content area, percent of students certified college ready by Kentucky's multifaceted process, high school grade point average, percent of students earning 30 hours their freshman year, and percent of students starting their sophomore year as scheduled (whether they were sophomore status or not). The analysis yields data that indicated moderate and some strong correlations between the walkthrough data and several of the key outcome measures including the college success measure; percent of students that start their sophomore year as expected. The analysis creates a potential for identifying institutional rigor in a manner feasible for school-level administrators to administer. The results provide evidence that incorporating appropriate instructional practices that support higher level learning expectations do provide students with greater opportunity to be successful in college.

The third article adopts a policy perspective to inform stakeholders how they might incorporate key results from the research in article 2 into their practice. With the passing of the Every Student Succeeds Act in 2015, a new era of accountability was established. States were tasked with creating new accountability systems for each state. In Kentucky the new system continues to have a testing focus but also provides schools and school districts opportunity to change the way they approach college and career readiness. Given the new system, the final article will look at how schools in Kentucky can further the goals of preparing students for postsecondary success given what we know since the inception of NCLB, high stakes assessments, and the needs of highpoverty students as they attempt to enter college to attain a degree or prepare to enter to workforce. The third article explores promising practices as well as innovative models in Kentucky that provide models for other districts in the state to consider or replicate. The 
new system no longer focuses on the ACT or outside workforce readiness assessments and provides opportunity for students to show their preparation through hands-on experiences, especially in the area of career readiness. The new system also rewards schools for creating innovative approaches to meet not only the employment demands of their community but the interests of their students. With the shift away from the ACT as a primary indicator of college readiness the state is also allowing students to showcase their college readiness through alternative means, including success in dual credit and Advanced Placement type courses. The article will explore the opportunities for students as well as provide guidance for schools as they begin navigating the new system.

The third article in the dissertation summarized lessons learned in Kentucky as a new accountability system is implemented. The article will explore recommendations for implementing practices and policies that prepare Kentucky students to be successful as they strive to enter college and attain a degree. The article will identify practices that schools can and do implement and provide gauges for determining the efficacy of those practices.

Kentucky has been working diligently to improve education opportunities for its children for well over two decades. The three articles that make up this dissertation address Kentucky's recent efforts to ensure quality and equitable outcomes for its students, investigates feasible school-level approach to planning and evaluating schoollevel approaches to building rigorous instruction to meet the demands of reform, and highlights promising approaches Kentucky schools can implement in support of their students. Kentucky has shown the willingness to design well thought out approaches to reform since the Kentucky Education Reform Act of 1990 was passed and now have 
opportunity to show the nation Kentucky's commitment to the future. 


\section{CHAPTER 2}

\section{INFLUENCES ON COLLEGE READINESS IN KENTUCKY AT THE BEGINNING OF THE $21^{\text {ST }}$ CENTURY}

Concerns and questions about college readiness of our K-12 graduates continue to increase in prominence in today's world. Before exploring the context of college readiness, this manuscript will outline a primary precursor that established context, expectations, and policies that continue to impact the education world's perspective on college readiness; this precursor is No Child Left Behind (NCLB). After reviewing the impact of this policy on schools, we will discuss the need for college readiness in Kentucky and then the different college readiness frameworks that inform design of preparation in Kentucky school districts.

\section{Kentucky Educational Reform Act}

The Kentucky Educational Reform Act (KERA) was passed in 1990. KERA was introduced as a response to a Kentucky Supreme Court ruling declaring the state's schools were inefficient and inequitable (Education in Kentucky, N.D.). KERA was considered the most sweeping of any education reform bill in the United States at the time of its passing (Goetz \& Debertin, 1996). KERA was a legislative response to the court ruling through providing a reorganization of how money was spent in the Kentucky education system and not the amount spent. The result was a complete restructuring of how Kentucky's schools work including reallocation of authority. 
revamped state testing, and school governance (Day \& Ewalt, 2013). There were six goals of the act, to ensure that students were able to:

- use basic communication and mathematics skills for purposes and situations they will encounter throughout their lives.

- develop their abilities to apply core concepts and principles

- develop their abilities to become self-sufficient individuals.

- develop their abilities to become responsible members of a family, work group, and community

- develop their abilities to think and solve problems

- develop their abilities to connect and integrate experiences.

(Kentucky Educational Reform Act, 2018)

To achieve the six goals, key components of the reform act were implemented including;

- Ungraded or multiage/multi-ability primary program

- School based decision making councils that returned control back to the school community

- Implementation of Kentucky Instructional Results Information System, a statewide assessment testing to provide a complete picture of a student's performance. The initial assessment system focused on open-ended questions, portfolios, and performance assessments in order to ensure that instruction was rigorous enough to achieve the lofty goals outlined in KERA (Catterall, Mehrens et al. 1998). KERA was initiated because of a Kentucky Supreme Court ruling, but the legislation was the first of 
many audacious responses from the state to move from the $49^{\text {th }}$ ranked state in terms of education to a leader, and sets the stage for reform in the state moving forward. .

\section{No Child Left Behind}

In 2001 George W. Bush worked with overwhelming support from congress to pass the No Child Left Behind (NCLB) bill into law on January 8, 2002. NCLB was the latest installment of the Elementary and Secondary Education Act of 1965, which provided federal support for education. NCLB significantly increased the expectations that the federal government had in holding states and schools responsible for educating all students, especially English-language learners, special education students, and poor and minority students (McGuinn, 2006). Included in NCLB was the expectation that all students would perform at the proficient level within the next decade. This ushered in the era of high-stakes accountability for schools (Simpson, Lacava et al. 2004). An increase in funding accompanied these increased expectations for learning. The increased emphasis on student success was also accompanied by a rewards and punishments component, with the most stringent punishment being closing of schools and removal of administration and staff. NCLB shifted the role of the federal government from support to states and schools to fiscal restraints as a result of assessment scores for both (Hardman \& Mulder, 2003). NCLB ushered in extensive changes in the status quo for state and local education agencies as well as the era of high stakes accountability in United States education.

\section{Greater flexibility in allocating federal funds}

Part of the process to get support for NCLB was the capacity for schools to react in innovative ways to the new expectations. This capacity was establishing more lenient 
ways schools and districts could spend federal dollars (U.S. Department of Education, 2012). As part of NCLB, states were also promised increases in federal funding for school improvement (U.S. Department of Education 2005a, 2010). By 2005 funding for the Education Department had increased by $\$ 10$ billion, part of which was an increase in Title 1 funds by 52\% (U.S. Department of Education, 2005b).

Ability to use these Title I Grant funds with greater adaptability was a key driver of NCLB. The bill reduced the number of grant programs and gave larger bulk grants to schools. The goal of this design was to reduce the administration of the grants and allow schools to use the money as they needed (Bush, 2001). Multiple studies early in the implementation of the NCLB program indicated that the additional monies allocated to improve the education system did not fully fund the mandates (Imazeki \& Reschovsky, 2004; Sunderman \& Orfield, 2006). The lack of funding left states like Kentucky to try to positively impact classroom instruction and institute response to intervention programs to reduce the number of students at the novice level, without professional supports that included sufficient intensity and duration (The National Center for Fair and Open Testing, 2018).

Additional federal resources were limited to the first year but were accompanied by major new requirements, meaning ultimately that funds had to be shifted from one area to another to try to achieve the goals of the project (Darling-Hammond et al, 2007). Joining funding with accountability caused states to make decisions that were focused on avoiding penalties rather than achieving the grand goals of the program (Sunderman \& Orfield, 2006). Tying the increased flexibility of spending to accountability was a controversial aspect of the law. Some states rights advocates saw this as an overreach of 
federal powers and a ruse to increase federal oversight of states' rights (NY Times 2013;

US News and World Report 2011; Redalevige 2005).

\section{Increased options for parents}

NCLB also called for increased options for parents whose students attended lower performing schools (Great Schools, 2016; Bush, 2001). The goal was to allow parents of students in these underperforming schools to send their children to other schools in the district or to allow them to go to charter schools. According to the National Charter School Resource Center, charter schools are public schools operating under a contract with an authorizing agency determined by each state. Charters allow for greater decision making by the school itself in regards to curriculum, personnel, and budget. Students almost exclusively attend charter schools by the choice of their parents or guardians rather than by assignment to a school district (NCSRC, 2018).

Before 2017 in Kentucky this aspect of NCLB was less than efficacious for multiple reasons. In Kentucky's school districts $87 \%$ have only one high school and $75 \%$ have only one middle school to choose from, and $48 \%$ of the districts with more than one option through $8^{\text {th }}$ grade feed into the same high school (KDE, 2017). In addition, $48 \%$ of the districts that have multiple options for middle grade students are classified at Rural and Low-Income Schools (RLIS) creating transportation problems for any parents wishing to put their students in a different school (U.S. Department of Education, 2017; Burns, 2011). Finally, through 2017 there was no charter school option. In spring of 2017, the Kentucky General Assembly passed HB 520 which legalized charter schools in Kentucky for the first time (Maxwell, 2017). If a school was low performing in

Kentucky parents had very few options for alternatives. Even though research indicates 
that rural schools do not always meet college preparation standards these parents were not provided equal opportunity for alternatives (Reid \&Moore, 2008; Strange et al, 2012).

\section{Highly qualified teachers}

Another significant focus of NCLB was the expectation that all teachers be highly qualified to teach in their respective content area. This component was based on extensive research that highly qualified teachers had stronger impacts on their students' learning (Ehrenberg \& Brewer, 1994; Darling-Hammond, 2000; Darling-Hammond \& Youngs, 2002). Darling-Hammond noted that in 2003 an already depleted teaching cadre would be negatively impacted by the immediate expectations that all teachers be highly qualified (Simpson et al, 2004). Kentucky implemented the highly-qualified aspect of NCLB and has across the state increased the certification of teachers to meet the definitions. As of 2014, the KDE reports that $99.7 \%$ of courses taught in Kentucky are taught by a highly certified teacher (Highly Qualified Teacher Report, 2015).

The impact of this aspect of NCLB has been debated by some states, especially those with high rural populations. For instance in Louisiana, one of the ten most rural states in the country, administrators argued that long-term less qualified teachers who were committed to teaching the population were often more effective than more highly qualified teachers. Additionally turnover in these schools by more highly qualified teachers often created situations where students were taught by long-term substitute teachers who were even less qualified (Eppley, 2009).

\section{Research-based instruction}

Instructional practices were also addressed in NCLB as Scientifically ResearchBased instructional practices were expected to be employed as the routine in classroom 
instruction. This policy established the Institute for Educational Sciences (IES) and the What Works Clearinghouse (WWC). WWC has become an important tool for educational research in America since its inception. WWC provides educators access to practices that meet specific research design standards in order to understand potential impacts of implementing the strategies. Federally funded research strives to meet WWC standards in order for findings to be shared more widely. The WWC uses established standard criteria for determining if a product or strategy can or will be listed on the site, providing educators with a clearer understanding of the efficacy of any practice or program (Clearinghouse, 2014).

The gold standard places an emphasis on randomized control trials (RCTs) which are more generalizable and are better at predicting causality than quasi-experimental designs when finding similar results (Angrist, 2003). RCTs can be problematic in k-12 academic settings (Smeyers, 2006). Goldstein and Blatchford (1998) reported a lack of within school independence that impacts generalizability of findings. A major component of RCTs is the double blind aspect in which those administering and receiving the treatments are not aware who is receiving the treatment or control (Rowe \& Oltmann, 2016). Because in education it is virtually impossible to keep the treatment from the teacher who is implementing, educator bias comes into play (Goldstein \& Blatchford, 1998). Because schools are mandated to provide students with interventions to address learning needs, they are hesitant to wait for research to get funded and then to learn that they will not receive the treatment. That often puts them at a disadvantage for meeting their responsibility and potentially impacts which schools or districts are willing to go through the randomization practice, calling into question the impact of RCTs (Morrison, 
2001). The quasi-experimental design does not meet the What Works Clearinghouse Recommendation without Reservations but can meet the Recommendation with Reservations criteria. These ratings have provided structure for inquiry but it has also narrowed the kinds of research that can be accomplished (Simpson, Lacava et al. 2004).

Research-based instruction provides starting points for teachers to implement but changes to instruction take intentional planning and time. For teachers to effectively integrate new instructional practices effectively and with fidelity professional learning activities need specific characteristics, including; active engagement, job-embedded with on-going support, reflection and feedback, and prolonged interactions (Forward, Killion, \& Crow, 2011; Penuel, Fishman et al., 2007; Desimone, Porter et al., 2002). Some research indicates that teachers need minimally $49+$ hours of professional learning activities spread out across at least a year of implementation and up to three years for optimal implementation (Johnson 2009; Croft, Coggshall et al., 2010). Additionally, effective professional learning supports teachers implementing new interventions so that the interventions are implemented with fidelity (O'Donnell, 2008). Without fidelity difficult and important characteristics of interventions may not be included in teacher practice.

Kentucky incurred reductions in the state budget routinely following the 2001 economic bubble and the 2007 Great Recession (Commonwealth of Kentucky, 2009). Deficits in state budgets caused reductions in funding to school districts from both the state and federal levels. These reductions negatively impacted the ways districts were able to respond to teacher professional learning needs. The Prichard Committee noted in 2013 that the State Funding Budget for Teacher’s Professional Growth in 2007 was $\$ 23.4$ 
million dollars but had dropped to $\$ 10.6$ million by 2013 (Prichard, 2012). This reduction of funding for professional learning opportunities coincided with implementation of Common Core State Standards (CCSS). Kentucky’s 2009 Senate Bill 1 mandated the adoption of new more rigorous, internationally competitive academic standards. On February 10, 2010 Kentucky was the first state to adopt the National Governors Association and the Council of Chief State School Officers Common Core State Standards initiative (KDE, 2015).

The new academic standards were considered an improvement over the Core Content standards that were in place beforehand. The Thomas B. Fordham Institute analyzed the new standards and rated them with an A- in mathematics compared to a D for the previous Core Content Standards. In English the Institute rated the new CCSS with a $\mathrm{B}+$ while the previous version was again rated a $\mathrm{D}$ (KDE, 2014).

\section{Need for College Readiness}

\section{Recent history of education status in Kentucky}

In Governor Paul Patton's 1995 Inaugural Address, he recognized the need for a strong education system in order to move Kentucky forward in the developing new economy.

"Only our institutions of higher education can equip our people with the knowledge and skills which will make us productive in this new economy..." Gov.

Paul Patton, Inaugural Address, December 12, 1995

Kentucky has for years languished at the bottom of education attainment data in the United States, and this change would not occur overnight. Bauer, Schweitzer, and Shane (2006) paint a poor picture in regards to Kentucky's Gross State Product per capita 
with Kentucky ranking 41st in Gross State Product (GSP) per capita with \$32,943. Kentucky's GSP per capita growth from 1997 to 2004 ranked 43rd with an average annual growth of 1.6 percent. In 2005, a decade after Patton's call, Kentucky ranked 49th in the percent of the adult population with a high school diploma (Sanford \& Troske, 2007). In order to pursue college, vocational career, or military career, students need a general set of postsecondary skills, including proficient reading and math knowledge and skills (ACT, 2011).

Career readiness in Kentucky continues to shift to an increased need for postsecondary attainment. Kentucky's Cabinet for Workforce Development predicts an increase to $32 \%$ of all new jobs requiring a postsecondary degree by 2024 (Statistics, 2016). Additionally, those occupations requiring only a high school diploma or equivalent or less than high school are expected to continue to decline indicating a shift toward occupations requiring an increasing amount of education (Carnevale \& Smith, 2013). Even jobs that do not require postsecondary attainment for entry level positions will increasingly require technical training for advancement. More importantly the earnings gap between those with postsecondary education and those without will continue to worsen. High earning jobs with the fastest growth rate are all predicted to be engineering jobs that require minimally a bachelor's degree (Cunningham, 2017). However, in 2009 Kentucky ranked 47th in percent of population with bachelor's degree, and $45 \%$ of Kentucky students require remedial courses when they choose to enter college (Statistics 2016a; Timmell, 2014). In 2007, the Council on Postsecondary Education set the goal of doubling the number of college graduates with either a bachelors or associates by 2020 . 
Preparing a population for the requirements of the new economy can be difficult given Kentucky's high levels of poverty. There is often little difference noted between different types of poverty; including situational poverty, working-class poverty, and generational poverty (Beegle, 2003). Situational poverty is a period of poverty caused by an event. The event might be divorce, death of a family member, illness, or loss of a job, but people in this category often have a different set of knowledge and skills than a population with a more prolonged experience with poverty (Payne, 2005). Generational poverty is defined as a person or family having lived in poverty for at least two generations. Research indicates that offspring often inherit their parent's socioeconomic status (Bowles and Gintis, 2002; Gofen, 2009). Given Kentucky's long history of poverty and lack of educational attainment, many of Kentucky's population languish in this latter class of generational poverty. As these students progress through the K-12 education system they believed that outsiders perceived poverty to be their fault. These students often face physical, emotional, sociological, and economic barriers to education at all stages of their lives (Beegle, 2003; Howley, Howley et al., 2006). Howley also noted that schools often either ignored or demonized students of poverty causing alienation of parents and students alike. In Kentucky this is especially troubling in Appalachia and the South Central areas due to cultural norms that cause inhabitants to be skeptical of outside people and influences (Phillips, 2015).

Graduating seniors in Kentucky graduating after 2010 faced hardships that result from the state's high rural population and lack of history of education. During this same period close to a twenty percent of Kentucky's population lived at or below the poverty level ranking Kentucky 45th in poverty nationally (Bishaw \& Benson, 2017). Eighty-five 
of one hundred and twenty counties are classified as rural by the department of agriculture, and face additional hurdles in economic development (Davis, 2009). In her economic report Davis identifies two parts of Kentucky's economy, the urban areas and the lagging rural areas. Whatever the factors that contribute to the lack of education and economic attainment, there are clear delineations between different sections of Kentucky. Appalachia and South Central have the highest percentage of poverty followed by Western Kentucky and then Central Kentucky. These poverty numbers also roughly follow educational attainment data (Davis, 2009).

There are several factors that cause rural status to negatively influence college readiness. Reid and Moore (2008) identify four such factors: poor preparation at inferior secondary schools; less assistance from family who do not know the (education) process; lower expectations for course selection from school and family; and selection of less selective institutions based on proximity and price rather than academic fit.

In Kentucky these factors are compounded by generational low educational attainment. Students entering Kentucky colleges are more than 50\% first-generation (Statistics, 2016b; Wells, 2009). First-generation students tend to have lower college entrance scores and lower grade point averages (Soria \& Stebleton, 2012). These lower entry criteria are accompanied by other factors that inhibit graduation. In Kentucky $70 \%$ of graduating high school students require some remedial courses before being able to take credit bearing courses in higher education. Those numbers are better for collegegoing students, but still at least $45 \%$ require at one or more remedial courses before graduating (Statistics, 2016b). This is more than 13\% above the national average (Bettinger \& Long, 2009). After five years, students that take remedial courses are more 
than twice as likely to drop out and three times less likely to graduate than students who do not take remedial courses (Bettinger \& Long, 2009).

Other rural, first-generation influences that accompany college going include college fit. Students in this category often tend to matriculate to schools that are less selective and do not have a good fit (Pascarella, Pierson et al., 2004; Smith, Pender et al., 2013). There are several factors that contribute to attending these schools; lack of knowledge of other schools, ability to stay home and attend classes both lessening the financial burden and allowing for greater family interaction (Gofen, 2009; Wilbur\& Roscigno, 2016). For a variety of factors, often high school advisors do not encourage high-poverty, first generation students to apply to or attend more selective universities, even when they have similar preparations as other students (Pascarella, Pierson et al., 2004). This population of student also receives less support from their family when they attend school away from home (Maietta, 2016). Support from parents is more than just financial supports, it also includes passing on advice for how to handle situations as they arise on campus; like how to handle interactions with professors and faculty or how to address late or delayed financial assistance funds (Phillips, 2015; Maietta, 2016).

One of the most influential factors in college graduation may be social capital. Bourdieu's (1986) framework identifies privileged knowledge, resources, and information obtained through social networks as important in navigating higher education (Maietta, 2016; Pascarella, Pierson et al., 2004). Interestingly, Pascarella found evidence that these students derived greater growth in openness and learning than their non-first generation counterparts when they were able to attend more selective universities, despite the lack of supports. 
The high levels of remediation needed to enroll in college, $45 \%$, and graduate, $50 \%$, for Kentucky students are not all equal. According to Bettinger and Long (2009) the national average for remediation is closer to $33 \%$. Remedial or developmental course taking for students enrolled in a four year degree program is negatively associated with graduating (Bettinger \& Long, 2009). For students enrolled in a two year program remedial course enrollment is not correlated with lower graduation as long as the number of development courses is below 3 (Shields \& O’Dwyer, 2017). The connections between students of poverty being overly represented in this population is troubling for overcoming the issues associated with generational poverty.

\section{Education reform in Kentucky}

In 1997 Kentucky passed House Bill 1, the Kentucky Postsecondary Education Improvement Act of 1997, to address the postsecondary education challenges of the time (Commonwealth of Kentucky, 1997). Several key change were; a goal for the reforms to be achieved by 2020, the development of the Council on Postsecondary Education (CPE), re-organizing the community college system across the state, address the transition points to increase college readiness, college going, and retention, and ensure funding was available for the reforms.

The CPE was charged with guiding the reform efforts envisioned by state policy leaders as part of HB 1 in 1997. The Council is tasked with multiple responsibilities, including; 1) Developing and implementing a strategic agenda and accountability system for postsecondary and adult education; 2) Coordinating statewide efforts to improve college readiness, access to postsecondary education, and student success, including statewide transfer agreements, adult learner initiatives, KY GEAR UP, and postsecondary 
work related to SB1 (2009) implementation (college and career readiness legislation); 3) Collects and analyzes comprehensive data about postsecondary education performance. The basis for the aggressive reform is the historically low education attainment across Kentucky. The bill was designed to address the disjointed nature of the system to reduce the leakage at every transition point. A major goal of the bill was to align financial policy with the strategic agenda of improving Kentucky's educational attainment (Powell, 2017).

The community college system in Kentucky was reorganized to support the goals of greater opportunity and retention of students. The community colleges were removed from the University of Kentucky umbrella and organized as a separate system the Kentucky Community and Technical College System (KCTCS). The comprehensive system of colleges was tasked with multiple goals, including; 1) To develop a two (2) year course of general studies designed for transfer to a baccalaureate program, the training necessary to develop a workforce with the skills to meet the needs of new and existing industries, and remedial and continuing education to improve the employability of citizens; 2) Create a system of institutions that deliver educational services to citizens that are of quality and diversity to meet the areas needs that minimally meet national averages and standards; and 3) Creates a comprehensive system that enables and encourages students to progress through the system to degree completion (HB 1).

The creation of CPE to create a more aligned set of expectations for postsecondary institutions in the commonwealth along with creating an independent system of community colleges responsible for providing needed services for their constituents were two of the biggest reforms from HB 1. 
In 2009, Kentucky continued its focus on improving education opportunities for its residents with Senate Bill 1 (SB 1). Partially in response to NCLB, Kentucky further unified the P-20 system to address the continued leakage during transitions. It also established an aligned set of academic standards from preschool through postsecondary and an accountability system designed to measure progress toward these standards. The law brought Kentucky into compliance with NCLB (Commonwealth of Kentucky, 2009)

\section{College Readiness Frameworks}

Postsecondary success has been identified as a goal across America as the increased needs for an educated workforce becomes increasingly apparent. Along with the need for an increasingly educated workforce comes the reality that many of our students are not being successful in pursuing an education after graduating high school. There are multiple college readiness frameworks that attempt to establish skills necessary for postsecondary success, and identify characteristics of successful college graduates in order to prepare students and predict their success. David Conley (2007) has expanded his thinking about the four keys of college and career readiness. The College Board and ACT also have College Readiness frameworks that parallel the college readiness assessments they produce. While NCLB did not produce its own framework, it mandated that all students be proficient by 2014. This mandate forced all states to define what proficient meant and how they would assess it using an accountability system, subsequently producing fifty more college readiness frameworks with varying degrees of authority.

In Conley's framework, he identified several indicators of college readiness including Grade Point Average (GPA), rigorous course selection, entrance exams, and a 
lesser utilized metric performance in college courses taken during high school. Anderson and Fulton (2015) analyzed indicators of college readiness they added class rank to the list of predictors of college success. These indicators only explain approximately $30 \%$ of variation in college success, depending on which metric is used (i.e. college GPA, credits earned, graduation) (Anderson \& Fulton, 2015). As Kentucky looked to align high school graduation requirements and college admissions, the indicators that provide strongest predictions became increasingly important.

One of the most prominent predictors is college readiness assessments. For instance meeting the college readiness benchmark cut score on a subject-area test on the ACT represents the level of achievement required for students to have a 50\% chance of obtaining a B or higher or about a $75 \%$ chance of obtaining a $\mathrm{C}$ or higher in corresponding credit-bearing first-year college courses (Allen, 2013). College Board states that meeting the benchmark score on the SAT indicates at least a $75 \%$ chance of achieving a $\mathrm{C}$ in correlated courses (College Board, 2017). Along with test scores, high school GPA provides strong insights into students' chances of graduating college. High school GPA is a better indicator of college success than standardized tests at least for students entering college directly upon graduation from high school (Mattern \& Wyatt, 2012). For students who postpone admission high school GPA isn't necessarily as good a predictor (Spitzer, 2000).

Besides the indicators that work to predict student success there are expectations that accompany college admission. For instance students are expected to act like adults. Once they reach the age of 18 the universities can no longer interact with their parents in the same way because the students are legally adults (U.S. Department of Education, 
2015). Along with the increased expectations for managing one's own behaviors come increased expectations in the classroom, including, more work and reading, higher quality expectations for work, faster pace, and more critical thinking (Conley, 2007; Barnes, Slate et al., 2010; Ishitani. 2016).

Before the increased expectations, increased demand on time and increased expectations regarding behavior, students must meet specific academic performance criteria. There are a variety of academic criteria that have been identified in most university admissions policies; grade point average (GPA), performance on college readiness predictor test like ACT or SAT, rigorous course selection, and to lesser degrees class rank and performance in college courses (Hodara \& Lewis, 2017).

In their research Hodara and Lewis found that the combination of student characteristics, standardized exam scores, and high school grade point average explained 15-27 percent of the variance in college course grades (2017) leaving a vast majority of variance to be explained by other factors. These findings are important as schools, districts, and states work to increase student success in college and beyond.

David Conley's Educational Policy Improvement Center (EPIC) outlines a framework that includes the Four Keys to college readiness; think, know, act, go. In the first key, think, students must be challenged to do more than retain information. According to Conley students must work more intentionally in the higher levels of Bloom's Taxonomy, doing things like creating, analyzing, synthesizing, looking for patterns, and developing thinking processes they will be able to apply in the kinds of activities they will be asked to do after high school (Conley 2008). To know, students must have a strong academic foundation and the aptitude to know they can develop the 
knowledge necessary to be successful at in-depth study of new challenging concepts, skills, processes. Along with the aptitude to learn new content students need a variety of non-cognitive or postsecondary skills, including, self-awareness, goal setting, selfefficacy, and motivation (Lombardi, Seburn et al. 2011). Along with these cognitive skills Conley has identified academic behaviors including time management, note-taking, study skills, collaboration, and proficiency with technology (Conley 2014). The importance of these cognitive skills and academic behaviors that make up two of the four dimensions of college readiness including and content knowledge, and contextual skills and awareness (Conley 2007), are supported in other frameworks as well (Van Driel, Verloop et al. 1998, Counsell 2000, Kavanagh and Drennan 2008, Dede 2010).

In ACT's benchmark report Broadening the Definition of College and Career Readiness: A Holistic Approach (Mattern, Burrus et al. 2014) they lay out a framework that includes; core academic skills (mathematics, science, and English Language Arts), cross-cutting capabilities such as critical thinking and collaboration, behavioral skills such as dependability and adapting, and a broader category of career skills such as selfknowledge and knowledge of careers. This framework is further supported in ACT's A Multidimensional Perspective of College Readiness: Relating Student and School Characteristics to Performance on the ACT in which analysis confirms the prediction of their ACT content assessments (predicting $44 \%$ reading to $61 \%$ composition) as well as the impact of the behavioral and non-cognitive skills (an additional $4 \%$ to $7 \%$ ) on predicting college readiness (McNeish, Radunzel et al. 2015). The ACT framework also identifies the predicting nature of course selection ( $8 \%$ reading to $17 \%$ mathematics) and high school grade point average (HSGPA) which explained the most individual student 
variance (20\% to $31 \%$ ). In examining school characteristics, ACT builds on Oake's Seven Critical Conditions for Equity in identifying school characteristics that school climate and culture influence a student's aspirations, engagement, academic behaviors, and achievement (Oakes 2003; Akey 2006).

Non-cognitive skills, success skills, or postsecondary success skills as indicated above provide a significant impact on individual student success in persevering toward a college degree. These skills are defined as "sets of behaviors, skills, attitudes, and strategies that are crucial to students' academic performance and persistence in post-secondary education” (Borsato, Nagaoka et al. 2013, Nagaoka, Farrington et al. 2013, Conley 2014). These skills are noted in multiple frameworks including Conley's, ACT's, and William Tierney's (Tierney and Duncheon 2015). Dede (2010) references the importance of these skills as well as identifies the fact that these skills have typically fallen outside of being explicitly supported by school curriculum (Dede, 2010; Amadio, 2013).

Research into teaching and developing these postsecondary skills indicate there are reliable methods for explicitly teaching and developing these skills (Kautz et al, 2014; Kautz \& Zanoni, 2014; Alan et al, 2016). However a system that places emphasis on standardized test scores is not equipped to implement these kinds of programs (Bissel, 2017). There is mounting evidence that these skills significantly impact student postsecondary success, and research supporting efficacy in developing these skills in students create a compelling case for schools supporting explicit skill development as part of their curriculum. However, Bridgstock noted in 2009 that implementation of these programs was not proving to provide students the skills they need in "a rapidly changing information- and knowledge-intensive economy." 
Identifying school characteristics for creating college ready students provides structures that schools can use to address the needs of their students. As identified previously (Reid \& Moore, 2008; Strange et al., 2012), the rural, high poverty nature of Kentucky schools means students are not always prepared to be successful in college after graduating. The importance of identifying characteristics that prepare students to be successful after graduation is more important for Kentucky students than ever before. As students reflect on their high school experiences they identify multiple issues that get in the way of being prepared, including, lack of self-awareness of abilities and interests, gap in career interests as well as realistic career outcomes, and in preparation for the processes necessary to be successful academically

\section{Impacts of Tightly Defined College Readiness in High-Stakes Accountability}

Now that the NCLB approach to education has been in place for nearly two decades we are able to see impacts of the policy. As with any large comprehensive system there are some positive outcomes as well as outcomes that had negative impacts.

Students are performing better on state assessments, potentially indicating that more students are better prepared to be successful in college (Jennings, 2006; Dee, 2011). However the improvements on international assessments have not reflected the same kind of improvements, including National Assessment of Educational Progress (NAEP) (Ladd, 2017). NCLB has had a greater impact on national and international assessments in mathematics than in reading (Dee, 2011). A point of contention for the researchers has been that each state defines college readiness differently and designs its own accountability assessments. This range of assessments and expectations makes it very difficult to determine the true impact of NCLB on student learning (Dee, 2011; Ladd 
2017; Ravitch 2016). The varied state assessments are also calculated differently contributing to concerns about validity of the scores (Brewer, Knoeppel, \& Lindle, 2015). Improvements to state accountability scores have been contributed to teaching to the test (Jennings, 2006). In addition, states have different expectations for being considered college ready. In Kentucky ACT benchmark numbers have been modified to reflect lowered expectations (CPE, 2014), see Table 1 below.

\section{Table 1}

Kentucky Benchmark Scores on the ACT Compared to National Scores

\begin{tabular}{lcc}
\hline Subject & Kentucky Benchmark Score & ACT Benchmark Score \\
\hline English & 18 & 18 \\
Mathematics & 19 & 22 \\
Reading & 20 & 22 \\
Science & None & 23 \\
\hline
\end{tabular}

Lower expectation serves several functions including keeping more schools from not achieving Annual Yearly Progress (AYP) expectations, reducing the number of schools who are considered persistently low-achieving (Ravitch, 2016; Ladd 2017). In Kentucky students continue to lag behind their national peers on the ACT (see Table 2..

\section{Table 2}

Percent of Students Making College Readiness Benchmarks in Kentucky

\begin{tabular}{lcllll}
\hline & Composite & English & Reading & Math & Science \\
\hline \multicolumn{5}{c}{2011 ACT } \\
KY & $20 \%$ & $57 \%$ & $43 \%$ & $28 \%$ & $21 \%$ \\
National & $21 \%$ & $66 \%$ & $52 \%$ & $45 \%$ & $30 \%$ \\
KY & $20 \%$ & $58 \%$ & $41 \%$ & $30 \%$ & $31 \%$ \\
National & $27 \%$ & $61 \%$ & $47 \%$ & $41 \%$ & $37 \%$ \\
\hline
\end{tabular}

(KDE, 2012; ACT 2017) 
The focus on high-stakes accountability has not translated into greater scores in English, reading, and mathematics. The only content to show improvement is science, a content that is not currently benchmarked in Kentucky.

As a result of the accountability system, in Kentucky, 12th grade college readiness courses have emerged, and are defined as "courses, learning modules, or online tutorials developed jointly by secondary and postsecondary faculty and offered no later than 12th grade to students at risk of being placed into remedial math or English in college" (Barnett, Fay, Bork, \& Trimble, 2013). These courses are focused on getting students to achieve college readiness designation through alternative means. As the number of students are who making benchmark on the ACT in Kentucky is stagnant, students are pressed to make college ready status through alternative assessments like ACT's Compass (no longer offered), and the Kentucky Online Testing (KYOTE) placement system (KDE, 2017). The transition courses provide focused practice on content from the assessments. The alternative assessments increase the number of students identified as college ready, but Ravitch (2010) recognized that college ready is not created equally through this tiered testing system.

Another impact of teaching to the test mentioned above is a severe narrowing of the curriculum (Ladd, 2017; Pellet, 2012; Dee \& Jacob, 2010; Jennings \& Rentner, 2006). Lee (2006) identified that schools increased the amount of time students received mathematics and reading instruction, this time came as a result of reducing time in other subjects. In most grades, subjects that were not tested received less focus (Bird \& Varga, 2018). Schools also reduced the number and variety of electives like foreign language and music (Sanders, 2014; Pufahl \& Rhodes, 2011; Powell et al., 2009). Darling- 
Hammond (2004) also noted that items that appear on tests are focus of instruction. This focus on test items not only limits the content that students are being exposed to but limits the depth of knowledge (DOK) as well as exploration of how concepts and skills are explored in extension opportunities.

One positive aspect of the testing culture has been the use of formative assessment data to identify what students know and provide focus for differentiation of instruction. Several practices have been identified as wide-spread including small group instruction to meet the needs of all learners and individualized learning curriculum through computer based programs (Williams, 2013). The other side of this specific concept focused instruction is a greater reliance on massed practice as a learning strategy (Smyth, 2016). For classrooms without computer based programs, worksheets have become one method for differentiating instruction.

Another important component of NCLB is school choice for students attending schools that consistently do not meet AYP goals. This school choice policy has been widely debated for several reasons. Prior to 2010 few students took advantage of the opportunity to change schools (less than $1 \%$ of eligible students) and still less than $3 \%$ take advantage of the opportunity (Hess \& Finn, 2004; Grady \& Bielick, 2010). This is problematic, especially in Kentucky where a majority of schools are in rural settings and students do not have choice where they can realistically attend. Hodge and Welch (2016) note that in many cases students must attend failing schools because there is just no other option. Zimmer and Gill (2007) note that unless the school that the student transfers to is considerably more effective there is little impact on student learning. If students choose 
to not leave and their school is able to leave low-achieving status, the impact long-term is not consistent (Gay, 2007).

College Readiness in Kentucky over the last decade has been a mixed bag of successes and failures. It is important as we look at implementing the new accountability model that we keep in mind what we have learned and what we now know as a result of research into the knowledge, skills, and dispositions of college graduates to better prepare all students in Kentucky for success in the $21^{\text {st }}$ century. 


\section{CHAPTER 3- DEVELOPING AND MEASURING RIGOR AT THE SCHOOL LEVEL Characteristics of Rigorous Instruction}

In my work with schools and school leaders, I have found that the discussion about rigor is difficult. Everyone agrees that if our students are going to be college and career ready, courses need to be rigorous. Deciding what rigor looks like in everyday classroom instruction presents three problems; identifying a definition of rigor, what role does rigor play in education, and how do we measure rigor in instruction. In this article, I will attempt to answer three questions:

- What is the landscape of high school courses in terms of incorporating rigorous instruction that can prepare students for postsecondary success?

- How can rigorous instruction at the school level be measured?

- Can institutional rigor measured at the school level predict college readiness?

To meet the demands of an educated $21^{\text {st }}$ Century workforce, America has introduced a greater focus on College and Career Ready (Bush, 2001). This focus on college ready comes as America's lead in the educated workforce is diminishing. In a number of studies, America has slipped to the middle of the pack on education assessments like the National Assessment of Educational Progress (NAEP) and the Program for International Student Assessment (PISA) (Desilver, 2017). Schools have moved to increase expectations for students to meet the need for increased expectations for students upon graduation, including increased test performance that is part of 
accountability systems. One strong potential way to support students' acquisition of these increased expectations is often expressed as a desire for rigorous instruction.

Rigor is defined in a variety of manners and is considered a concept that is difficult to determine (Adelman, 1999). The Southern Regional Education Board (SREB) defines rigor as the expectation that students will be able to perform at levels of cognitive complexity necessary for proficiency at each grade level, and readiness for postsecondary education and the workplace (including advanced training) (SREB, 2000). Strong, Silver, \& Perini (2001) defined rigor as the goal of helping ALL students develop the capacity to understand content that is complex, ambiguous, provocative, and personally or emotionally challenging.

Both of these definitions have a central focus on the expectations for students, and neither identifies the expectations for teachers and schools in developing rigor. For this work, I have chosen to adopt Barbara Blackburn's (2018) definition of rigor as "creating an environment in which each student is expected to learn at high levels, each student is supported so he or she can learn at high levels, and each student demonstrates learning at high levels" (p. 13). This definition creates focus on both the learning that students are expected to achieve and the instructional environment necessary for that to happen.

Rigor isn't just about making the problems harder or raising the Lexile of a reading; it is a multi-faceted set of expectations that must be created by a school in order for teachers and students to be successful in raising the expectations for what students can do and are expected to do (Paige, Smith, \& Sizemore, 2015). Paige, Smith, and Sizemore go on to define rigor as a continuum of instruction and not a present/not present dichotomy. They use Webb's Depth of Knowledge Framework (1997) and a scale from 
simplicity to complexity ( $1=$ recall, $2=$ application, $3=$ strategic thinking, $4=$ create $)$ to measure the continuum. This gradation is similar to Daggett's Rigor/Relevance Framework $(2005 ; 2014)$ that identifies a tangible progression of thinking (recall, application, assimilation, adaptation).

\section{Student Engagement as an Indicator of Rigor}

Important in the discussion of rigor is student engagement. McClenney, Marti, and Adkins (2012) defined engagement in school as the intensity and emotional quality of children's involvement in learning activities. Additional researchers have defined it as "a psychological process, specifically, the attention, interest, investment, and effort students expend in the work of learning" (Marks, 2000, p. 154) and "the student's psychological investment in and effort directed toward learning, understanding, or mastering the knowledge, skills, or crafts that academic work is intended to promote" (Lamborn, Newmann, \& Wehlage, 1992, p. 12).

Students who are engaged in their learning and the learning tasks they are asked to perform, show sustained behavioral involvement as well as a positive emotional attitude. Engagement is significantly related to student learning, persistence, and academic attainment (McClenney, Marti, \& Adkins, 2012). There are several factors that influence student engagement including; relevance of instruction (Shernoff, Csikszentmihalyi, Schneider, and Shernoff, 2014), input/control over learning activities (Deci, Nezlek, \& Sheinman, 1981), school membership (Gowing, 2017; Plasman, 2018) and authentic work (Ellison, 2015; Kintz, 2015). School membership can be defined as a student's social bond with the school. The bond with the school is dependent on the extent to which the student is attached to adults and peers within the school, accepts the 
norms of the school, is involved in school activities, and believes in the value of the institution (Mastrorilli, 2016). Authentic work is defined as work that intellectually involves the student in a meaningful inquiry to solve real life problems that may extend beyond the classroom (Lamborn, Newmann, \& Wehledge, 1992). Shernoff, Csikszentmihalyi, Schneider, and Shernoff (2014) went on to include student autonomy over their learning activities as a component of authentic academic work. Student engagement has been tied to classroom factors including instructional format and subject with lecture as the dominant strategy most connected to low engagement (Gilboy, Heinerichs, \& Pazzaglia, 2015; Holmes, 2015).

\section{Institutional Indicators of College Readiness}

Much work has been done to identify student level characteristics of college readiness. Research indicates that there are a variety of indicators including high school grade point average (HSGPA), college predictor scores on standardized tests, socioeconomic status (SES), and academic courses taken (Akey, 2006; Conley, 2014; Kavanagh \& Drennan, 2008; McNeish, Radunzel \& Sanchez 2015, Hodara \& Lewis, 2017). These student level indicators of success explain a great deal of the variance but do not address how schools impact college readiness of their students.

Differences between urban and high-poverty rural schools have been identified, with urban schools offering more electives, having higher expectations, having better college-going rates, and higher postsecondary graduation rates (Reid \& Moore 2008, Strange, Johnson et al. 2012). Rural schools are faced with a variety of issues including less funding, qualified teacher shortage, lack of leadership development, and lower expectations (Boser, Wilhelm, \& Hanna, 2014; Harmon, 2001). 
Adelman (1999) was the first to identify academic intensity as a key component for institutional indicators of college readiness. He defines academic resources as "a composite measure of the academic content and performance the student brings forward from secondary school into higher education. This measure is dominated by the intensity and quality of secondary school curriculum" (Adelman, 1999, p. vi). Academic intensity identifies expectations beyond transcript and HSGPA. Adelman determines that academic rigor is challenging to measure but that academic intensity can be quantified. Adelman $(1999,2006)$ went on to identify the impact of a high school curriculum of high academic intensity as having a particularly strong impact on gap groups and minorities, creating an opportunity where all students can be successful after graduation.

It is important to note that comprehensive school reform programs recognize that increasing expectations for all students is critical to school reform efforts (Conley, 2007; Martinez \& Klopott, 2003; Newmann, 1996), and rigorous instruction is an integral component of current school reform efforts including Redesigned High Schools (RHS), High Schools that Work (HSTW), and Early College High Schools (ECHS). All three models have core components that increase a students' opportunity to be ready for postsecondary success (see Table 3).

\section{Table 3}

\section{Core Components of High School Reform Models}

\begin{tabular}{l}
\hline Core components across all three models include: \\
HSTW
\end{tabular}

(Arshavsky et al., 2014; Glancy, Fulton, Anderson, Zinth, \& Millard, 2014). 
Research has shown that increased student achievement is connected to rigorous assignments, higher levels of thinking embedded in instruction, application of knowledge, and expectations for supporting evidence during discourse (Newmann, Bryk, \& Nagaoka, 2001; Newmann, Lopez, \& Bryk, 1998). Mathematics achievement has also proven to be highly correlated to rigorous instruction and quality of student work (Jacob, Hill, \& Corey, 2017; Shkolnik et al., 2007). Providing instruction aligned to produce these skills has also been positively related to student learning through the MET Project (2010, 2012).

The strategies are similar across content areas. The National Research Council identified specific strategies that support conceptual understanding. These practices include students working collaboratively, and to express their learning through a variety of literacy strategies ([NRC], 2002). In addition, the council identifies classroom discourse as valuable so that students can process content as they develop and present solutions, construct viable arguments, and provide evidence to support claims ([NRC], 2013a). This focus on discourse in mathematics and science classes mirrors the Common Core Instructional shifts that are represented in the Literacy Anchor Standards for English Language Arts, Social Studies and Science coursework as well as the Mathematical Practice Standards (MPS) and the Science and Engineering Practices (SEP) that are a component of the Next Generation Science Standards ([NRC], 2013b). The recommendations go on to describe "engage students in worthwhile tasks that provide access to powerful ideas and practices" ([NRC], 2002) which mirrors the language from the MPS and SEP again. All of these practices provide specific frameworks for rigorous instruction. 
The discourse and sense making expectations mirror the work that Bill Dagget espouses in his Rigor/Relevance framework when modeling learning and achievement in two dimensions. The first dimension (or y-axis) is rigor, referring to academic rigor or level of knowledge and learning reflected in Blooms Taxonomy (Bloom, 1956). The second dimension (or $\mathrm{x}$-axis) is relevance, meaning the ability to apply concepts or skills to solve real-world problems. Relevance, as defined in the Application Model of the Rigor/ Relevance Framework, has a five-level continuum:

- Level 1-knowledge in one discipline

- Level 2-applying knowledge in one discipline

- Level 3-applying knowledge across multiple disciplines

- Level 4-applying knowledge to predictable real-world situations

- Level 5-applying knowledge to unpredictable real-world situations (W. Daggett, 2014; W. R. Daggett, 2005)

The National Research Council (2013a, 2013b) goes on to identify instructional practices that should receive more emphasis in order to achieve greater student understanding, these practices include:

- Guiding students through active and extended inquiry and facilitating studentcentered learning

- Incorporate strategies that take student prior knowledge, ability and interests into account

- Foster collaboration and student learning communities

- Shift focus to student-centered instructional strategies 
- Create learning experiences that provide students with sufficient time, space, and feedback for learning

- While participating in extended learning activities, students progress through cycles of assessment, active feedback, and revision

- Create interactions between teacher-student and between students

- In mathematics and science classes students are challenged to formulate questions, propose and support hypothesis, plan procedures, design and analyze data, discuss results and repeat experiments with modifications.

Along with increased expectations, it is essential to understand that less rigorous courses have lower expectations and often the least qualified teachers (Contreras, 2005; Darling-Hammond, 2004). Research indicates both of these factors negatively impact standardized test performance and college readiness (Moore et al., 2010). Moore also identifies that teachers need professional learning in supporting their students' development of college-readiness skills. Training might focus on instructional strategies that develop key skills and higher level thinking processes. According to Kuh et al. (2005), schools can offer programs and support services to assist students at risk, so these students receive the assistance they need to be successful in courses with increased expectations. Kuh identifies programs, policies, and services that enhance all students learning including; transition courses, tutoring, study groups, and study skills support programs.

Paige, Smith, and Sizemore (2015) further define the complex system of rigorous instruction within which a teacher designs and delivers instruction. They identify the key components, including which standards are to be taught, the pedagogy that will be 
utilized, the level of cognitive complexity at which students will be asked to think, the various materials which will be required, and how the lesson will be differentiated to engage all students successfully.

The trio did an analysis of the Common Core standards that suggests that approximately $53 \%$ of English and $17 \%$ of mathematics standards are expected to be taught at the depth of knowledge (DOK) levels of 3 and 4. Their findings indicate that only $17 \%$ and $12 \%$ of English and mathematics content, respectively, is being taught at those levels. Paige, Smith, and Sizemore use the relationship between DOK and instruction to make the case that instructional practices directly impact a student's ability to learn content at a level to be considered proficient.

In addition to increased student expectations and student-centered instructional practices, educational aspirations have been identified as a key variable in predicting college going rates (Adelman, 1999). Educational aspirations are defined as student expectations they will go on to postsecondary education. In fact researchers indicate there was very little difference between their $8^{\text {th }}$ grade aspirations, $10^{\text {th }}$ grade aspirations and $12^{\text {th }}$ grade aspirations when it came to college-going (Hu, 2003). Hu goes on to identify that rural students lagged significantly behind their urban and suburban counterparts, reinforcing the importance of supports for this population of students. Why rural students lag behind their peers in college aspiration is a complex answer. In many cases rural communities tend to be poor and working class which also results in less funding for schools (Johnson, Showalter, Klein, \& Lester, 2014), fewer resources (Siskar \& Theobald, 2008), schools with less qualified staff (Bailey \& Zumeta, 2015), and community perception of "brain drain" (the belief that if students go away to college they 
will have greater economic opportunities and not return to the community) (Carr \& Kefalas, 2009). Demi, Coleman-Jensen, \& Snyder (2010) identified the role a school plays in student aspirations and ultimate enrollment in postsecondary institutions as central to future educational attainment, especially in the rural area. In the rural area the school often plays a more important role than it does in other areas. In addition they identified the importance of students feeling supported at school as an important indicator. Ultimately, student aspirations can be influenced through a variety of ways including: feeling of support, getting along with teachers, perception of fairness, liking school, and feeling safe. Although these factors did not directly lead to enrollment, they influenced aspirations therefore mediating enrollment (Demi, Coleman-Jensen, \& Snyder, 2010).

\section{GEAR UP}

The Gaining Early Awareness and Readiness of Undergraduate Programming (GEAR UP) program follows two cohorts of high poverty students from grades six and seven through graduation. GEAR UP is focused on supporting non-traditional students in being successful in graduating from a 2 or 4 year college or university. The projects provide targeted programming to prepare them to be successful in aspiring to attend college, applying for, enrolling in, and graduating from college. In addition to student level programming, the GEAR UP Kentucky state project provided a school improvement component designed to better prepare students for the rigors of college instruction. The study reported in this paper is based on data from the GEAR UP school improvement component. 
The school improvement services provided schools walkthrough data which offered a snapshot of instruction in the schools based on four key characteristics: presence of the ACT College Readiness Indicators; quality of instruction based on the Common Core Literacy Anchor Standards and Mathematical Practice Standards; Rigor, Relevance and Differentiation of instruction; and a school level self-report School Performance Guide for a College-Going Culture (See Appendix B for the full Guide) that utilized existing frameworks to identify practices that support access for all students to college preparatory practices.

\section{Methods}

\section{Sample}

The sample consists of 21 high-poverty high schools in Kentucky. For GEAR UP, high-poverty is defined as at least 50\% Free/Reduced Middle/High School Population. Fifteen of the schools qualified as rural as defined by the Rural Low Income Schools (RLIS) Program in 2011. Four of the districts are small independent districts in small towns that operate independent of the county school systems. One high school is a magnet school within the second largest school system in Kentucky. The school was the

primary feeder from the high poverty middle school and was therefore added to the grant as the representative for that district. Schools ranged in size from 337 in grades kindergarten through grade twelve to 2,087 in a comprehensive grade 9-12 high school with the average enrollment being 780 students.

\section{Walkthrough Process - Classroom Observations and School Self-Report}

The walkthrough process was conducted by personnel from an educational nonprofit agency external to all schools and districts and contains two components; School 
Performance Guide for a College-going Culture self-assessment (SPG), and observer visits to classrooms. For the self-report, leadership in each school worked as a team to rate where on the rubric they feel the school rates for each indicator. The recommended leadership team consisted of the principal, assistant principals, counselors, and lead teachers. Teams varied in size from the school principal analyzing individually to a team of seven. The SPG indicators are discussed below in Table 7.

During the same period of time, a team of external observers visited the school to observe instruction in core content courses (English Language Arts, Mathematics, Social Studies, and Science). All sections of courses (AP, honors, advanced, comprehensive, etc.) were observed to provide insights into instructional practices throughout the building. Collaboration model classes with special education students were observed as a distinct section, but self-contained special education course were not part of the observation process. Prior to arriving, all observation protocols were provided to schools to share with teachers. It was stressed that this was not an evaluation of individual teachers, but an analysis of instruction throughout the entire school. Observers planned a schedule that allowed for every course and every level of that course to be observed at least once. Additionally, every teacher was observed at least once and every attempt was made not to observe a teacher more than 3 times to keep that teacher from skewing the data. Observers spent 15-20 minutes in each observation collecting data electronically. Observers generated ratings in four categories. Ratings were generated on the presence of the ACT College-Readiness Standards; Common Core Instructional Shifts (Literacy Anchor Standards and Mathematical Practice Standards); Rigor, Relevance, and Differentiation; and qualitative description of instruction. At the end of the process, 
observers submitted observation data along with narrative description of overall patterns observed throughout the school.

Once the school was visited, observation data were organized into a comprehensive report. Leadership teams participated in data-analysis workshops to examine the report and identify areas of strength and areas where additional efforts continued to be necessary. The GEAR UP project used the data as a way to target supports for schools to build sustainability for students beyond the scope of the project.

\section{Input Measures}

The first set of school-level input measures were the ACT College Readiness Standards for Classroom Instruction. ACT developed the ACT College Readiness Standards to provide clarity for ACT assessment expectations. ACT identified the standards as describing essential skills and knowledge students need to become ready for college and career (ACT, 2018). ACT classified the standards by ACT score band. For instance, for students to achieve an ACT score of 13-15 on Writing requires them to have mastered the knowledge of what ACT characterized as the 200 level standards, and a score of 16-19 requires the knowledge of the 300 level standards. For example, to be able to benchmark (eligible to take credit bearing courses without remedial courses upon enrollment in college) in English a score of 18 is necessary, so all 300 level standards were included in the rating process for this study. Select 200 level indicators were included if they were significantly different from the 300 level standards. See Table 4 for details of ACT College Readiness Standards.

Because the observations were made in classrooms from grade 9 through grade 12 , some of the courses required the presence of the lower level standards for their course 
content, since the higher-level classroom standards were established as expectations for junior and senior-level courses, and not always appropriate for high school entry-level courses. For instance, in Algebra I students may still be interacting appropriately with a 200-level standard, N 202: "Recognize equivalent fractions and fractions in lowest terms" as they grapple with applying linear functions to contextual situations. Thus, this instruction in $9^{\text {th }}$ grade could be considered appropriate for eventually supporting students to be college/career ready by the end of high school when the latter mathematics courses appropriately increase the expectations as documented by higher-level ACT instructional standards.

\section{Table 4}

ACT College Readiness Standards for Classroom Instructions Documented during

\section{Classroom Observation}

\begin{tabular}{ll}
\hline $\begin{array}{l}\text { Standards were coded } 0,1 \text { by the classroom observer as either present in instruction or not present } \\
\text { during the observation } \\
\text { (https://www.act.org/content/act/en/college-and-career-readiness/standards.html) }\end{array}$ \\
\hline English & $\begin{array}{l}\text { 33 writing standards were included as potentially observable in the walkthrough } \\
\text { process. Topics include: Production of Writing, Knowledge of Language, and }\end{array}$ \\
& Conventions of Standard English Grammar, Usage, and Punctuation \\
Reading & 27 standards with topics Key Ideas and Details, Craft and Structure, and Integration of \\
& Knowledge and Ideas \\
Mathematics & 64 standards in topic areas Number and Quantity, Algebra, Functions, Geometry, and \\
& Statistics and Probability \\
Science & 23 standards in science topics areas were included as potentially observable in the \\
& walkthrough process. Topics include: Interpretation of Data, Scientific Investigation, \\
and Evaluation of Models, Inferences, and Experimental Results
\end{tabular}

Note. The list of specific ACT College Readiness Standards used by the classroom

observers is in Appendix A.

The second set of data document the implementation of the recommended

Common Core Instructional Shifts for Literacy and Mathematics. The observation process documented the inclusion and use of literacy anchor standards for English, social studies, and science. For mathematics, a selection of the Mathematical Practice Standards 
were chosen that provided evidence of how students were interacting with the content

they studied, see Table 5.

\section{Table 5}

$\underline{\text { Recommended Common Core Instructional Shifts Documented during Classroom }}$

\section{Observation}

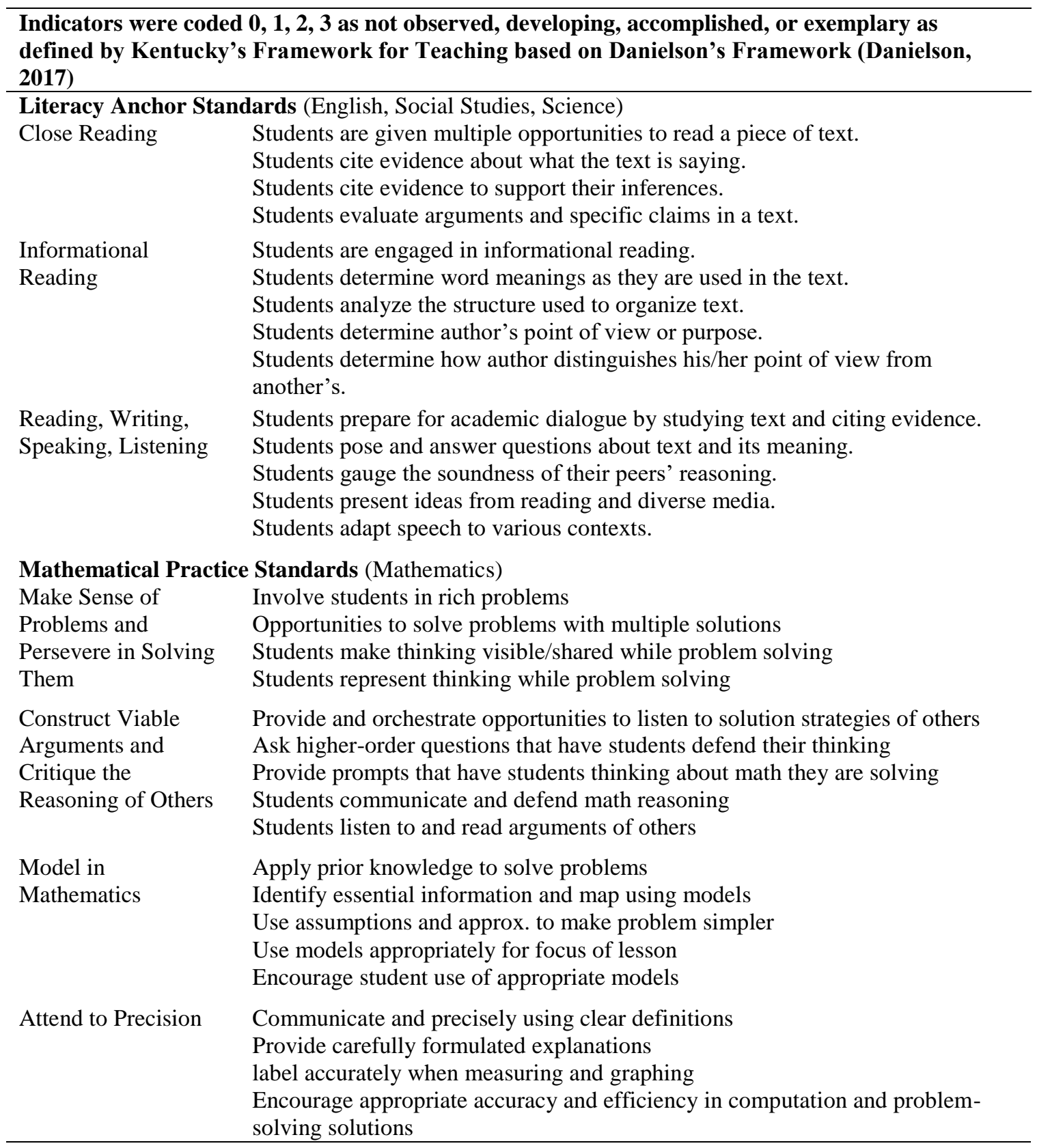


The second set of input measures are Rigor, Relevance, and Differentiation data (Table 6), which were documented during classroom observations to determine if students were being instructed at the appropriate levels of thinking to accomplish the goals of the learning standards. In addition, the indicators attempt to determine if all students are supported sufficiently to learn at high levels.

\section{Table 6}

Rigor, Relevance, and Differentiation Indicators Documented during Classroom

\section{$\underline{\text { Observation }}$}

\begin{tabular}{ll}
\hline Indicators were coded $\mathbf{0 , 1}, \mathbf{2}, \mathbf{3}$ as not observed, minimal, moderate, or exemplary \\
\hline Rigor/Relevance & $\begin{array}{l}\text { Application of knowledge to solve problems } \\
\text { Assimilation to extend and refine knowledge } \\
\text { Adaptation by applying to unpredictable situations } \\
\text { Relevance of activities and materials } \\
\text { Assessment to demonstrate learning }\end{array}$ \\
& $\begin{array}{l}\text { High Standards for all students } \\
\text { Differentiation }\end{array}$ \\
& $\begin{array}{l}\text { Range of Materials } \\
\text { Scaffolding to to accommodate students }\end{array}$ \\
& Demonstrations of Learning over time \\
\hline
\end{tabular}

As part of the walkthrough process observers captured qualitative notes to accompany ratings. The notes identified specific information regarding the instructional strategies, classroom processes, and provide contextual input about instruction as it was happening.

In addition to the three sets of input measures captured and coded during the classroom observations, one additional input measure was a school-level self-report on the school culture. The School Performance Guide for a College-going Culture was created for the project using existing college readiness frameworks including Conley (2007; 2014), Tierney and Garcia (2008), and ACT (2008) to help schools assess the 
extent to which such a culture exists, pinpoint strengths, and target areas for

improvement. The School Performance Guide (SPG) explores the key components of creating a college-going culture through the five attributes that were parts of the GEAR

UP Kentucky Project goals; aspiration, rigor, expectations, accountability, and sustainability. See Table 7 below.

\section{Table 7}

$\underline{\text { School Performance Guide Indicators Included in School Self-Report about College- }}$ going Culture

\begin{tabular}{|c|c|c|c|}
\hline \multicolumn{2}{|c|}{$\begin{array}{l}\text { Indicators were coded } 0,1,2 \text { as square one, transitioning to a college-going } \\
\text { culture, achieving a college-going culture }\end{array}$} & Min/Max & Normed \\
\hline $\begin{array}{l}\text { Aspiration } \\
\text { (6 indicators) }\end{array}$ & $\begin{array}{l}\text { Students dream big dreams } \\
\text { Individual learning plans for success } \\
\text { Strong transition supports } \\
\text { Classroom instruction emphasizes college knowledge and } \\
\text { skills } \\
\text { Highest level courses are the default and open to all } \\
\text { Courses aligned with career for increased engagement }\end{array}$ & $0 / 12$ & $0 / 16$ \\
\hline $\begin{array}{l}\text { Rigor } \\
\text { (5 indicators) }\end{array}$ & $\begin{array}{l}\text { All students have access to advance/accelerated learning } \\
\text { Instruction provides both challenge and support } \\
\text { Evidence of standards-based instruction } \\
\text { Supports for student independence and self-sufficiency } \\
\text { Student work is revised for success }\end{array}$ & $0 / 10$ & $0 / 16$ \\
\hline $\begin{array}{l}\text { Expectation } \\
\text { (6 indicators) }\end{array}$ & $\begin{array}{l}\text { Comprehensive and systemic student advising } \\
\text { Continual monitoring of student progress } \\
\text { College planning supported } \\
\text { Expectation of college-going the norm for all } \\
\text { Exposure to college and college expectations } \\
\text { Academic pursuits equal other including sports }\end{array}$ & $0 / 12$ & $0 / 16$ \\
\hline $\begin{array}{l}\text { Accountability } \\
\text { (5 indicators) }\end{array}$ & $\begin{array}{l}\text { Data-analysis from a variety of sources } \\
\text { Commitment by school to increasing students meeting } \\
\text { benchmark } \\
\text { Comprehensive student data profiles } \\
\text { School monitors student planning/application to college } \\
\text { School commits to all students applying for college }\end{array}$ & $0 / 10$ & $0 / 16$ \\
\hline $\begin{array}{l}\text { Sustainability } \\
\text { (4 indicators) }\end{array}$ & $\begin{array}{l}\text { Comprehensive approach } \\
\text { Continuous improvement focus } \\
\text { Data-analysis impacts student experience } \\
\text { Parent and Community Engagement }\end{array}$ & $0 / 8$ & $0 / 16$ \\
\hline
\end{tabular}

\section{Summary of Input Measures}


Table 8 summarizes the input measures and describe the data collected as part of

the walkthrough process.

\section{Table 8}

$\underline{\text { Summary of College-Ready Rigorous Instruction Input Measures for this Study }}$

\begin{tabular}{|c|c|c|c|}
\hline $\begin{array}{l}\text { Input Measure } \\
\text { Category }\end{array}$ & $\begin{array}{l}\text { Table } \\
\text { (for } \\
\text { details) }\end{array}$ & Brief Description & $\begin{array}{l}\text { Coding } \\
\text { Scheme }\end{array}$ \\
\hline $\begin{array}{l}\text { ACT College } \\
\text { Readiness } \\
\text { Standards for } \\
\text { Classroom } \\
\text { Instruction }\end{array}$ & 4 & $\begin{array}{l}\text { ACT-recommended instructional approaches for } \\
\text { supporting development of students to be college } \\
\text { ready. Between } 23-64 \text { specific observable standards } \\
\text { across the four core content area classes. }\end{array}$ & $\begin{array}{l}0-1 \\
\text { (not present - } \\
\text { present) }\end{array}$ \\
\hline $\begin{array}{l}\text { Recommended } \\
\text { Common Core } \\
\text { Instructional Shifts }\end{array}$ & 5 & $\begin{array}{l}\text { Four or five instructional techniques for each of } \\
\text { seven categories grouped under literacy ( } 3 \\
\text { categories) or mathematics ( } 4 \text { categories) from the } \\
\text { Common Core State Standards }\end{array}$ & $\begin{array}{l}\quad 0,1,2,3 \\
\text { (not observed, } \\
\text { developing, } \\
\text { accomplished, } \\
\text { or exemplary) }\end{array}$ \\
\hline $\begin{array}{l}\text { Rigor, Relevance, } \\
\text { and Differentiation } \\
\text { Indicators during } \\
\text { Classroom } \\
\text { Instruction }\end{array}$ & 6 & $\begin{array}{l}\text { Ten indicators of the rigor and relevance of } \\
\text { instruction designed using Bill Daggett's } \\
\text { Rigor/Relevance Framework as the basis }\end{array}$ & $\begin{array}{l}0,1,2,3 \\
\text { (not observed, } \\
\text { developing, } \\
\text { accomplished, } \\
\text { or exemplary) }\end{array}$ \\
\hline $\begin{array}{l}\text { School Performance } \\
\text { Guide Indicators } \\
\text { (self-report) }\end{array}$ & 7 & $\begin{array}{l}\text { 4-6 indicators in each of } 5 \text { categories that school } \\
\text { leadership teams self-analyze progress toward } \\
\text { implementing practices that support college-going for } \\
\text { high poverty students, based on research of Conley, } \\
\text { Tierney and others. }\end{array}$ & $\begin{array}{l}0,1,2 \\
\text { (square one, } \\
\text { transitioning, } \\
\text { achieving a } \\
\text { college-going } \\
\text { culture) }\end{array}$ \\
\hline
\end{tabular}

\section{Moderator Variable}

The population of schools participating in this study all contain high-poverty students. The GEAR UP program specifies that participating schools have a population with at least $50 \%$ Free/Reduced lunch status. Free/reduced status has been identified as impacting not only student success but identifying how schools with high-poverty populations do in preparing students for college (Burney \& Beilke 2008, Tierney and Garcia 2008, Simon and Johnson 2015). Free/Reduced lunch (\%FRL) is a potential 
moderator variable that will be included in upcoming analysis with the outcome measures to further explore how schools succeed at preparing students for college success.

\section{Outcome Measures}

Outcome measures that have been shown to measure some component of collegegoing success will be the other set of data this study will use. These outcome measures are separated into two categories; measures of college readiness, and measures of college success. The measures of college readiness are further split into two sub-categories: internally-generated (GPA and percent going to college) and externally-generated (ACT and KY accountability measures). See Table 9 below.

\section{Table 9}

Outcome Measures of Postsecondary Success

\begin{tabular}{|c|c|c|}
\hline $\begin{array}{l}\text { Category of } \\
\text { Outcome }\end{array}$ & Description & $\begin{array}{l}\text { Variable } \\
\text { names }\end{array}$ \\
\hline $\begin{array}{l}\text { College Readiness } \\
\quad \text { - internal }\end{array}$ & Mean High School GPA & HSGPA \\
\hline \multirow[t]{2}{*}{$\begin{array}{l}\text { College Readiness } \\
\text { - external }\end{array}$} & $\begin{array}{l}\text { ACT mean scores on the four content areas and the } \\
\text { composite: }\end{array}$ & $\begin{array}{c}\text { ACT_eng } \\
\text { ACT_math } \\
\text { ACT_read } \\
\text { ACT_sci } \\
\text { ACT_comp }\end{array}$ \\
\hline & $\begin{array}{l}\text { Percent of students determined to be college-ready by } \\
\text { Kentucky's Accountability System }\end{array}$ & KYCollR \\
\hline College-going & $\begin{array}{l}\text { Percent of students from the school that go to a } 2 \text { or } 4 \text { year } \\
\text { college }\end{array}$ & CGRate \\
\hline College Success & $\begin{array}{l}\text { Earn } 30 \text { hours during college freshman year } \\
\text { Return for the beginning of sophomore year }\end{array}$ & $\begin{array}{l}\text { Earn30 } \\
\text { Soph }\end{array}$ \\
\hline
\end{tabular}

All of the outcome data for this study was collected from the Kentucky Center for Education and Workforce Statistics (KCEWS). The analysis used the 2017 Kentucky High School Feedback College Success Public Access Data File. This data is for the high school graduating class of 2014-15; these students were seniors during the GEAR UP 
classroom observations. A complete list of variable abbreviation, variable names, and descriptions is in Table C3 of Appendix C.

\section{Walkthrough Training}

Before the walkthrough process, the team of observers went through a three day inter-rater reliability training. The training consisted of careful review and discussion of the instruments to define each indicator. Along with a review of the indicators, each team of observers watched a series of classroom instruction videos. All reviewers met a minimum threshold of at least $80 \%$ agreement on indicators for their content area of expertise.

Depending on the size of the school, 4-7 content experts were sent to the school to perform classroom observations in all core content (mathematics, English, science, social studies) classrooms. Observers saw each teacher at least once, each course at each level (i.e., comprehensive, advanced/honors, etc.) at least once with the goal of not seeing any one teacher more than three times, to avoid any one specific teacher from overly impacting school-level results. Observations of an individual classroom lasted between fifteen and twenty minutes depending on activities being conducted. Observers used tablet devices to gather data for upload using the secure Harvest Your Data App.

\section{Analysis}

Each set of content walkthrough data contained ACT College Readiness Standards, Rigor, Relevance, and Differentiation indicators, and Common Core Instructional Shifts data as defined previously. A school's average score for each indicator was created by summing the ratings and dividing by the number of observations for that item, and the collection of indicators for each content area were used to generate 
four separate content scores for each school. See Table 10 below for sample item scoring for a small high school with 3 mathematics teachers teaching algrebra 1, geometry, algebra II, precalculus, and senior math. In this school there were no honors classes but there were algebra I, geometry, and algebra II classes taught with collaboration teachers and these classes were observed along with the non-collaboration sections. Table 11 contains the score ranges for each content section, the overall score for each content, and overall walkthrough score for each school. Cronbach's Alpha was calculated for each of the content subscores to establish internal consistency (Cronbach, 1951). All four content subscores met the minimum threshold of 0.70 to be considered adequately reliable (Schmitt, 1996). In addition, Levene's Test for homogeneity was run, and the data meets the threshold at the 0.05 level.

\section{Table 10}

\section{$\underline{\text { Sample Item Score Calculation for Mathematics in one High School }}$}

\begin{tabular}{|c|c|c|}
\hline School 2 & $\begin{array}{c}\text { ACT Math Standard 1. Solve routine one- } \\
\text { step arithmetic problems using positive } \\
\text { rational numbers, such as single-step } \\
\text { percent }\end{array}$ & $\begin{array}{c}\text { Rigor, Relevance, Differentiation 6. High } \\
\text { Standards: All students expected to meet } \\
\text { same high standards }\end{array}$ \\
\hline Observation 1 & 1 & 2 \\
\hline Observation 2 & 1 & 2 \\
\hline Observation 3 & 0 & 3 \\
\hline Observation 4 & 0 & 2 \\
\hline Observation 5 & 0 & 2 \\
\hline Observation 6 & 1 & 1 \\
\hline Observation 7 & 1 & 3 \\
\hline Observation 8 & 0 & 0 \\
\hline Total $n=8$ & $\begin{array}{c}\text { Score for ACT.M. } 1=4 / 8 \\
=0.5\end{array}$ & $\begin{array}{c}\text { Score for RRD.M.6 = } \\
15 / 8=1.875\end{array}$ \\
\hline
\end{tabular}

\section{Table 11}

$\underline{\text { Walkthrough Content and Subscores with All Indicators Included }}$

Four Content Areas

ELA

Social Studies

(SS) (reading)
Science

Math 


\begin{tabular}{|c|c|c|c|c|}
\hline $\begin{array}{l}\text { Total \# of Items on walkthrough tool (Tables 4- } \\
6 \text { combined) }\end{array}$ & $\begin{array}{l}\text { (reading } \\
\text { and } \\
\text { writing) } \\
85\end{array}$ & 53 & 48 & 94 \\
\hline $\begin{array}{l}\text { Content Section } 1 \text { (CS1): } \\
\text { ACT Stds Score Min/Max- \# varied by content } \\
\text { (Table } 4)\end{array}$ & $0 / 60$ & $0 / 27$ & $0 / 23$ & $0 / 64$ \\
\hline $\begin{array}{l}\text { Content Section } 2 \text { (or below for math) (CS2): } \\
\text { Lit Anchor Stds Score Min/Max (up to } 3 \text { points } \\
\text { on } 15 \text { indicators) (Table } 6 \text { ) }\end{array}$ & $0 / 45$ & $0 / 45$ & $0 / 45$ & \\
\hline $\begin{array}{l}\text { Content Section } 2 \text { (CS2): } \\
\text { Math Practice Stds Score Min/Max (up to } 3 \\
\text { points on } 18 \text { indicators) (Table 6) }\end{array}$ & & & & $0 / 54$ \\
\hline $\begin{array}{l}\text { Content Section } 3 \text { (CS3): } \\
\text { RRD Items Score Min/Max (up to } 3 \text { points on } \\
\text { 10indicators) (Table 5) }\end{array}$ & $0 / 30$ & $0 / 30$ & $0 / 30$ & $0 / 30$ \\
\hline Total Scale Pts. Possible & 135 & 102 & 98 & 148 \\
\hline Cronbach Alpha & 0.92 & 0.95 & 0.88 & 0.94 \\
\hline
\end{tabular}

Because of the large number of potential items in each observation (the sum of all the standards and indicators in Tables 4-6; up to 92 potential items could be rated in a mathematics class, for example), the frequency of items actually rated across all 21 schools in the sample was calculated to identify items that may not have been observed enough to be able to contribute meaningfully to the analysis. Also, items that were very frequently observed in many schools would not be able to help discriminate in the upcoming analysis among those instructional practices that might differentially impact a school's ability to prepare its students for postsecondary success.

Item frequency ranged from $0.2 \%$ to $90.4 \%$. Minimum and maximum frequency of observation thresholds were identified to create a set of items that would provide the best discrimination in upcoming analysis. Based upon an inspection of the actual observational frequency distribution across the set of items to identify reasonable cut 
points, I chose to exclude any items with observational frequencies below $10 \%$ and above 90\%. See Table 12 for the breakdown of how many items were removed from each portion of the content subscore.

\section{Table 12}

Select Classroom Observation Items with greater than 10\% Frequency and less than $90 \%$ Frequency

\begin{tabular}{lcccc}
\hline \multicolumn{1}{c}{ Four Content Areas } & $\begin{array}{c}\text { ELA } \\
\text { (reading and } \\
\text { writing) }\end{array}$ & $\begin{array}{c}\text { Social Studies } \\
\text { (SS) (reading) }\end{array}$ & Science & Math \\
$\begin{array}{l}\text { Total \# of Items after frequency analysis } \\
\text { (removed below 10\% and above 90\% } \\
\text { frequencies) }\end{array}$ & 44 & 33 & 29 & 42 \\
\hline $\begin{array}{l}\text { Content Section 1 (act): } \\
\text { ACT Stds Score Min/Max }\end{array}$ & $0 / 22$ & $0 / 11$ & $0 / 8$ & $0 / 17$ \\
$\begin{array}{l}\text { Content Section 2 (or below for math) (cc): } \\
\text { CC Lit Anchor Stds Score Min/Max (up to 3 } \\
\text { points on 15 indicators) }\end{array}$ & $0 / 39$ & $0 / 39$ & $0 / 36$ & \\
$\begin{array}{l}\text { Content Section 2 (cc): } \\
\text { CC Math Practice Stds Score Min/Max (up to 3 } \\
\text { points on 18 indicators) }\end{array}$ & & & & \\
$\begin{array}{l}\text { Content Section 3 (rrd): } \\
\text { RRD Items Score Min/Max (up to 3 points on }\end{array}$ & $0 / 27$ & $0 / 30$ & $0 / 30$ & $0 / 27$ \\
$\begin{array}{l}\text { 10indicators) } \\
\text { Total Scale Pts. Possible }\end{array}$ & 88 & 80 & 74 & 92 \\
Cronbach Alpha & 0.92 & 0.95 & 0.88 & 0.94 \\
\hline
\end{tabular}

\section{Norming item analysis.}

The content subscores (ACT standards) were reduced from their initial large number, but were still not equivalent size, potentially creating an issue of interpretations when combining differently-weighted content areas for a whole-school score, and subsequently analyzing the outcomes based on this aggregate school-level inputs. Because some of the rating scales went up to 3 points, while others went up only to 2 or 
even 1 point (see Table 8), there were also concerns with the different total point values for each of the input measure rating scales in terms of how these unequal weightings might inadvertently skew the upcoming analysis. To equalize the point-value ratings across each of the four content subscores as well as for each input measure used, the rating scores were normed.

Each of the three sections (see Table 12) of the content scores was weighted to 10 points, creating a sum of 30 points per content area, and a total of 120 points for a total school score with all four content areas combined. Refer to Table 13 and Table 14 for a comparison of the unnormed and normed scores for a high school. Table $\mathrm{C} 1$ of Appendix C has the normed section and content scores for each school in the study, and Table C2 has the total comparison scores for the all item, reduced item, and reduced item normed scores for each school.

\section{Table 13}

$\underline{\text { Sample Unnormed Scoring for All Four Content Areas for a High School }}$

\begin{tabular}{lccccc}
\hline Unnormed & ELA & SS & Science & Math & $\begin{array}{c}\text { School } \\
\text { Score }\end{array}$ \\
\hline ACT Stds & 2.44 & 1.57 & 0.77 & 9.62 & \\
CC Lit & 4.44 & 6 & 8.46 & 10.39 & \\
Anchor Stds & 0.11 & 2.57 & 3.85 & 4.77 & \\
RRD Itemts & $\mathbf{4 . 5 6}$ & $\mathbf{1 0 . 1 4}$ & $\mathbf{1 3 . 0 8}$ & $\mathbf{2 4 . 7 7}$ & $\mathbf{5 2 . 5 5}$ \\
$\begin{array}{l}\text { Total Content } \\
\text { Score }\end{array}$ & 80 & 80 & 74 & 92 & 334 \\
$\begin{array}{l}\text { Total Scale } \\
\text { Pts Possible }\end{array}$ & 88 & & & & \\
\hline
\end{tabular}

\section{Table 14}

$\underline{\text { Sample Normed Scoring for All Four Content Areas for Same High School in Table } 13}$

\begin{tabular}{lccccc}
\hline Normed & ELA & SS & Science & Math & $\begin{array}{c}\text { School } \\
\text { Score }\end{array}$ \\
\hline ACT Stds & 0.41 & 0.58 & 0.27 & 1.5 &
\end{tabular}




\begin{tabular}{lccccc} 
CC Lit & 1.52 & 2 & 2.82 & 3.46 & \\
Anchor Stds & 0.99 & 0.57 & 0.85 & 0.99 & \\
RRD Itemts & $\mathbf{2 . 9 1}$ & $\mathbf{3 . 1 5}$ & $\mathbf{3 . 9 4}$ & $\mathbf{5 . 9 6}$ & $\mathbf{1 5 . 9 6}$ \\
$\begin{array}{l}\text { Total Content } \\
\text { Score }\end{array}$ & & 30 & 30 & 30 & 120 \\
$\begin{array}{l}\text { Total Scale } \\
\text { Pts Possible }\end{array}$ & 30 & 30 & & & \\
\hline
\end{tabular}

\section{Impact of instruction.}

I will perform a correlational analysis of the input and outcome data.

Correlational analysis does not determine causal relationships, but there is considerable research into the impact of instructional practice on preparing students for college success (ACT, 2012; Conley, 2007; Jacob, Hill, \& Corey, 2017; Mitchell et al., 2005; Radcliffe \& Bos, 2013; Sambolt \& Blumenthal, 2013; Shkolnik et al., 2007; Symonds, Schwartz, \& Ferguson 2011). The analysis will attempt to determine the relationship between instruction that has what I have defined as rigorous instructional approaches and college success outcomes. There may be other causes for the relationships including the presence of the GEAR UP programs in each of the schools, characteristics of the students, and other unaccounted for programming. However, the impact of instruction has been well documented. Even though multiple causes likely impact the results of this analysis, my premise is that instruction is likely to account for much of the impact.

I will explore the predictive value of each of the 4 input measures (see Table 8). The analysis will look at each of the content areas, the three sections (ACT, CC, RRD) of each content area and how they correlate with the outcome measures and moderator variable. This will be accomplished by computing the Pearson product-moment correlation coefficients. This correlation analysis will provide a measure of the strength of the linear association between the input and output measures. A t-test will be used to 
establish if the correlation is significantly different from zero, and hence evidence of association between the two variables.

\section{Results}

Table 15 provides a shading legend used for all Pearson product-moment correlation coefficient tables. This shading scheme is utilized to provide an at-a-glance opportunity for reading the broad patterns to be found in the correlation tables for all of the results presented. For this study, the shading will provide an easier way of identifying strong (between 0.6 and 1 or -0.6 and -1$)$ and moderate (0.4 to $0.6,-0.4$ to -0.6$)$ correlations (Kozak 2009).

\section{Table 15}

\section{$\underline{\text { Shading Legend for Results Correlation Tables }}$}

\begin{tabular}{ccc}
\hline & $\begin{array}{c}\text { Pearson product-moment correlation } \\
\text { coefficient values }\end{array}$ & Description \\
\hline $\mathbf{0 . 6 1}$ & Greater than 0.6 & Strong positive correlation \\
0.50 & Between 0.4 and 0.6 & Moderate positive correlation \\
-0.50 & Between -0.4 and -0.6 & Moderate negative correlation \\
$\mathbf{- 0 . 6 3}$ & Lower than -0.6 & Strong negative correlation \\
0.0 & None of the Above & Weak or no correlation \\
\hline
\end{tabular}

\section{Establishing equivalence of reduced item and normed scales.}

Because the proposed analysis was based on removing items with extremely low $(<10 \%)$ and extremely high $(>90 \%)$ frequency of occurrence in the overall data set, it is helpful to first explore if the resulting reduced item scales return scores equivalent to the non-reduced, full data set. Additionally, the norming process described above was incorpop rated to give equal weight in a school total score to each of the four content areas which all had different numbers of potential indicators and hence different numbers 
of score points possible. The analysis below also explores if the normed scores returned results equivalent to non-normed scores.

Tables 16 through 19 are the correlations between the content sections and overall content scores developed from the three methods of exploring the data (TOT_**_all- all items, TOT _**_10- below 10\%/above 90\% removed, TOT _**_norm- content section normed). The first set of results presented will explore whether the normed scores created for each content from the reduced item scale produces scores that are substantially similar to the full-item scale and the reduced item scale (omitting items less than $10 \%$ and more than 90\%). I also explore if each of the 3 content sections (see Table 12) that aggregate to each content score total intercorrelate with each other as well as the total score in order to establish if these multiple input measures (see Table 8) capture similar evidence about rigor of the instruction in each content area.

In each content analysis table I will explore the section scores for each content as well as the overall scores. The section scores are explored to understand if instruction in each content includes all three areas used to identify rigorous instruction (standardsbased, literacy instructional shifts, and appropriate rigor).

\section{Table 16}

\section{$\underline{\text { English Normed Section and Overall English Scores Pearson Product-Moment }}$}

\section{Correlation Coefficients}

\begin{tabular}{lcccccc}
\hline & E_act_n & E_cc_n & E_rrd_n & TOT_E_norm & TOT_E_all & TOT_E_10 \\
\hline E_act_n & & 0.77 & 0.71 & 0.88 & 0.88 & 0.92 \\
E_cc_n & - & 0.67 & 0.85 & 0.86 & 0.87 \\
E_rrd_n & & & - & 0.94 & 0.91 & 0.90 \\
TOT_E_norm & & & & - & 0.98 & 0.99 \\
TOT_E_all & & & & & - & 0.98 \\
TOT_E_10 & & & & & & - \\
\hline
\end{tabular}




\section{Table 17}

$\underline{\text { Social studies Normed Section and Overall Social Studies Scores Pearson Product- }}$ $\underline{\text { Moment Correlation Coefficients }}$

\begin{tabular}{lcccccc}
\hline & SS_act & SS_cc_n & SS_rrd_n & TOT_SS_norm & TOT_SS_all & TOT_SS_10 \\
\hline SS_act_n & - & 0.15 & 0.63 & 0.71 & 0.88 & 0.65 \\
SS_cc_n & & - & 0.55 & 0.69 & 0.86 & 0.77 \\
SS_rrd_n & & & - & 0.96 & 0.91 & 0.93 \\
TOT_SS_norm & & & & - & 0.98 & 0.99 \\
TOT_SS_all & & & & & - & 0.98 \\
TOT_SS_10 & & & & & - \\
\hline
\end{tabular}

\section{Table 18}

$\underline{\text { Science Normed Section and Overall Science Scores Pearson Product-Moment }}$

\section{$\underline{\text { Correlation Coefficients }}$}

\begin{tabular}{lcccccc}
\hline & SC_act_n & SC_cc_n & SC_rrd_n & TOT_SC_norm & TOT_SC_all & TOT_SC_10 \\
\hline SC_act_n & 0.71 & 0.39 & 0.67 & 0.76 & 0.69 \\
SC_cc_n & & - & 0.51 & 0.80 & 0.84 & 0.84 \\
SC_rrd_n & & & - & 0.92 & 0.84 & 0.88 \\
TOT_SC_norm & & & & - & 0.98 & 1.00 \\
TOT_SC_all & & & & & - & 0.98 \\
TOT_SC_10 & & & & & & - \\
\hline
\end{tabular}

\section{Table 19}

$\underline{\text { Math Normed Section and Overall Math Scores Pearson Product-Moment Correlation }}$

\section{$\underline{\text { Coefficients }}$}

\begin{tabular}{lcccccc}
\hline & M_act & M_cc_n & M_rrd_n & TOT_M_norm & TOT_M_all & TOT_M_10 \\
\hline M_act_n & - & 0.50 & 0.79 & 0.85 & 0.90 & 0.89 \\
M_cc_n & & - & 0.82 & 0.84 & 0.81 & 0.81 \\
M_rrd_n & & & - & 0.99 & 0.95 & 0.97 \\
TOT_M_norm & & & & - & 0.99 & 1.00 \\
TOT_M_all & & & & & & 1.00 \\
TOT_M_10 & & & & & & - \\
\hline
\end{tabular}


Overall, the correlations between each content by section indicates a generally strong positive association between the three different sets of indicators of rigorous instruction. However, there were a few exceptions to this pattern. For instance, in Social Studies the ACT Standards (SS_act_n) has very little correlation (0.15) with the Common Core Instructional Shifts (SS_cc_n) which are about how students are expected to read and interact with written material in the social studies classroom. More closely aligning those two items may provide a greater impact on the teaching of social studies. In science there were weak to moderate correlations between the ACT Standards (SC_act_n) and Common Core Instructional shifts (SC_cc_n) and the Rigor, Relevance, and Differentiation Items (SC_rrd_n), potentially indicating that while instruction includes the standards and instructional shifts, students may not be asked to think at higher levels, lessoning the impact of the instructional practices.

Across all content areas, there were strong positive correlations between the overall normed score, overall reduced item score, and overall all items score $(r>0.98, n$ $=21, \mathrm{p}=0.05)$. The strong correlations suggest the reduced item score and normed scores adequately capture all of the walkthrough data for each content area. Combining all of the four content areas into a school-total score (see Table 20) shows that the total scores computed in all three ways (full data, reduced item data, normed reduced items) are very strongly correlated. For the rest of the analysis in this study, the school-level total reduced item normed (TOT_norm) will be used for comparison to the outcome measures. Use of the normed data will allow for more consistent interpretation of the results of additional section and subscore analysis.

\section{Table 20}


Walkthrough Overall Score Analysis

\begin{tabular}{lccc}
\hline & TOT_all & TOT_10 & TOT_norm \\
\hline TOT_all & - & 0.98 & 0.98 \\
TOT_10 & & - & 0.99 \\
TOT_norm & & & - \\
\hline
\end{tabular}

\section{Inter-content analysis.}

This analysis will explore the relationship between the different content areas (see Table 21). I will explore how instruction in the building is related or not related across contents to establish the presence of consistent instructional expectations across the school. To further investigate content across the building I will explore the relationships of each section of the content scores looking for areas of instruction within the contents that may be consistent.

\section{Table 21}

$\underline{\text { Walkthrough Content Score Inter-Correlations }}$

\begin{tabular}{lcccc}
\hline & TOT_E_norm & TOT_SS_norm & TOT_SC_norm & TOT_M_norm \\
\hline TOT_E_norm & - & 0.19 & -0.22 & 0.08 \\
TOT_SS_norm & - & -0.08 & -0.02 \\
TOT_SC_norm & & - & 0.22 \\
TOT_M_norm & & & - \\
\hline
\end{tabular}

The Pearson product-moment correlation coefficients between the different normed content areas $(\mathrm{r}<|0.25|, \mathrm{n}=21, \mathrm{p}>0.05)$ show little consistency in the rigor of instructional approaches between departments in the schools, potentially suggesting a lack of systemic approaches to instruction in schools. The largest positive correlations (0.22 math and science, 0.19 English and social studies) do indicate some potential relationship between those two contents, but not at a strong level. Interestingly there was 
equal negative correlations between science and English. There are several potential reasons for this to be examined in later research, including the focus on testing in English and lack of focus in science, and/or difficulty in many rural areas to find highly qualified teachers to fill all positions.

I will examine the three sections of each content area's instruction ratings (Table 12) independently to identify any areas where consistencies in approaches may occur. Table 22 through 24 show the results of these analyses. For each content section an overall score was calculated by adding the four content section scores together. This overall all content section score (TOT_**_n) would have a scale score of 0 to 40.

\section{Table 22}

Walkthrough Content ACT Standards Subscores with Overall ACT Standards Score $\underline{\text { Inter-Correlations }}$

\begin{tabular}{lccccc}
\hline & E_act_n & SS_act_n & SC_act_n & M_act_n & TOT_ACT_n \\
\hline E_act_n & - & 0.11 & -0.06 & -0.22 & 0.41 \\
SS_act_n & & - & 0.03 & -0.15 & 0.69 \\
SC_act_n & & & - & -0.04 & 0.26 \\
M_act_n & & & & - & 0.39 \\
TOT_ACT_n & & & & & - \\
\hline
\end{tabular}

The ACT standards subscores have no moderate or strong correlations between the content areas. In fact they tend to have weak negative correlations, again indicating a lack of systemic approaches to addressing the ACT standards across buildings. Moderate and strong correlations between English and total ACT standards score, and between Social Studies and total ACT standards score, may indicate a more consistent approach to addressing the ACT standards in these two contents, but there was very little correlation between their subscores $(0.11)$. 


\section{Table 23}

$\underline{\text { Walkthrough content Common Core Instructional Shifts Subscores with Overall CC }}$ $\underline{\text { Score Inter-correlations }}$

\begin{tabular}{lccccc}
\hline & E_cc_n & SS_cc_n & SC_cc_n & M_cc_n & TOT_CC_n \\
\hline E_cc_n & - & 0.30 & 0.21 & 0.20 & 0.63 \\
SS_cc_n & & - & 0.15 & 0.05 & 0.75 \\
SC_cc_n & & & - & 0.14 & 0.57 \\
M_cc_n & & & & - & 0.49 \\
TOT_CC_n & & & & & - \\
\hline
\end{tabular}

All four content subscores correlate at least moderately with the overall Common Core Instructional Shifts score, indicating some consistency. Social studies and English were both strong correlations with overall, and science and math moderately correlated with overall Common Core Instruction. There were still no or little correlation between the content areas, with the exception of the English content being weakly correlated with all three of the other content areas, indicating little commonality in approach across content areas.

\section{Table 24}

Walkthrough Content Rigor, Relevance, and Differentiation Subscores with Overall RRD $\underline{\text { Score Inter-correlations }}$

\begin{tabular}{lccccc}
\hline & E_rrd_n & SS_rd_n & SC_rrd_n & M_rrd_n & TOT_RRD_n \\
\hline E_rrd_n & - & 0.17 & -0.35 & 0.04 & 0.35 \\
SS_rrd_n & & - & 0.00 & 0.27 & 0.40 \\
SC_rrd_n & & & - & 0.12 & 0.69 \\
M_rrd_n & & & & - & 0.67 \\
TOT_RRD_n & & & & & - \\
\hline
\end{tabular}


There was a lack of strong correlations between the four content areas, indicating a lack of consistent focus on RRD across content departments. The Pearson productmoment correlation coefficients between math and overall RRD score, and between science and overall RDD score $(r>0.67, n=21, p=0.05)$ show that these two content areas are more positively related to the overall RRD score. The English subscore had the weakest correlation with overall RRD score and have the weakest correlations between contents, further suggesting greater variability in between content instruction within schools.

\section{Outcomes analysis.}

In Table 25 below, the college readiness (HSGPA, ACT, and KYCollR) and college-going data (CG_Rate) have moderate to strong Pearson product-moment correlation coefficients with each other in 27 of 28 correlations indicating the readiness data is measuring student college-going behaviors, confirming previous research. The ACT data is strongly intercorrelated with itself as expected. Moderate correlations exist between HSGPA and ACT data with the exception of ACT Science. This lack of correlation is likely influenced by the fact that that Kentucky does not benchmark science on the ACT for admission to college. The Kentucky Accountability System College Readiness (KYCollR) indicator has moderate correlations with all of the college readiness data. All of the indicators correlate negatively with the moderator variable Percent of population qualifying for free/reduced lunch status (\%FRL) with only KYCollR not being a strong negative correlation.

\section{Table 25}


$\underline{\text { Pearson Product-Moment Correlation Coefficients between the Selected Outcome }}$

$\underline{\text { Measures }}$

\begin{tabular}{|c|c|c|c|c|c|c|c|c|c|c|c|}
\hline & $\%$ FRL & HSGPA & $\begin{array}{c}\mathrm{ACT}_{-} \\
\text {ela }\end{array}$ & $\begin{array}{c}\mathrm{ACT}_{-} \\
\text {math }\end{array}$ & $\begin{array}{c}\mathrm{ACT}_{-} \\
\text {read }\end{array}$ & $\begin{array}{c}\mathrm{ACT}_{-} \\
\mathrm{sci}\end{array}$ & $\begin{array}{l}\mathrm{ACT}_{-} \\
\text {comp }\end{array}$ & $\begin{array}{l}\mathrm{KY}_{-} \\
\text {CollR }\end{array}$ & $\begin{array}{l}\mathrm{CG}_{-} \\
\text {Rate }\end{array}$ & Earn30 & Soph \\
\hline$\%$ FRL & - & -0.49 & -0.64 & -0.63 & -0.67 & -0.63 & -0.67 & -0.29 & -0.68 & -0.38 & -0.72 \\
\hline HSGPA & & - & 0.52 & 0.53 & 0.59 & 0.38 & 0.53 & 0.44 & 0.44 & 0.33 & 0.60 \\
\hline ACT_ela & & & - & 0.85 & 0.96 & 0.86 & 0.97 & 0.51 & 0.67 & 0.68 & 0.47 \\
\hline ACT_math & & & & - & 0.89 & 0.84 & 0.93 & 0.44 & 0.55 & 0.71 & 0.64 \\
\hline ACT_read & & & & & - & 0.86 & 0.98 & 0.54 & 0.69 & 0.68 & 0.54 \\
\hline ACT_sci & & & & & & - & 0.93 & 0.4 & 0.64 & 0.81 & 0.43 \\
\hline ACT_comp & & & & & & & - & 0.5 & 0.67 & 0.75 & 0.54 \\
\hline KYCollR & & & & & & & & - & 0.57 & 0.24 & 0.42 \\
\hline CGRate & & & & & & & & & & 0.35 & 0.39 \\
\hline Earn30 & & & & & & & & & & - & 0.37 \\
\hline Soph & & & & & & & & & & & - \\
\hline
\end{tabular}

The Pearson product-moment correlation coefficients between the college readiness, college-going, and college success are less consistent. While the ACT measures correlate moderately and strongly with both college success measures, the other college-readiness indicators do not correlate as strongly. The ACT measures are the strongest correlations with both success measures but have less relationship with sophomore year than with earning 30 hours as a freshman. Most specifically the percentage of students who earned 30 credit hours during their freshman year only correlated strongly with the ACT data. HSGPA and KYCollR have moderate correlations with sophomore year but a weak correlation with earning 30 hours as a freshman. KYCollR measure had weaker correlations with the other measures of college readiness and college success. In addition, the CGRate did not correlate even moderately with the two college success variables, supporting the findings that a large number of Kentucky high school graduates may enroll in college but do not progress toward graduation successfully. The lack of correlation between the Kentucky's College Readiness 
indicators may mean Kentucky's accountability index is not a strong measure of college success. Because students are able to receive college readiness status through less rigorous alternative assessments (the KYOTE, or ACT's Compas) the measure may allow more students the opportunity to enter college their freshman year, because the status means students are able to enter without having to take remedial coursework. Unfortunately, the college ready status had weak or low moderate correlations with college success. The two college success outcomes (Earn30, Soph) correlate with the external or internal measures of college readiness, indicating they are measuring some portion of college success.

The showing up for the sophomore year outcome has moderate correlations with all eight of the other outcome measures with ACT math being the only strong positive value $(r=0.64, n=21, p=0.05)$. Of importance, the Free/Reduced lunch status was most strongly negatively correlated with attending sophomore year a concern since this data derived from a high-poverty, first generation college-going program. Percent Free/Reduced lunch status was not significantly correlated with earning 30 hours or Kentucky College Readiness Accountability measure.

\section{Walkthrough data comparison with outcome measures.}

The input measures data were compared to the outcome measures to examine if school level measures of rigorous instruction correlated with increased college readiness, college-going, and college success (see Table 25). The reduced item normed (TOT_norm) scores were used for the overall analysis.

\section{Table 26}

\section{$\underline{\text { Input Measures Scores Compared to Outcome Measures }}$}




\begin{tabular}{lccccccccccc}
\hline & HSGPA \%FRL & $\begin{array}{c}\mathrm{ACT}_{-} \\
\text {ela }\end{array}$ & $\begin{array}{c}\mathrm{ACT}_{-} \\
\text {math }\end{array}$ & $\begin{array}{c}\mathrm{ACT}_{-} \\
\text {read }\end{array}$ & $\begin{array}{c}\mathrm{ACT} \\
\text { sci }\end{array}$ & $\begin{array}{c}\text { ACT_} \\
\text { comp }\end{array}$ & CGRate KYCollR & Earn30 & Soph \\
\hline TOT_norm & 0.56 & -0.69 & $\mathbf{0 . 6 8}$ & $\mathbf{0 . 6 0}$ & $\mathbf{0 . 6 6}$ & 0.54 & $\mathbf{0 . 6 5}$ & 0.45 & 0.35 & 0.25 & 0.55 \\
\hline
\end{tabular}

The norm scores were consistent in their correlation with the outcome measures, have strong correlations with the ACT Composite Score as well as the English and reading scores and moderate correlations with math and science, potentially indicating that rigor of instruction contributes $27 \%$ to $46 \%$ of variance in school level ACT scores. The Earn 30 hours data did not correlate well but the beginning the sophomore year had high moderate Pearson product-moment correlation coefficients. A two tailed t-test confirms that this relationship is significant at the 0.05 level $(r=0.55, n=21, p=0.05)$, providing perhaps the most substantial evidence for the input data's ability to inform student college success.

\section{Analysis of input data by content and content section.}

The following analysis of the input data by content and content section (Table 27) provides a more in-depth analysis of each content set of data in an attempt to examine the ability of the different sections of the content data to predict college success.

\section{Table 27}

Content Subscore and Content Section Pearson Product-Moment Correlation Coefficients with Outcome Data

\begin{tabular}{|c|c|c|c|c|c|c|c|c|c|c|c|}
\hline & $\%$ FRL & HSGPA & $\underset{\text { ela }}{\mathrm{ACT}_{-}}$ & $\underset{\text { math }}{\mathrm{ACT}_{-}}$ & $\begin{array}{c}\mathrm{ACT}_{-} \\
\text {read }\end{array}$ & $\begin{array}{l}\mathrm{ACT} \\
\text { _sci }\end{array}$ & $\begin{array}{l}\mathrm{ACT}_{-} \\
\text {comp }\end{array}$ & CGRate & KYCollR & Earn30 & Soph \\
\hline E_act_n & -0.01 & -0.09 & 0.19 & 0.03 & 0.07 & 0.14 & 0.12 & -0.02 & -0.02 & 0.04 & 0 \\
\hline SS_act_n & -0.04 & 0.39 & 0.23 & 0.26 & 0.18 & 0.33 & 0.25 & 0.02 & -0.03 & 0.25 & -0.07 \\
\hline SC_act_n & -0.23 & 0.36 & 0.03 & 0.14 & 0.17 & -0.02 & 0.08 & 0.09 & 0.13 & -0.15 & 0.12 \\
\hline M_act_n & -0.5 & 0.27 & 0.2 & 0.28 & 0.23 & 0.3 & 0.26 & 0.18 & 0.13 & 0.31 & 0.53 \\
\hline TOT_ACT_n & -0.41 & 0.51 & 0.39 & 0.41 & 0.35 & 0.48 & 0.42 & 0.14 & 0.09 & 0.35 & 0.31 \\
\hline & -0.12 & -0.05 & 0.2 & 0.23 & 0.15 & 0.13 & 0.19 & -0.09 & 0.13 & 0.02 & 0.2 \\
\hline SS_cc_n & -0.13 & 0.26 & 0.32 & 0.15 & 0.21 & 0.06 & 0.21 & 0.21 & 0.36 & -0.2 & 0.05 \\
\hline
\end{tabular}




\begin{tabular}{lccccccccccc} 
SS_cc_n & -0.13 & 0.26 & 0.32 & 0.15 & 0.21 & 0.06 & 0.21 & 0.21 & 0.36 & -0.2 & 0.05 \\
M_cc_n & $\mathbf{- 0 . 6 3}$ & 0.31 & $\mathbf{0 . 6}$ & 0.39 & 0.59 & 0.5 & 0.55 & 0.53 & 0.22 & 0.36 & 0.41 \\
TOT_CC_n & -0.42 & 0.37 & 0.52 & 0.4 & 0.48 & 0.27 & 0.45 & 0.36 & 0.45 & -0.06 & 0.35 \\
\hline \hline E_rrd_n & -0.2 & 0.18 & 0.56 & 0.38 & 0.5 & 0.49 & 0.51 & 0.24 & 0.27 & 0.43 & 0.24 \\
SS_rrd_n & -0.35 & 0.45 & 0.57 & 0.51 & 0.48 & 0.44 & 0.53 & 0.24 & 0.14 & 0.3 & 0.25 \\
SC_rrd_n & -0.38 & 0.24 & 0.04 & 0.13 & 0.14 & -0.12 & 0.05 & 0.23 & 0.22 & -0.33 & 0.34 \\
M_rrd_n & $\mathbf{- 0 . 6 3}$ & 0.22 & 0.27 & 0.25 & 0.33 & 0.33 & 0.31 & 0.32 & 0.07 & 0.22 & 0.45 \\
TOT_RRD_n & $\mathbf{- 0 . 7 4}$ & 0.52 & $\mathbf{0 . 6 8}$ & 0.6 & $\mathbf{0 . 6 7}$ & 0.54 & $\mathbf{0 . 6 6}$ & 0.48 & 0.3 & 0.3 & 0.59 \\
\hline \hline TOT_ACT_n & $-\mathbf{- 0 . 4 1}$ & 0.51 & 0.39 & 0.41 & 0.35 & 0.48 & 0.42 & 0.14 & 0.09 & 0.35 & 0.31 \\
TOT_CC_n & $-\mathbf{- 0 . 4 2}$ & 0.37 & 0.52 & 0.4 & 0.48 & 0.27 & 0.45 & 0.36 & 0.45 & -0.06 & 0.35 \\
TOT_RRD_n & $\mathbf{- 0 . 7 4}$ & 0.52 & $\mathbf{0 . 6 8}$ & 0.6 & $\mathbf{0 . 6 7}$ & 0.54 & $\mathbf{0 . 6 6}$ & 0.48 & 0.3 & 0.3 & 0.59 \\
TOT_norm & $\mathbf{- 0 . 6 9}$ & 0.56 & $\mathbf{0 . 6 8}$ & $\mathbf{0 . 6}$ & $\mathbf{0 . 6 6}$ & 0.54 & $\mathbf{0 . 6 5}$ & 0.45 & 0.35 & 0.25 & 0.55 \\
\hline
\end{tabular}

The walkthrough sbscore analysis does not provide consistent finding across the four content areas or sections of content subscores, but does provide some potential relationships. The Rigor, Relevance, and Differentiation content data for English and social studies, and Social Studies subscore had moderate to strong correlations with several of the outcome measures including the ACT data. The overall RRD subscore was more closely correlated with the outcome measures than the other section subscore data.

The ACT standards data for the content sections had no or weak correlations for everything except math. I believe there are two contributing factors; the ACT standards, although connected are not the academic standards courses are designed around, and most of the ACT standards (English, reading, and science) are process standards while the math standards are discrete content standards which may contribute to the lack of individual content correlation. However the overall data was moderately correlated with five of the eleven outcome measures, indicating standards based instruction does potentially have some predictive college readiness/success power.

The Common Core instructional shifts data had moderate overall correlations with five of the ten outcome measures (only one overlapped with ACT standards correlations- 
ACT Composite) and had a moderate negative correlation with \%FRL. The math CC subscore data had moderate to strong correlations with six of the outcome measures, indicating implementation of the recommended shifts in mathematics instruction have some predictive power on college readiness and success. Interestingly enough the Common Core instructional data for math did not correlate well with ACT math scores, potentially identifying a key misalignment between instruction that prepares students for long-term college success and the ACT math assessment.

The negative correlation between the input data and Free/Reduced Lunch status is consistent with previous college readiness data suggesting poverty or the perception of poverty has a negative impact on instructional practices teachers use with students of poverty.

\section{Analysis of the school performance guide for a college-going culture.}

The School Performance Guide for a College-going Culture (SPG) was also correlated with the outcome measures. Cronbach's alpha was calculated with three of the subscores meeting the threshold for internal consistency (Cronbach, 1951). The Rigor and Accountability subscores did not meet the threshold having Cronbach alpha values of 0.55 and 0.45 , respectively, and so any conclusions based on those two subscores should be treated with caution. The SPG data (Table 28) was normed for an overall score of 80 , giving each section a 16 point scale. The results in Tables 28 and 29 below.

\section{Table 28}

$\underline{\text { School Performance Guide Section Correlation Comparisons }}$

\begin{tabular}{lcccccc}
\hline & Asp_n & Rigor_n & Exp_n & Acc_n & Sus_n & SPG_n \\
\hline Asp_n & - & 0.40 & $\mathbf{0 . 7 1}$ & 0.38 & 0.48 & $\mathbf{0 . 7 9}$ \\
Rigor_n & & - & 0.37 & 0.24 & 0.45 & $\mathbf{0 . 6 7}$
\end{tabular}




\begin{tabular}{|c|c|c|c|}
\hline Exp_n & 0.58 & 0.47 & 0.85 \\
\hline Acc_n & - & 0.18 & 0.65 \\
\hline Sus_n & & - & 0.71 \\
\hline SPG_n & & & - \\
\hline
\end{tabular}

The SPG subscores correlate at the moderate and strong levels for six of the ten correlations. The accountability subscore was the least well correlated with the other subscores.

\section{Table 29}

$\underline{\text { Normed School Performance Guide for a College-Going Culture Pearson Product- }}$ $\underline{\text { Moment Correlation Coefficients with Outcome Measures }}$

\begin{tabular}{lccccccccccc}
\hline & $\%$ FRL & HSGPA & $\begin{array}{c}\mathrm{ACT}_{-} \\
\text {ela }\end{array}$ & $\begin{array}{c}\mathrm{ACT}_{-} \\
\text {math }\end{array}$ & $\begin{array}{c}\mathrm{ACT} \\
\text { read }\end{array}$ & $\begin{array}{c}\mathrm{ACT} \\
\text { sci }\end{array}$ & $\begin{array}{c}\text { ACT } \\
\text { comp }\end{array}$ & CGRate & KYCollR & Earn30 & Soph \\
\hline Asp_n & -0.10 & 0.41 & 0.33 & 0.17 & 0.30 & 0.27 & 0.28 & 0.22 & 0.01 & 0.27 & 0.04 \\
Rigor_n & -0.21 & 0.43 & 0.26 & 0.37 & 0.31 & 0.09 & 0.27 & 0.01 & 0.10 & 0.22 & 0.48 \\
Exp_n & -0.09 & 0.37 & 0.20 & 0.09 & 0.23 & 0.16 & 0.18 & 0.15 & -0.18 & 0.28 & 0.06 \\
Acc_n & 0.21 & 0.31 & -0.12 & -0.11 & -0.13 & -0.05 & -0.11 & -0.12 & -0.28 & 0.13 & 0.01 \\
Sus_n & -0.39 & 0.44 & 0.53 & $\mathbf{0 . 7 2}$ & $\mathbf{0 . 6 0}$ & $\mathbf{0 . 6 0}$ & $\mathbf{0 . 6 3}$ & 0.38 & 0.05 & 0.53 & 0.45 \\
SPG_n & -0.17 & 0.53 & 0.33 & 0.35 & 0.36 & 0.30 & 0.35 & 0.18 & -0.08 & 0.40 & 0.29 \\
\hline
\end{tabular}

The individual sections of the SPG do not show consistent correlations with the outcome measures. The Sustainability subscore correlated strongly with the ACT data and moderately with HSGPA, Earning 30 as a freshman, and returning for the sophomore year. The Accountability Subscore negatively correlated with seven of the outcome measures. The Accountability Subscore, also, had only one Pearson product-moment correlation at the moderate or strong level when correlated with the other subscores (Table 28), did not meet the Cronbach alpha threshold for consistency and was therefore removed from the SPG score. The resulting reduced School Performance Guide (omitting 
the Accountability subscale) (SPG-Acct_n; see Table 30) was better correlated with the outcome measures, with six of the ten outcome measures having moderate Pearson product-moment correlation coefficients. The Sustainability subscore still had the most consistent overall correlations with the outcome measures, potentially indicating the selfreport survey provides schools with a framework for building college-going practices and policies. The strong Pearson product-moment correlation coefficient between the subscores and HSGPA was noted.

\section{Table 30}

Overall School Performance Guide without Accountability Subscore Compared to $\underline{\text { Outcome Measures }}$

\begin{tabular}{lccccccccccc}
\hline & $\%$ FRL & HSGPA & $\begin{array}{c}\mathrm{ACT}_{-} \\
\text {ela }\end{array}$ & $\begin{array}{c}\mathrm{ACT}_{-} \\
\text {math }\end{array}$ & $\begin{array}{c}\mathrm{ACT} \\
\text { read }\end{array}$ & $\begin{array}{c}\mathrm{ACT} \\
\text { sci }\end{array}$ & $\begin{array}{c}\mathrm{ACT} \\
\text { comp }\end{array}$ & CGRate & KYCollR & Earn30 & Soph \\
\hline $\begin{array}{l}\text { SPG_n } \\
\text { SPG- }\end{array}$ & -0.17 & 0.53 & 0.33 & 0.35 & 0.36 & 0.30 & 0.35 & 0.18 & -0.08 & 0.40 & 0.29 \\
Acct_n & -0.27 & 0.53 & 0.43 & 0.45 & 0.47 & 0.37 & 0.45 & 0.25 & 0.00 & 0.43 & 0.34 \\
\hline
\end{tabular}

Without the accountability subscore the SPG overall score had moderate correlations with six of the ten outcome measures. Again \%FRL correlated negatively indicating there are practices and policies that high-poverty schools can implement, potentially providing areas of focus for increasing college-readiness. Table 31 contains a Total Normed Walkthrough, SPG without Accountability, and a Combined Walkthrough and SPG Score (TOT\&SPG) comparison to the outcome measures.

\section{Table 31}

Walkthrough and SPG Scores Combined for Overall Process Score Compared to $\underline{\text { Outcome Measures }}$

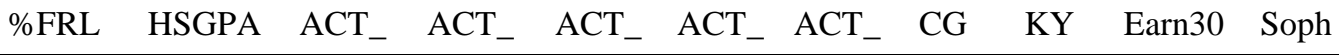




\begin{tabular}{|c|c|c|c|c|c|c|c|c|c|c|c|}
\hline & & & ela & math & read & sci & comp & Rate & CollR & & \\
\hline TOT_norm & -0.69 & 0.56 & 0.68 & 0.60 & 0.66 & 0.54 & 0.65 & 0.45 & 0.35 & 0.25 & 0.55 \\
\hline SPG-Acct_n & -0.27 & 0.53 & 0.43 & 0.45 & 0.47 & 0.37 & 0.45 & 0.25 & 0.00 & 0.43 & 0.34 \\
\hline TOT\&SPG & -0.49 & 0.65 & 0.62 & 0.59 & 0.64 & 0.51 & 0.62 & 0.38 & 0.14 & 0.44 & 0.49 \\
\hline
\end{tabular}

The combined Walkthrough and School Performance Guide score has moderate to strong correlations with eight of the ten outcome measures. The combined score correlates strongly with both internal measures of college readiness (HSGPA), and external measures (ACT_ela, ACT_read, and ACT_comp). The combined score correlates moderately with the external measure of college readiness (ACT_math) and moderately with both measures of college success (Earn30 and Soph), indicating the process as a whole provides a comprehensive review of rigorous instruction at the school level. Independently the walkthrough process has stronger individual correlations with the ACT measures, but the combined score has more consistent correlations indicating the two pieces together (walkthrough and SPG) can give school leadership a more informed global view of how successful the school is being in working toward preparing students for college success.

\section{Discussion}

The results add support to research indicating that standards-based, engaging, rigorous instruction prepares students for postsecondary success. The results suggest that at the school level it may be possible to measure institutional rigor and to inform how well students are being prepared for postsecondary success. This offers opportunities for schools to choose targets for improvements in the rigor of their instruction, which these results suggest could then lead to stronger postsecondary success for their students. I will 
discuss the implications from the School Performance Guide analysis first and then move on to the Walkthrough Process before discussing overall findings.

Previous research has indicated that quantifying rigor at the school level is difficult (Adelman 1999; Conley, 2007), and because of that researchers have chosen to use measures like course selection as a way of measuring academic intensity. However, not all courses are created equally, and a focus on course selection reinforces potential inequities within a system. If a student is taking algebra II, for example, it is vital that all algebra II courses of different levels (advanced, regular, etc.) use rigorous instructional approaches that engage and prepare all students for postsecondary success. The need for rigor in instruction has been supported by research (Kaplan, 2004; Matusevich, O'connor et al. 2009).

\section{Implications for School Performance Guide Results}

The two portions of the input data; the Normed Walkthrough Total (TOT_norm) and the Normed School Performance Guide without Accountability (SPG-Acct_n) both provide insights into how comprehensive the school's approach to preparing students for college success is. During the self-reporting process, if schools have multiple areas where they feel they need improvement, then focusing on the Sustainability Indicators provides the greatest opportunity to ensure the school is preparing its students for postsecondary success. . The attribute sections of the SPG give the school a good picture of how well they are supporting their students academically as indicated by their GPA. The policies and practices in the SPG support establishing a culture of student success which seems to be reflected in stronger student GPAs. 
The accountability attribute did not correlate well with the rest of the SPG. The implications are that schools during this period were overly focused on assessment scores and use considerable resources to track student progress as measured by different tests. The results indicated that when schools felt they were accomplished at developing extensive student data profiles, increasing assessment scores, and targeting instruction to assessments there was either no connection to student success postsecondary or even some negative impact on student college readiness. This does fit with research that indicates high-stakes testing narrows curriculum (Crocco \& Costigan, 2007; White \& Johnson, 2018), does not test all the characteristics that go into college success (Conley 2007; NCTE, 2014) and change how teachers teach by shifting extensive time allocations away from planning for instruction to tracking student data (Valli \& Buese, 2007).

\section{Implications from the Walkthrough Process}

The Total Normed score shows that institutional rigor can be measured. When analyzing the results the data does not necessarily predict if students will be on track to graduate in four years, but does provide good indication that schools who provide instruction that is standards based, engages students through literate approaches, and expects students to engage with the content at the appropriate level have students who persevere and show up for their sophomore year.

Institutional rigor is about a comprehensive approach to instruction and the ACT Standards data shows that impact may not show up in a single department, but if a school have an overall approach standards-based instruction that can have a cumulative effect on college-readiness indicators. The only ACT Standards that reflected directly on student 
success was mathematics. As discussed earlier the mathematics standards are discrete concept/skill standards are most likely easier to connect to college coursework.

The Common Core instructional shifts had consistent connection between math and science and the college readiness and success. Instruction in high school mathematics has been established as more procedural than conceptual (Yu \& Sinh, 2018; Blazar, Litke, \& Barmore, 2016). The instructional shifts have students doing more interaction and sense making with content through reflection, dialogue, and peer interactions. The instructional shifts in science also encourage more student-centered approaches and those approaches have students engage with the content to make predictions, gather evidence, use the language precisely, and make sense of the content rather than focus on answer finding. These align with the National Research Council recommendations for improving mathematics and science in high school (Council, 2002). These are relatively new practices for teachers and provide a specific recommendation for supporting teachers in developing capacity to incorporate these expectations into classroom practice.

The math data was most strongly correlated to college success supporting previous research that showed mathematics course taking as a predictor of college success (Adelman, 1999; Conley, 2007).

The walkthrough data may provide schools with a way of making sure instruction is equitable as well. The strong negative correlations between the Walkthrough Total and Percent of students with Free/Reduced Lunch status was disturbing, since this means that schools with large percentages of students in poverty status tend to have substantially lower amounts of rigorous instruction. The coefficient of determination identifies that almost $50 \%$ of the variance in rigorous instruction may be accounted for by student 
poverty. The impact of poverty has been established, and in these schools, the trend continues to impact student learning (Payne 2005, Burney and Beilke 2008, Simon and Johnson 2015). The walkthrough and self-analysis processes provide schools an intentional way of looking at expectations, policies, and practices that inform instruction to ensure that all students receive the rigorous kinds of educational experiences that prepare them for postsecondary success.

\section{Overall Score Implications}

Two other college-readiness measures were included, the Kentucky Accountability Measure for college readiness and the percent of students going to college. The Kentucky Accountability measure has no evidence for being a strong predictor of student college success, but is a measure that schools are held accountable for when reporting their NCLB and ESSA accountability data. This measure while not widely researched has a strong impact on schools because if they do not meet their accountability index measure they are considered underachieving. One potential issue with the school College-going Rate is that students make make their decision to go or not to go based on whether or not they have achieved College-readiness status as defined by the Kentucky College Readiness Index. Because the KYCollR data does not correlate well with college success data students may be making decision based on flawed data, especially if other measures of college-readiness (HSGPA, ACT) do not indicate they are ready.

The lack of correlation between the multiple measures of rigorous instruction and the Kentucky’s College Readiness indicator may indicate Kentucky’s accountability index is not a good measure of college success. The measure may allow more students 
the opportunity to enter college their freshman year, but is not a good measure of whether they will persevere and show up for college their sophomore year. The Walkthrough Total Score is a more robust measure of college readiness and college success at the school level. Schools going through the self-analysis and walkthrough processes will know if they are providing their students the kinds of experiences that prepare them for college and most importantly, if they are not, then they can use their data to identify specific areas for improvement.

If a student is identified as college ready they are typically encouraged by school counselors and other school personnel to apply and attend college, whether they have met other established measures or not. The consistent moderate and strong correlations indicate that the process of aligning classroom instruction with rigorous expectations can predict better prepare students for college. The two processes (walkthrough and SPG) combined to provide a foundation for strong content knowledge as evidenced by the connection to the ACT content scores as well as HSGPA. In addition the processes correlated with the measures of college success meaning that students from the schools who were rated higher on the walkthrough and SPG were more successful in college, I believe the coupling of observed instructional practice and schools' self-perception of their own strengths and weaknesses suggest an approach to instruction that is standardsbased, implements the Common Core instructional shifts, teaches are the appropriate depth of knowledge, and uses policies and practices suggested for supporting all learners, can have an impact on overall student achievement.

The lack of correlation between instructional practices across the four core content areas within a school (Tables 21-24) suggests that having a whole school focus 
on instruction that is embedded in standards, encompasses the Common Core instructional shifts and containing high learning expectations for all students is difficult. The data still shows that even in a group of high-poverty population schools, the schools with the higher percent free/reduced population have less rigor in instruction. The reasons for this issue are complex, but instruction in these buildings had fewer characteristics of rigor which are controllable through planning and professional learning. Creating a college-going culture in these high-poverty schools, means changing school practice and school culture, this is difficult, time-consuming work (Conley, McGaughy et al. 2010, Deal and Peterson 2016).

The findings from this study do provide some evidence that instruction that leads to college readiness and college success - rigorous instruction - can be quantified. More research is needed to confirm the impacts and to further identify if each section (ACT, $\mathrm{CC}, \mathrm{RRD}$ ) of the walkthrough process provides equal impact on preparation for college. The ACT standards section had the lowest impact on scores but was weighted equally with the instructional shifts and Rigor, Relevance, and Differentiation data. Further study may identify different weights between the three sections, providing more information for where it might be most productive to focus instructional change efforts. 


\section{CHAPTER 4}

\section{EVERY STUDENT SUCCEEDS IS MORE THAN AN ACT}

\section{Introduction}

Every Student Succeeds Act (ESSA) was passed in 2015 as the reauthorization of the Elementary and Secondary Act (ESEA) of 1965. ESSA reworks many of the key components of troubled No Child Left Behind (NCLB) Act, the 2002 renewal of ESEA. In 2015 ESSA reduced the focus on testing to providing students greater opportunity to achieve college and career success. This shift provides states greater flexibility in reaching those expectations and consequently presents schools opportunity to create programs that allow all students to succeed. The law keeps key components with some significant shifts; greater flexibility by states, less focus on testing as the only measure for students to show their learning, greater emphasis on English Language Learners, while continuing to focus on low-performing school reform. States have worked for the last two years to mold their responses to ESSA and are now ready to begin implementing the new systems.

Kentucky’s ESSA plan was approved May 7, 2018 by the U.S. Department of Education. The plan sets lofty goals for the coming twelve year cycle. The long-term academic goal is "to reduce the percentage of students scoring lower than Proficient by 50 percent from 2019 by 2030” Kentucky Department of Education, 2018, p. 42). Trends from the National Assessment of Educational Progress (NAEP) since 2005 have shown for instance that Kentucky fourth graders in mathematics have been able to reduce the percent of 
students who have not met proficiency in mathematics by $19 \%$, growing the percent making proficiency by $48 \%$ (NAEP, 2018). In order to reach this long-term goal, Kentucky will need to reduce the percent of students not meeting proficiency from $60 \%$ to $30 \%$ producing an increase of students making proficiency by $75 \%$. See Tables 32 through 35 for more trends in the NAEP data since 2005 and 2030 projections needed to meet the ESSA goals. Collins and Porras (1994) proposed setting "Big Hairy Audacious Goals" which are likely to be considered questionable from external sources, but regarded as possible internally. Moving this number of students into proficiency would be considered by many to be Big Hair Audacious Goals needing clear focus and energy to shoot for the finish line.

\section{Table 32}

Grade 4 Mathematics Proficiency and Below Proficiency Scores on NAEP and K-PREP $\underline{\text { with ESSA Projections for } 2030}$

\begin{tabular}{ccccc|cccc}
\hline \multicolumn{4}{c}{ Below Proficient } & \multicolumn{2}{c|}{ Proficient } & \multicolumn{4}{c}{ Below Proficient } & \multicolumn{2}{c}{ Proficient } \\
\multicolumn{2}{c}{ Percent } & \% Change & Percent & \% Change & Percent & \% Change & Percent & \% Change \\
\hline 2005 & 74 & & 27 & & 54.82 & & 45.18 & \\
2017 & 60 & $-19 \%$ & 40 & $48 \%$ & 51.4 & $-6 \%$ & 48.6 & $8 \%$ \\
\multicolumn{2}{l}{ ESSA Projections } \\
2030
\end{tabular}

*KDE reports 5th grade math for 2005 KPREP Data

\section{Table 33}

Grade 8 Mathematics Proficiency and Below Proficiency Scores on NAEP and K-PREP with ESSA Projections for 2030

\begin{tabular}{|c|c|c|c|c|c|c|c|c|}
\hline & \multicolumn{4}{|c|}{ NAEP } & \multicolumn{4}{|c|}{ K-PREP } \\
\hline & \multicolumn{2}{|c|}{ Below Proficient } & \multicolumn{2}{|c|}{ Proficient } & \multicolumn{2}{|c|}{ Below Proficient } & \multicolumn{2}{|c|}{ Proficient } \\
\hline & Percent & $\%$ Change & Percent & $\%$ Change & Percent & $\%$ Change & Percent & $\%$ Change \\
\hline 2005 & 78 & & 22 & & 63.66 & & 36.34 & \\
\hline 2017 & 72 & $-8 \%$ & 29 & $32 \%$ & 51.3 & $-19 \%$ & 48.7 & $34 \%$ \\
\hline
\end{tabular}




\section{Table 34}

Grade 4 Reading Proficiency and Below Proficiency Scores on NAEP and K-PREP with $\underline{\text { ESSA Projections for } 2030}$

\begin{tabular}{|c|c|c|c|c|c|c|c|c|}
\hline & \multicolumn{4}{|c|}{ NAEP } & \multicolumn{4}{|c|}{ K-PREP } \\
\hline & \multicolumn{2}{|c|}{ Below Proficient } & \multicolumn{2}{|c|}{ Proficient } & \multicolumn{2}{|c|}{ Below Proficient } & \multicolumn{2}{|c|}{ Proficient } \\
\hline & Percent & $\%$ Change & Percent & $\%$ Change & Percent & $\%$ Change & Percent & $\%$ Change \\
\hline 2005 & 69 & & 31 & & 32.5 & & 67.5 & \\
\hline 2017 & 62 & $-10 \%$ & 38 & $23 \%$ & 50.1 & $54 \%$ & 49.9 & $-26 \%$ \\
\hline \multicolumn{9}{|c|}{ ESSA Projections } \\
\hline 2030 & 31 & $-50 \%$ & 69 & $82 \%$ & 25.05 & $-50 \%$ & 74.95 & $50 \%$ \\
\hline
\end{tabular}

\section{Table 35}

Grade 8 Reading Proficiency and Below Proficiency Scores on NAEP and K-PREP with $\underline{\text { ESSA Projections for } 2030}$

\begin{tabular}{lcccc|cccc}
\hline & \multicolumn{4}{c|}{ NAEP } & \multicolumn{4}{c}{ K-PREP* } \\
& \multicolumn{2}{c}{ Below Proficient } & \multicolumn{2}{c}{ Proficient } & \multicolumn{3}{c}{ Below Proficient } & \multicolumn{2}{c}{ Proficient } \\
& Percent & \% Change & Percent & \% Change & Percent & \% Change & Percent & $\%$ Change \\
\hline 2005 & 69 & & 31 & & 38.18 & & 61.82 & \\
2017 & 66 & $-4 \%$ & 34 & $10 \%$ & 45.4 & $19 \%$ & 54.6 & $-12 \%$ \\
$\begin{array}{l}\text { ESSA Projections } \\
2030\end{array}$ & & & & & & & \\
\hline
\end{tabular}

*KDE reports 7 th grade reading for 2005 KPREP Data

The purpose of this paper is to identify the expectations that Kentucky has outlined for itself in response to the goals of ESSA, and to identify approaches that will allow Kentucky students to meet these Goals. I will explore ESSA itself to identify changes from NCLB and areas where Kentucky can approach accountability differently, and then examine Kentucky's approved ESSA Accountability System to further identify approaches Kentucky can implement to move more Kentucky students toward postsecondary preparedness and success. 
The ESSA era in Kentucky is going to take considerable action and focus to achieve the outlined vision. There are specific areas where Kentucky has already made growth and has shown the ability to increase opportunity for all students. I will examine the focus on transitions in Kentucky's plan, it's efforts to use dual enrollment programs as agents to get more students college ready and get more students to go to college, and the opportunity to increase rigor in high school instruction while supporting underserved students in being successful in the challenges of being successful in courses with higher expectations.

\section{Every Student Succeeds Act}

The Obama administration along with bipartisan support from Congress designed ESSA to address some of the "one size fits all" policies of NCLB (Munoz, 2015). The bill was also a move away from assessments being the only measure of student proficiency to a more balanced approach. The critical sections of ESSA continue the federal goals while allowing states to build their responses to them. Table 36 outlines the main parts of ESSA.

\section{Table 36}

\section{$\underline{\text { Key components of ESSA }}$}

\begin{tabular}{|c|c|}
\hline $\begin{array}{l}\text { Accountability } \\
\text { Plans }\end{array}$ & $\begin{array}{l}\text { - States created individual responses to ESSA and submitted plans for approval by } \\
\text { Department of Education. } \\
\text { - States identify specific goals both long-term and smaller interim goals that allow } \\
\text { the state to respond to the different needs of their populations. The goals must } \\
\text { still address proficiency as measured by a state assessment system, graduation } \\
\text { rate, and as mentioned English-language learner (ELL) proficiency previously } \\
\text { - The state must design an Accountability System for elementary, middle, and } \\
\text { high schools. }\end{array}$ \\
\hline $\begin{array}{l}\text { Accountability } \\
\text { Systems }\end{array}$ & $\begin{array}{l}\text { - Elementary and Middle must measure at least four indicators: proficiency, ELL } \\
\text { proficiency, plus another academic factor that can be analyzed by subgroup. }\end{array}$ \\
\hline
\end{tabular}


- Identify an additional indicator that is different from the ones identified above. This indicator can be student engagement, teacher engagement, access to and completion of advanced coursework, postsecondary readiness, school climate/safety, or something different than the state feels can further educational attainment for its students.

- Participation rates are a separate factor with $95 \%$ being the expected threshold.

- High Schools have the same expectations as elementary and middle but also have graduation rates added to the set of indicators.

- Finally, each state will determine the algorithm for determining school performance. The academic factors (tests, graduation rate, etc.) will have to have more significant impact than factors that get at students' opportunities to demonstrate learning and postsecondary readiness.

Lowperforming Schools

School Interventions

- Schools that continue to perform poorly in the accountability ratings, the bottom $5 \%$ of schools, will still be targeted for intervention.

- High schools that graduate less than $67 \%$ of students will receive intervention as will schools where subgroups of students are struggling.

- Interventions for the bottom 5 percent of schools and high schools with high dropout rates include:

- Districts will develop an evidence-based plan along with teachers and staff

- If turnaround efforts are not achieved in four years, then the state will be required to step in with a plan of its own, including taking over the school if deemed necessary, fire the principal, or turn the school into a charter.

- Districts can also allow parents to school choice out of low-performing schools as long as the highest need population has priority.

- For schools with subgroup gaps, interventions include:

- Development of an evidence-based plan to support particular groups of students who are falling behind.

- If the plan does not bridge the gap, then districts must step in.

- For schools with chronic subgroup underperformance, a comprehensive improvement plan must be created with the state, district, and school.

- Funding for low-performing schools is shifted to the Title I block grant with states being allowed to set aside up to $7 \%$ of that funding for low-performing schools, an increase of $3 \%$ from NCLB.

- States are required to adopt 'challenging' academic standards. The federal government (specifically the Secretary of Education) is prohibited from

Standards encouraging a state to pick a particular set of standards (including the Common Core).

- States are required to disaggregate assessment data by subgroup including ELL, special education, race, and poverty) and are not allowed to combine groups for 'super subgroup' analysis

- States can consider piloting local assessments if they choose, but only seven states will be provided that waiver and only for a limited time. 


\begin{tabular}{|c|c|}
\hline & $\begin{array}{l}\text { - At the high school level, districts can use local or nationally recognized } \\
\text { assessments with state permission. }\end{array}$ \\
\hline $\begin{array}{l}\text { English- } \\
\text { language } \\
\text { Learners }\end{array}$ & $\begin{array}{l}\text { ELL proficiency is a priority and the reason for this subgroup moving from Title } \\
\text { III to Title I } \\
\text { - States can include ELL scores can be counted after students have been in the } \\
\text { country for a year, as is current law. During the first year, student test scores will } \\
\text { not count toward schools rating, but ELLs will need to take the exams and have } \\
\text { results reported publicly. } \\
\text { ELL proficiency is a priority and the reason for this subgroup moving from Title } \\
\text { III to Title I }\end{array}$ \\
\hline $\begin{array}{l}\text { Special } \\
\text { Education }\end{array}$ & $\begin{array}{l}\text { - Only } 1 \text { percent of students overall can be given alternative tests, approximately } \\
10 \% \text { of students in special education.) }\end{array}$ \\
\hline Teachers & $\begin{array}{l}\text { - Teacher evaluation will no longer have to be connected to student outcome } \\
\text { - No longer is there a 'highly qualified teacher' requirement. } \\
\text { - The Teacher and School Leader Innovation Program provides grants to districts } \\
\text { to pilot different pay and teacher-quality improvement programs. } \\
\text { - ESSA includes resources for helping train teachers on literacy and STEM } \\
\text { instruction. }\end{array}$ \\
\hline Funding & $\begin{array}{l}\text { - A new } 1.6 \text { billion dollar block grant consolidates program funding giving } \\
\text { schools and districts greater flexibility in how they allocate funding moving } \\
\text { forward. } \\
\text { - Districts that get more than } \$ 30,000 \text { have to spend at least } 20 \text { percent of their } \\
\text { funding on at least one activity that helps students become well-rounded, and } \\
\text { another } 20 \text { percent on at least one activity that helps students be safe and healthy. } \\
\text { Moreover, part of the money can be spent on technology. } \\
\text { - Title I funding formula not changed but there are changes to Title II } \\
\text { - States are required to keep state funding above minimum thresholds to } \\
\text { receive federal funding }\end{array}$ \\
\hline
\end{tabular}

(Every Student Succeeds Act, 2015; Education Week, 2015; Munoz, 2015)

In May of 2018, Kentucky received the final OK for its response to ESSA. While greater state flexibility will allow for states to develop responses tailored to their individual needs and hopefully create stakeholder buy-in for the policies, the finalization process for most of the state plans took longer than expected (Munoz, 2015). Reviewers looked at each component of each plan and provided detailed feedback so that states could revise their plan to be sure to meet the expectations of ESSA. Kentucky's state plan creates a new accountability system for schools and districts. The system focuses on 
transitions from elementary to middle, middle to high, and high to postsecondary. The Kentucky Department of Education (KDE) has defined transition readiness as "the attainment of the necessary knowledge, skills and dispositions for a student to successfully transition to the next level of his or her educational career." (Kentucky Department of Education, 2018e, p. 2). The system at the elementary and middle school levels does not look substantially different and includes the components as outlined in Table 37 below. Reviewers praised several of the components of Kentucky plan including those identified in Table 38 below. The new approach to accountability also allows Kentucky to address important aspects of its State Systemic Improvement Plan to serve Kentucky students more effectively. One characteristic of Kentucky's plan is continuous improvement process and the implementation of innovations to address student needs (Kentucky Department of Education, 2018d). KDE wants schools to build creative responses to issues, monitor implementation, and use data to refine the implementation process.

\section{Table 37}

Kentucky’s ESSA accountability system components

- Transition Readiness is the attainment of the necessary knowledge, skills and
dispositions for a student to successfully transition to the next level of his or her
educational career.




\begin{tabular}{|c|c|}
\hline & $\begin{array}{l}\text { - Students at the high school level must earn a high school diploma and meet one type of } \\
\text { readiness (Academic or Career). } \\
\text { - In addition, students who have received English Language services during high school } \\
\text { must meet criteria for English language proficiency. }\end{array}$ \\
\hline 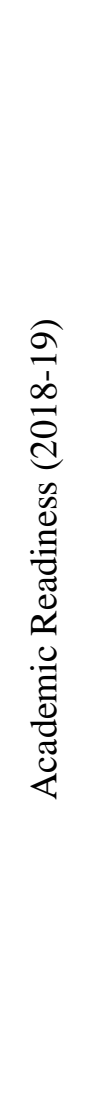 & $\begin{array}{l}\text { - Benchmarks, determined by Council on Postsecondary Education (CPE) on a college } \\
\text { - Admissions exam; OR } \\
\text { OR grade of B or higher in each course on } 6 \text { or more hours of KDE-approved dual credit; } \\
\text { - A score of } 3+\text { on exams in } 2 \text { or more Advanced Placement courses; OR } \\
\text { - A score of 5+ on } 2 \text { exams for International Baccalaureate Courses; OR } \\
\text { - Benchmarks on } 2 \text { or more Cambridge Advanced International examinations; OR } \\
\text { - Completing a combination of academic readiness indicators above. } \\
\text { - Demonstration of academic readiness shall include one quantitative reasoning or natural } \\
\text { sciences and one written or oral communication, arts and humanities, or social and } \\
\text { behavioral sciences learning outcomes. } \\
\text { - Demonstration of academic readiness shall include one quantitative reasoning or natural } \\
\text { sciences and one written or oral communication, arts and humanities, or social and } \\
\text { behavioral sciences learning outcomes. } \\
\text { - Within each bucket, students may choose to demonstrate readiness through } \\
\text { Benchmark(s) on a college admissions exam } \\
\text { or*, Approved dual credit coursework and scoring a B or higher, or*, AP Exam Score of } \\
\text { 3+, or*, IB Exam Score of } 5+, \text { or*, benchmarks on a CAI exam } \\
\text { *Students are permitted to complete a combination of academic readiness indicators. }\end{array}$ \\
\hline 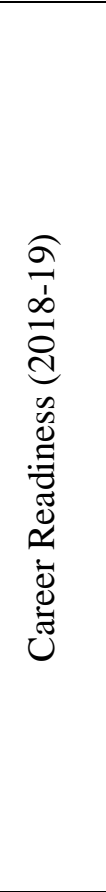 & $\begin{array}{l}\text { - Benchmarks on Industry Certifications (Approved by the Kentucky Workforce } \\
\text { - Snnovation Board on an annual basis); OR } \\
\text { Pcoring at or above the benchmark on the Career and Technical Education End-of- } \\
\text { Program Assessment for articulated credit; OR } \\
\text { - A grade of B or higher in each course on } 6 \text { or more hours of KDE-approved Career and } \\
\text { Technical Education dual credit OR } \\
\text { - Completing a KDE/Labor Cabinet-approved apprenticeship; OR } \\
\text { - Completing a KDE-approved alternate process to verify exceptional work experience. } \\
\text { - KDE/Labor Cabinet-Approved Apprenticeship (TRACK - Tech Ready Apprentices for } \\
\text { Careers in Kentucky) - Students enrolled in a TRACK Pre-Apprenticeship or Youth } \\
\text { Apprenticeship who receive the TRACK certificate will be identified as career ready. } \\
\text { - KDE-approved Exceptional Work Experience - Exceptional Work Experience is } \\
\text { approved when a secondary student proves extraordinary recognition, achievements, } \\
\text { growth and essential skills through a work experience beyond traditional work-based } \\
\text { learning by demonstrating superior knowledge, exposure, and/or skills that are aligned } \\
\text { with a valid industry-recognized certification or CTE End-of-Program Assessment } \\
\text { (formerly known as KOSSA) in the same area as the work experience. }\end{array}$ \\
\hline
\end{tabular}




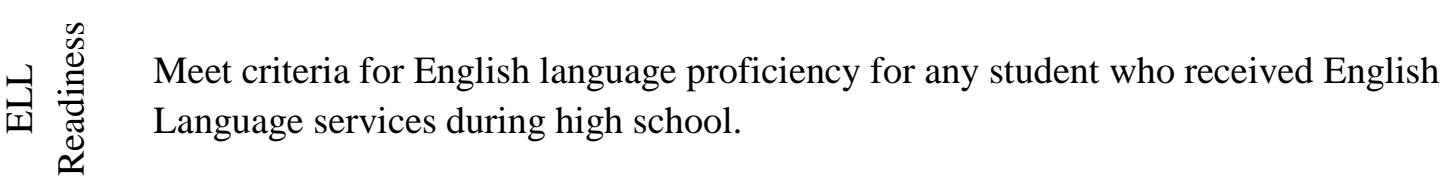

(Kentucky Department of Education, 2018)

Table 38

Peer reviewer feedback on Kentucky's ESSA plan

A panel of four peer reviewers specifically cited these strengths of Kentucky's plan:

- the inclusion of growth of individual students toward proficiency and beyond

- focus on reducing the achievement gap

- inclusion of social studies and science in accountability

- identification of both Title I and non-Title I schools for comprehensive support and improvement

Reviewers also noted the state's unique opportunity and access indicator, which includes multiple measures of school quality and student success.

Among the strengths mentioned:

- inclusion of visual and performing arts, physical education, career exploration, cultural studies, and career and technical education including a work ethic certification

- focus on high-achieving students in addition to those who are low-performing

- whole-child supports to address a variety of student and family needs

- opportunity for schools and districts to highlight their focus or priorities

- $\quad$ plan to report additional measures not included in the accountability system

(Kentucky Department of Education, 2017; Northern Kentucky Tribune, 2017)

\section{Assessing local standards}

Standards-based instruction is one of the most important aspects of high-stakes accountability. The premise is that if standards help define what students will be assessed on, instruction can be developed around those standards and teachers can support student learning focused on the acknowledged standards. Since the adoption of the Common Core State Standards, this has been a key issue with several of the assessments used to measure student learning. In high school, the end-of-course assessments used to measure what high school students in Kentucky were learning had been based on ACT's Quality Core Standards and not Kentucky’s Academic Standards. 
ACT developed the Quality Core Curriculum as a response to its research with the Education Trust into what it takes to be on course for college success (ACT, 2004). KDE cross walked the standards to identify alignment to the Common Core State Standards. As an example, examination of the algebra Common Core standards had a much greater inclusion of problem-solving, some standards were not covered or were covered with a different focus, and importantly, the Quality Core standards did not have the Mathematical Practice Standards. See Table 39 for example comparison of differences between the Common Core and Quality Core algebra II standards. This paper is not an analysis of the ACT Quality Core Standards, but the comparison provides a backdrop for the problem that teachers in Kentucky had been expected to teach Kentucky's Academic Standards while being assessed through an end-of-course exam aligned to Quality Core Standards. Upon hearing that Kentucky would adopt the Quality Core End-of-Course exams, one teacher announced in 2010, "Kentucky is not a Common Core state; it's a Quality Core state." This split in focus kept Kentucky mathematics instruction from meeting the goals of aligned

\section{Table 39}

Comparison between Quality Core and Common Core algebra II standards

\begin{tabular}{|c|c|c|c|c|c|c|}
\hline \multirow{2}{*}{$\begin{array}{l}\text { Common Core } \\
\text { MPS }\end{array}$} & \multicolumn{6}{|c|}{$\begin{array}{l}\text { N.CN.9 (+) Know the Fundamental Theorem of Algebra; show that it is true for } \\
\text { quadratic polynomials. }\end{array}$} \\
\hline & $\begin{array}{l}\text { Reason Abstractly } \\
\text { and quantitatively }\end{array}$ & & $\begin{array}{l}\text { ict Viable } \\
\text { ents }\end{array}$ & Attend to $\mathrm{Pr}$ & cision & $\begin{array}{l}\text { Look for and Make } \\
\text { use of Structure }\end{array}$ \\
\hline Quality Core & \multicolumn{6}{|l|}{ No equivalent } \\
\hline Common Core & \multicolumn{6}{|c|}{$\begin{array}{l}\text { A.SSE.1a Interpret expressions that represent a quantity in terms of its context.* } \\
\text { (*Modeling standard) a. Interpret parts of an expression, such as terms, factors, and } \\
\text { coefficients. }\end{array}$} \\
\hline MPS & \multicolumn{2}{|c|}{$\begin{array}{l}\text { Reason Abstractly and } \\
\text { quantitatively }\end{array}$} & \multicolumn{2}{|c|}{ Model with Mathematics } & \multicolumn{2}{|c|}{$\begin{array}{l}\text { Look for and Make use of } \\
\text { Structure }\end{array}$} \\
\hline Quality Core & \multicolumn{6}{|c|}{$\begin{array}{l}\text { QualityCore: A.SSE.1a and A.SSE.1b undergird many standards within the assessed } \\
\text { QC conceptual areas, including, but not limited to: F.1.a, F.1.b, G.1.c }\end{array}$} \\
\hline Common Core & \multicolumn{6}{|c|}{$\begin{array}{l}\text { A.SSE.1b Interpret expressions that represent a quantity in terms of its context.* } \\
\text { (*Modeling standard) b. Interpret complicated expressions by viewing one or more of }\end{array}$} \\
\hline
\end{tabular}




\begin{tabular}{|l|l|l|l|}
\hline \hline & \multicolumn{2}{|l|}{$\begin{array}{l}\text { their parts as a single entity. For example, interpret } \mathrm{P}(1+\mathrm{r})^{\mathrm{n}} \text { as the product of P and a } \\
\text { factor not depending on P. }\end{array}$} \\
\hline MPS & $\begin{array}{l}\text { Reason Abstractly and } \\
\text { quantitatively }\end{array}$ & Model with Mathematics & $\begin{array}{l}\text { Look for and Make use of } \\
\text { Structure }\end{array}$ \\
\hline Quality Core & $\begin{array}{l}\text { QualityCore: A.SSE.1a and A.SSE.1b undergird many standards within the assessed } \\
\text { QC conceptual areas, including, but not limited to: F.1.a, F.1.b, G.1.c }\end{array}$ \\
\hline
\end{tabular}

In Kentucky's response to ESSA, it moved from a vendor developed end-ofcourse assessment to one developed by the state to address the state standards. Kentucky has dropped alignment to the Common Core State Standards but has kept a vast majority of the standards including the MPS (standards are still going through the revision process at the time of this writing). Development of an end-of-course exam written directly for Kentucky Academic Standards will provide the possibility of better alignment between daily instruction and the assessments and will create the expectation that teachers address the MPS. The MPS describe varieties of expertise that mathematics educators at all levels should seek to develop in their students (Common Core, 2009).

A finding of high-stakes accountability is a narrowing of the curriculum to standards that are addressed on the assessments (Ladd 2017; Dee \& Jacob 2010; Jennings $\&$ Rentner 2006). Since the assessments were dominated by multiple choice questions, how students were expected to show what they had learned was limited. Kentucky is designing the new end-of-course assessments to include a variety of assessment items including; multiple choice, multiple select, extended response, and essay items. Also, the end-of-course exams have questions that are grouped in clusters, in which questions are related to a topic or contextual backdrop (Kentucky Department of Education, 2018a).

For instance, in algebra II the cluster of questions is developed around a contextual modeling situation and students are expected to be able to interpret data from the situation as well as answer procedurally (recall) oriented problems about the 
mathematics topic being modeled. This cluster design makes contextual situations paramount during instruction and pushes instruction beyond recall level approaches.

The clustering method will have less of an impact on English II as the reading and writing standards are process standards to be applied to situations (Pondiscio, 2016). In biology, assessments are already designed to have students look at a contextual situation, apply their knowledge to make sense of what is happening, and make predictions and analyze results (Kentucky Department of Education, 2018c). Kentucky science teachers have been implementing through course tasks for two years and will be able to adapt to the new assessments with greater ease.

In algebra II the new approach to assessment will mandate the most significant change to instruction as teachers will have to greater focus on application and modeling in mathematics than previously. The inclusion of the contextual clusters of questions will also force teachers to teach to a higher level of learning than recall increasing the rigor of instruction. Students will be expected to apply their learning to unique situations rather than perform recall level procedural manipulations (Schoenfeld 2014; Blum and Niss 1991). There are multiple promises with Kentucky's new end-of-course assessments including tight alignment to KAS, and expecting students to show their learning beyond the recall level and beyond multiple choice questions. One drawback is that this new, unique system will make it more difficult for Kentucky to compare how it is doing to other states.

Even before the new, more rigorous end of course assessments could go into effect, interim Commissioner for Education Wayne Lewis announced in his weekly Commissioner's Email that the end of course assessments would no longer be given and: 
The Kentucky Board of Education will also consider the department's proposal for revised high school graduation requirements. At its June 2018 meeting, I made the case to the board that receiving a diploma in Kentucky should require the demonstration essential skills and content knowledge necessary for transition to postsecondary and/or the workforce. The proposed regulation requires that students meet a passing point in reading and foundational mathematics on a new state-required test to be administered in the spring of grade 10. (July 23, 2018, p. 1)

This potential shift has implications for instruction and for course taking for all students, especially students who do not score proficient on the sophomore assessment. Kentucky's Big Hairy Audacious Goals (BHAGS) require focus and energy to accomplish. This shift in focus to minimal requirements may impact accomplishment of the BHAGS!

Kentucky will continue to offer its Kentucky Performance Rating for Educational Progress (K-PREP) tests throughout elementary and a writing test to sophomores and juniors in high school (Kentucky Department of Education, 2018b). The state will also offer a college readiness predictor exam to juniors (at the time of this writing the vendor for the college readiness predictor exam had not been determined).

\section{Opportunities for dual enrollment}

The increased flexibility in the system allows for districts to take advantage of their strengths while still providing excellent services for all students. Kentucky schools and school districts are not created equal. The new accountability system has a strong focus on academic readiness, but the increased flexibility with dual credit as a 
certification mechanism will have an impact on rural schools. Often rural schools do not have the teacher staffing to be able to teach a wide range of courses or have teachers with the necessary credentials to a wide range of Advanced Placement (AP), International Baccalaureate (IB), or Cambridge International (CI) courses. With the adjustment to be able to include dual enrollment courses as a qualifier for academic readiness, these schools will be able to supplement their internal capacity to teach these high-level courses with in intentional partnerships with regional public universities, local community colleges, and private colleges/universities.

It is crucial that students be provided dual credit opportunities that not only provide them with the knowledge they need to pass the class, but also the skills to be successful in a postsecondary setting after graduation. There has long been a debate about which program is better for students, AP like course or a dual credit course. Research has shown that both offer value to students' college-readiness (Klopfenstein, 2012; Sadler, Sonnert et al. 2016). Klopfenstein goes on to identify that dual enrollment versus AP, IB, or CI is likely contingent on such varied factors as a school's geographic factors, student's academic profile, and student postsecondary aspirations.

In Kentucky geographic location plays a large role as $48 \%$ of high schools classify as rural (U.S. Department of Education, 2017). Aspiration to go to college has long lagged for rural students (Tieken, 2016) but given that $86 \%$ of Kentucky students aspire to attend college (ACT, 2017), it is essential that schools provide students experiences that not only prepare them for college but give them the skills necessary to be successful. Adelman (2006) identified that the single most important predictor of college success is the rigor of the courses that students take in high school. Over 20 years 
ago, Swanson, Mehan, and Hubbard (1995) determined that in order for students to succeed in challenging courses, they need academic and social support, reinforcing the need for tools to be successful, the support to learn how to use those tools, and the time to embed those tools into practice.

\section{College-Readiness}

Under NCLB, Kentucky increased the percent of students who were college ready. In 2014, Kentucky's Legislative Research Commission analyzed Kentucky's College Readiness data. Percent of students college-ready increased 23 percentage points from 2011 to 2014. However, most of the increase, 18 percentage points, came through the KYOTE or Compass assessments and not from increased student success on the ACT assessment. Using alternative assessments rather than the ACT may indicate a less successful measure of college readiness. Students are being labeled college ready using a less rigorous set of expectation, potentially providing a false sense of preparedness. In an analysis of instruction in high-poverty GEAR UP schools, results found that Kentucky's college readiness indicator for these schools was only moderately correlated to ACT scores and college success outcomes, see Table 39. Kentucky's college readiness measure (KYCollR) is only moderately correlated with data that has been identified as predicting success in college or showing actual success toward attaining a degree: ACT score data (ACT_ela, ACT_math, ACT_read, ACT_sci, and ACT_comp), high school grade point average (HSGPA), attending college (CGRate), earning 30 hours your freshman year (Earn30), and students returning for their sophomore year as expected (Soph). It is most highly correlated with College-going rate potentially indicating that students are making college-going decisions based on this status. The lack of correlation may indicate that if 
Kentucky is going to create a college-going culture in its high schools it must make sure that students who are identified as college ready are supported while in high school and on the college campus to be successful.

In the new accountability system, the KYOTE is no longer used as a measure of transition readiness. This opens up new opportunities for using KYOTE including testing for students who have not met the prerequisites for placement into a dual credit course (

\section{Table 40}

$\underline{\text { Pearson Product-moment Correlation Coefficients between College Readiness Indicators }}$ and College Success Indicators in 21 high-poverty high schools

HSGPA ACT_ela ACT_math ACT_read ACT_sci ACT_comp CGRate Earn30 Soph

\begin{tabular}{ll|llllllll}
\hline KY CollR & 0.44 & 0.51 & 0.44 & 0.54 & 0.40 & 0.50 & 0.57 & 0.24 & 0.42 \\
\hline
\end{tabular}

In June the Kentucky Council on Postsecondary Education voted to establish minimum requirements for enrollment at the public universities across Kentucky. Western Kentucky University (WKU) established that students who do not have a high school grade point average of at least a 2.0 will not be admitted (Mudd, 2018). Students will need to go through an intensive five week summer program prior to enrollment or go to the Kentucky Community and Technical College System prior to enrolling at WKU. The goal is to make sure students have the skills and supports necessary to be successful. Students who need remediation will be enrolled in co-requisite courses which are credit bearing but have additional supports including additional instruction, tutoring, or mentoring. This is not part of the K-12 ESSA program but is part of a comprehensive approach to increasing the number of students who are enrolling in college and supported in being successful. 
As Kentucky moves into a new accountability era with ESSA, it must be very careful. Initial Proficiency scores are often arbitrary or influenced by political process (Ho, 2008). Kentucky may be using new assessments to measure college-ready which will present a situation where Ho warns that measuring proficiency is not the only concern. Proficiency must be coupled with a focus on gaps between groups in order to ensure all students are provided an opportunity to be successful. Kentucky's new system has this focus on gap reduction. Kentucky has increased its high school graduation rate to the seventh highest rate in the country (KDE, 2018). Results during the NCLB era indicate that Kentucky has made great progress toward preparing more students for postsecondary success, but the $88 \%$ cohort graduation rate is undermined by the fact that less than $60 \%$ of graduates pursue a postsecondary degree or credential at almost $40 \%$ of them require remediation in at least one course (Timmell, 2014

\section{Districts of Innovation}

In addition to the changes in accountability, Kentucky is moving to make it easier for schools to obtain the School/District of Innovation status. The innovation title allows schools to serve their students with greater flexibility, and to "rethink" how schools approach serving their students. With this flexibility, schools have already started looking at how they get students into more advanced coursework earlier, modify student schedules to give them more time on higher level courses to build an understanding of college-level study skills. Innovative early college programming is present in a variety of districts, including; Eminence Independent Schools' partnership with Bellarmine University, Bullitt County Advanced Math and Science program partnership with Jefferson Community and Technical College (JCTC) Bullitt County, Frankfort 
Independent's partnership with Kentucky State University Early College Academy, the Early College Academy of Daviess County, and a consortium of districts that came together to create a project-based learning school and early college program with JCTC Carrollton Campus, named iLead Academy.

These approaches are particularly interesting because some are the product of the innovation program and others are work through the existing framework to come to a different outcome for students. iLead Academy is not the product of schools of innovation, but just an innovative response to student needs. The five founding districts recognized student desire for more project-based learning (PBL) but struggled to find enough students by themselves to afford to offer a rigorous approach to PBL. The districts could though come together to afford Project Lead the Way and at the same time offer those students a unique opportunity to get an associate's degree upon graduating high school. Project Lead the Way is the nation's leading provider of science, technology, engineering, and math (STEM) programs (Project Lead the Way Kentucky, 2018). The school will have its first graduating class in 2019. These examples are not an exhaustive list of partnerships but do indicate how schools and school districts are already working to provide dual enrollment opportunities for a wider range of students. High Schools also offer dual credit courses throughout the state and with the new accountability rule in place; schools will continue to expand those offerings.

Kentucky is providing schools partners that offer the framework and guidance for schools to be successful in implementing innovative approaches. The partnerships can be with the University of Kentucky's Center for Innovation in Education, with local community colleges, with other regional colleges/universities, or with partners with the 
same goals but outside the higher education realm. The Center for Innovation in Education is working on several fronts with Kentucky schools including building skills and dispositions that students need to be successful in rigorous coursework, as well as, in the workforce. Transforming Education Kentucky is another partner working to prepare students for high-tech careers available across the state (University of Kentucky, 2018). In Kentucky, and especially in rural Kentucky, STEM and technology careers are the fastest growing component of the economy (Bureau of Labor Statistics, 2017). What was once considered a path to leaving the rural community can now be seen as a way of staying in many communities across Kentucky (Kolmar, 2018).

\section{Alignment of Instructional Practice}

While dual enrollment programs provide students a gateway to college, students cannot be expected to learn the skills they need to be successful in these dual enrollment courses alone. Students need time to learn process strategies prior to implementing them (Pearson and Dole 1987). Teachers need to be supported in embedding high expectations for all students in all courses. Implications for dual enrollment instruction are implications for all pedagogy (Hughes \& Edwards, 2012). The National Research Council has identified specific strategies that support conceptual understanding and deepen student learning. These practices include student-centered strategies like working collaboratively, and expressing their learning through a variety of literacy strategies ([NRC], 2002). As students grapple with more complex content, schools have to provide access to support services that enable students to be successful with higher expectations. The Southern Regional Education Board (SREB) identified the gap between college ready and college that manifests itself with dual credit courses because dual credit 
courses and seat time do not guarantee skills and knowledge (SREB, 2010). Along with increased expectations, it is essential to understand that less rigorous courses have lower expectations and often the least qualified teachers (Contreras, 2005; Darling-Hammond, 2004). Research indicates both of these factors negatively impact standardized test performance as well as college readiness (Moore et al., 2010).

Creating the pipeline for students to be successful in these dual enrollment situations means increasing instructional rigor. The concept of rigor has been challenging to measure, and Adelman has chosen to call it academic intensity and defines it as "a composite measure of the academic content and performance the student brings forward from secondary school into higher education. This measure is dominated by the intensity and quality of secondary school curriculum" (Adelman, 1999, p. vi). Adelman's definition focuses on what the student brings forward, without attempting to identify what the school contributes to the students' academic intensity. Barbara Blackburn defines rigor as "creating an environment in which each student is expected to learn at high levels, each student is supported so he or she can learn at high levels, and each student demonstrates learning at high levels" (p. 13). This definition develops rigor as more of an approach that the individual teacher and school as a whole can influence, which will be critical if Kentucky is to achieve its BHAGS.

Classroom practices can be defined that promote student engagement with learning and support more in-depth learning, but this kind of instruction takes intentionality and focus. The narrowing of the curriculum due to testing is also accompanied by a narrowing of instructional practice as teachers feel forced to focus on test scores and less on student learning (Faulkner and Cook 2006). With greater 
flexibility and less testing focus, it is hoped that Kentucky teachers can get back to the student-centered practices that develop critical thinking, allow students to develop their knowledge, and prepare them for rigorous learning later. The National Research Council has studied instructional practices that support advanced learning in high school and promote classroom discourse as valuable so that students can process content as they develop and present solutions, construct viable arguments, and provide evidence to support claims (National Research Council 2013).

\section{Postsecondary skills development.}

Conley (2007) identified postsecondary skills as critical to student success in college. These skills are a mix of cognitive and non-cognitive skills, see Table 41 below. Some of these skills are difficult to measure which therefore makes them difficult to develop, but others have specific characteristics that can be developed

\section{Table 41}

\section{$\underline{\text { Conley's College Readiness Skills }}$}

\begin{tabular}{cc}
\hline \multicolumn{2}{c}{ Key Cognitive Strategies } \\
Analysis & Reasoning, argumentation, proof \\
Intellectual openness & Inquisitiveness \\
Precision and accuracy & Problem-solving \\
\hline \multicolumn{2}{c}{ Academic Knowledge and Skills } \\
Writing & Research \\
Core Content knowledge: English, Mathematics, Science, World \\
Languages, Social Studies, Science, The Arts \\
\hline Academic Behaviors \\
Self-monitoring & Study Skills/Time Management \\
\hline
\end{tabular}

To prepare students for actual success, districts are committing to student skill development as part of their experience in the school system. Danville Independent Schools Danville Diploma Program, Trigg County Public Schools Graduate Profile, and 
Marshall County Public Schools "Six Critical Skills for Marshall County High School Students in the 21st Century" are just three examples showing how schools are committing to the development of the skills necessary for postsecondary success. Other districts in the state are moving in this same direction as evidenced by Frankfort Independent's Graduate Profile development plan announced June $1^{\text {st }}$. Frankfort Independent is garnering "input from local, regional, and international businesses, community members, state and public officials, parents, alumni, teachers, staff, students, internal stakeholders, and international stakeholders" (Barber, 2018). All of these programs take advantage of the focus on authentic, experiential opportunities for students (KDE, 2018), the decreased focus on testing, and Kentucky's commitment to preparing students for success in college and career to embed in instruction and intentionally develop the skills students need (Timerell, 2016; ESSA, 2015).

Above I discussed the importance of dual enrollment in this current system. The system also identifies AP, IB, CI as valid paths toward college readiness. These curricula also provide students opportunity to become college ready in a different way. The course syllabus is developed by a national or international entity and very specifically sets the expectations for garnering credit for the courses as students have to pass an end-of-course assessment developed by the governing body. In Kentucky, the vast majority of schools offer AP courses with fewer offering IB or CI. The AP program has been a cornerstone of advanced coursework in Kentucky for decades.

AP was also the basis for the Advance Kentucky Initiative beginning in 2008. The program had several elements that were keys to success including; open enrollment, taking an AP course in math, science, and/or English, student time-on-task (providing 15- 
18 hours of additional study sessions for each AP course taken along with other supports), and preparing a wider range of students for the high expectations in grades earlier than when AP is offered, especially for non-traditional students (Advance Kentucky, 2015). For teachers, the program offered a variety of professional learning supports including instructional strategies for teachers beginning in the middle grades to support students in developing the skills used in AP courses.

The results of this initiative have been that AP qualifying scores have risen $413 \%$ in the 88 participating high schools (Advance Kentucky, 2013). It is not that all schools have to participate in the initiative, but crafting programs that support equity for all students and that incorporate open enrollment, additional supports for students, early recruitment of non-traditional students, and exposing all students to rigorous instructional practices along with supports is an approach that Kentucky schools can implement and positively impact their students' success. Aside from college readiness accountability ratings, this kind of approach can go towards closing the gaps that have arisen between specific demographic groups in our state.

An example of the impact of the policies of Advance Kentucky is Barren County High School. In 2011, the principal, Keith Hale, directed his and his faculty's attention on ensuring that students met the ACT College Readiness Standards. He required all students to take Advanced Placement or dual credit classes as the default position. Parents had to meet with the principal to exempt their student from the requirement. During implementation, this policy significantly increased the number of students participating in Advanced Placement classes, 200\%, and at the same time increased the number of students passing the qualifying exam, nearly $280 \%$, over that same period 
(Walker \& O’Daniel, 2013). Table 41 represents the increases in qualifying scores, with Barren County outperforming the state and nation by raising expectations and engaging all students in challenging coursework. If Kentucky is going to reach its BHAGS, aligning instruction to ensure that all students are learning at high levels will be a key component.

\section{Figure 1}

Number of AP Math, Science, English Qualifying Score per 1,000 Juniors and Seniors

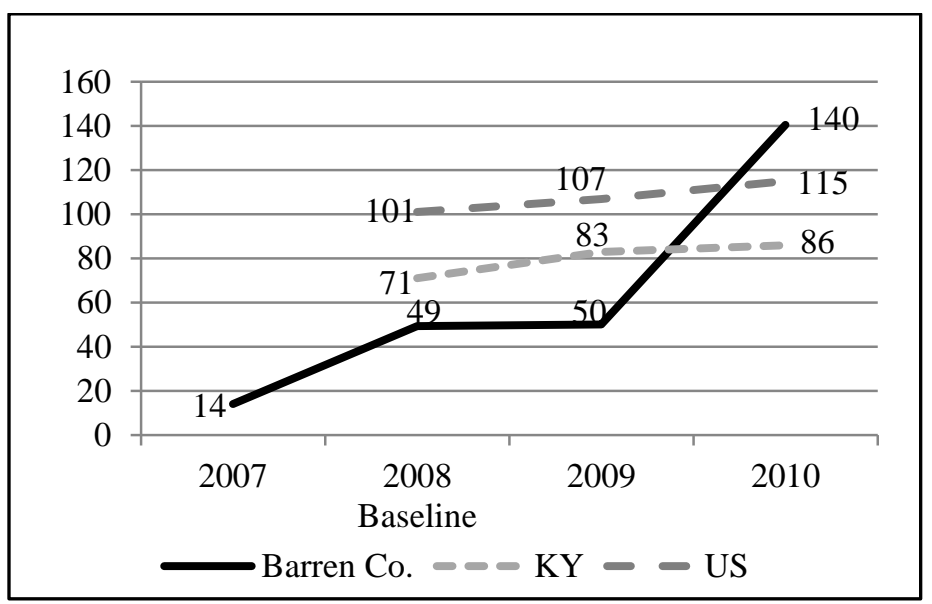

Enrollment in dual credit courses increased at the same rate as Advanced

Placement. Barren County students attended these classes on the college campus and on alternate days were provided tutoring and academic support at the high school to ensure their success.

In a second example, Dr. Jim Jury, principal at Ballard High School in Jefferson County, began to eliminate low-level courses, with implementation following the students as they moved from grade to grade. For the 2013-14 school year, all comprehensive level classes were eliminated in social studies for juniors, and in English, science and social studies for sophomores. The goal was to eliminate all tracked classes by the end of the 2015-16 school year, with the exception of Advanced Placement and 
ECE (special education) (Walker \& O’Daniel, 2013). These examples are models for how districts have embraced efforts to increase rigor for students and succeeded. Now that ESSA is lending an even greater focus on these kinds of courses, schools will be incentivized to explore these and other practices to bring rigor to all students to close the achievement gaps.

\section{Looking beyond math and reading.}

One aspect of Kentucky's plan that was reviewed positively was the inclusion of opportunity and access to a rich curriculum beyond math and reading, including the visual and performing arts, cultural studies, and/or world languages. The impact on the accountability system is limited, but mentioning these in the plan does mean that all students will have to have access to these curricula as they progress through their

education. Kentucky does mandate that all students in middle and high school complete a course in the arts, health and physical education, and world languages. This inclusion does help prevent some of the narrowing of the curriculum that resulted from NCLB (Ladd 2017; Dee \& Hodge 2010). These opportunities also represent opportunity for schools to offer courses that make connections between the content being taught, allowing for deeper learning possibilities. Ensuring that students receive a well-rounded balanced curriculum looks to be a lesson learned from the NCLB era where the focus on testing resulted in a narrowed curriculum focused on knowledge acquisition and not on application of knowledge.

Gifted education. Along with the inclusion of a variety of curriculum, the new system works to support struggling learners while at the same time pushes opportunities for gifted students. It is incumbent that schools identify students for these programs that 
are representative of the population if the achievement gap is to indeed be reduced.

Extensive research points to the negative impact of ability grouping on student learning, especially long-term (Slavin, 1987; Slavin, 1990; Sternberg \& Davidson, 2005; Entwisle \& Alexander, 2018). If Kentucky is going to ensure that all students receive the best instruction available, it will need to consider how students qualify for such programming to make sure that all students have access. Plucker and Barab (2005) discuss contextual giftedness to make sure to realize that in some cases people exhibit giftedness and in others, they do not. Minority students and students from less affluent situations are not as well represented in gifted programming ([NRC], 2002).

The new accountability system is an excellent opportunity for Kentucky schools to consider carefully their gifted identification process to ensure that all students have an opportunity to showcase their learning and ability to learn. In a study about gifted instruction in STEM, minority students who received gifted instruction outperformed the control group with twice the impact as their white counterparts (Young, Young, \& Ford, 2017). Given the potential implications for all students, provides Kentucky not only an opportunity to get more students to the proficient level, but to also move more students into the distinguished level.

\section{Career readiness}

The career readiness component of the accountability system also provides schools and districts enticement to create partnerships. Kentucky has already had a strong push to get more students career ready. How students show, their readiness is shifting

under the new system. WorkKeys assessments are no longer being offered in Kentucky as a career certification. Kentucky will continue to offer Kentucky Occupational Skills 
Standards Assessment (KOSSA), or students may show their readiness through other experiences as outlined in Table 42 below.

\section{Table 42}

Kentucky's High School Transition Readiness Indicators for Career Readiness

Achieve benchmarks on Workforce Innovation Board-approved Industry Certifications

- Earn Kentucky Occupational Skills Standards Assessments (KOSSA) as appropriate for articulated credit

- Earn a score of B or better on 6+ hours of approved CTL dual credit courses

- Complete 2 CTE credits and enroll in the next credit in a CTE program of study

- Complete a KDE/Labor Cabinet-approved apprenticeship

- Complete a KDE-approved alternate process to verify exceptional work experience. **

**To be further outlined and defined by September 2018

The range of options for achieving career readiness gives schools options for how they work with their students. For instance if a district has proximity to a leading industry in Kentucky (i.e. Toyota, Dow, UPS), they can work with that company to design specific and targeted work experiences that support students learning the necessary skills to be successful as well as prove to the company they will make a good employee. More traditional approaches are still supported. In Kentucky, there is a significant gap in the number of welders for the jobs available, 556 at current count, and the number of welders entering the field does not keep up with demand as welders retire (Indeed, 2018). Welding is still a critical pathway that students can take at many high schools across the state. In addition, the dual credit approach holds true for career readiness as well as academic readiness, $6+$ hours of a B or better in CTE coursework, allows a student to become career ready. This also means that if a student takes one English, arts, or social studies course they would be both career and academic ready. The Hechinger Reports the uniqueness of Kentucky's approach to career readiness as equal to college or academic readiness, as well as the unique focus on having students become both college and career 
ready (Felton, 2016). The report quotes Robert Learman in support of the approach, "If you look at what amount of jobs require Algebra II, for example, it's maybe 8 to 10 percent, and on the flip side there are all of these employability and occupational skills that students don't learn and aren't tested" (Felton, 2016). This early focus on career as equal to academic means that Kentucky has built a robust career pathways program and schools can now explore partners to increase opportunities for how students showcase their learning. Kentucky has provided schools a way of innovatively creating new career readiness programming through a phrase in Kentucky's ESSA plan “exceptional work experience" (2018). The alternative pathway has not been fully defined but offers schools and districts the opportunity to work with community stakeholders to clearly define expectations and design experiences for students that ensure students are connecting what they are learning in the classroom with what they experience in the workplace. Career readiness also ties into how schools are approaching the development of key employability skills, which closely mirror many of college readiness skills. As mentioned previously, schools are defining the skills students need to be successful postsecondary through their graduate profiles and enhanced diploma expectations. This is prompting schools to embed processes for developing these skills into classroom instruction as well as work experiences.

\section{Low-Performing Schools}

The 2018-19 school year will continue to be a transition year to new assessments, with the transition to new assessments and implementation of new programs. Assessments from the transition year will be used to determine lowperforming schools and whether targeted support and improvement (TSI) or comprehensive support and improvement (CSI) will be provided. All schools will 
have to work through the new system, but these schools will have the added struggle of being labeled as inferior. As schools move forward, Kentucky is required to support these schools with $7 \%$ of its Title I funding, and expertise from KDE will work with these schools to improve instruction for their students. Bonilla and Dee (2017) identified that students in low-performing schools increased their achievement by $17 \%$ in mathematics and $9 \%$ in reading. While it is not desirable for any school to perform poorly, Kentucky has shown a desire and willingness to support schools in this category for the better. In fact, in many states, lowperforming schools do not improve with the same kind of consistency and robustness as Kentucky schools (Hemelt \& Jacob, 2017; Dee \& Dizon-Ross 2017). In the new system, there will be an additional opportunity for schools to develop approaches that support rigorous instruction for long-term improvement to student learning. As Kentucky proceeds into the next era of accountability this understanding that reform is possible and the proof that Kentucky schools can and do succeed will help schools make sure Every Student Succeeds.

\section{Recommendations}

Under Kentucky's proposed ESSA plan, 2017-18 was a transition year. Kentucky was tasked with building consensus for its ESSA plan across the 173 school districts in the state (KDE, 2018). The BHAGS including closing the achievement gap, reducing students not making proficiency by $50 \%$, and creating the energy to support the twelve-year plan across the state. Jim Collins understood that BHAGS were not achieved in two or three years, but take a decade or more to achieve, and if Kentucky is going to change the education paradigm for its students we must get to work today with a level of intensity that is unrelenting. 
Schools and districts have to make decisions and take actions that will provide all students with the opportunity to be successful once they complete high school. There is not one policy or practice that will do this, but rather a compilation of approaches focusing on student learning, and not test scores, that will best support this outcome. To best make these informed decisions, I offer the following recommendations which are grounded in the results presented in article 2 . These recommendations fall into three categories: systematic approaches to instruction; expanding the focus on data to provide context; and providing models for districts and schools.

\section{Systematic Approaches to Instruction}

In order to impact student learning, we must ensure that all students experience instruction that provides many opportunities for higher level thinking. My research confirms that when students are provided rigorous instructional expectations, more students are prepared to be college ready. Each content area may have instructional characteristics that are unique to them, but the rigor, relevance, and differentiation framework provides a structure that allows schools to ensure that students are being asked to think at levels that prepare them for college.

Rigor, relevance, and differentiation framework. Instruction that expects all students to routinely think at various higher levels provides students a foundation that allows them to be more successful upon graduation. The rigor, relevance and differentiation (RRD) framework helps schools identify the depth of thinking that students are exposed to during instruction, as well as the supports provided to students during learning. It is crucial that schools and all of its key personnel for classroom instruction (administrators, classroom teachers) develop a common vision and 
understanding of rigorous classroom instruction. Using the RRD framework for analyzing daily classroom instruction is helpful for building this common understanding. This RRD analysis would be applied to both lesson plans as well as the actual learning experiences of students. For instance, in an algebra 1 class, if lesson plans indicate an intention for students to apply concepts to solve problems, but in actuality students are provided with only routine practice problem sets that are devoid of problem-solving contexts or applications, the lesson may in fact be recall learning. In this example, the lesson plan may indicate application level of a standard, but the implementation may in fact be recall level thinking.

Using the RRD framework provides structures for teachers and administrators to have conversation and build common understanding about what students are being asked to do and how they are being supported. If students are being asked to apply a concept to a new, unique setting (assimilation), it is important they are provided relevant materials that help them make contextual connections. In his work on critical thinking, Daniel Willingham (2010) identifies that without strong context it is virtually impossible to teach students to think critically. The RRD provides the necessary characteristics to help teachers design and implement instruction that enables students to be successful with more rigorous expectations.

There are some aspects of the RRD framework that are difficult to observe when observing instruction, but that still need to be present to ensure appropriate rigor. When observing in a classroom for 15 minutes or even for an entire lesson, an administrator or other outside observer may not observe flexible time to accommodate all students. This is an important characteristic of rigorous instruction, but one that may need additional 
points of data to confirm (e.g. additional observations, review of longer sequences of lesson plans, conversations with teachers about examples of how they incorporate flexibility by asking for specific, detailed examples, etc.). Another characteristic of rigorous instruction that can be hard to observe in a single observation is providing students multiple ways to demonstrate learning over time. This indicator of rigor, that students are being asked to provide evidence of learning through a variety of assessmentapproaches, is important to capture in ways that may need to extend beyond short classroom observations. . It is important that schools embrace higher expectations for all students in all learning environments, and identifying appropriate ways for both classroom teachers and administrators to capture when, how, and if this is happening is crucial for systematizing high-quality instructional approaches.

Systematizing high expectations over longer time-frames. Once instructional expectations are increased for daily instruction within a particular course by using RRD framework, it is important that expectations for course selection align. Systematically reviewing and bringing intentionality to supporting rigor over multi-year course selection will leverage and multiply the positive impacts of individual courses over time. Previous researchers have identified the importance of taking advanced coursework to better prepare for the rigors of college. It is common for more affluent students to be involved in honors tracks and to take dual enrollment coursework (The College Board, 2014; Conger, Long, \& Iatarola, 2009). By increasing expectations for all students early in their educational experience, and creating the expectation that all students can and will take advanced coursework, we know that more students will be successful (AdvanceKentucky, 2017). Students who successfully complete six hours of dual 
enrollment coursework with a B or higher automatically receive the academic ready designation. Students who take these more challenging Advanced Placement, and International Baccalaureate courses may not get college credit for the course, but the more rigorous expectations have a positive impact on their success in college courses.

School performance guide. As with the RRD framework, the School Performance Guide (SPG) provides schools a structured, detailed process for generating evidence about how they are preparing students for postsecondary success. The SPG moves beyond classroom instruction into the policies that schools implement, and provides evidence at a grain size useful for decision making and actionable implementation. The SPG can provide schools a comprehensive analysis of their schools' policies, and offers actionable guidance schools to take an intentional approach to aligning policies with expectations that all students are provided an opportunity to be college ready upon graduation. This tool is a mechanism that advances these recommendations from conception to actionable implementation.

\section{Focus Beyond Data Analysis}

Data analysis is an important aspect of school decision-making in this era of high stakes accountability. It is important that schools are looking at data, but to be most effective it is critical that key school stakeholders understand that data is multi-faceted. If school leaders are only looking at summative assessment data, this does not provide a full picture of how well they are preparing students for life after graduation.

\section{Models for Leaders}

This recommendation shifts from a focus on schools and districts to the state level. Even in the limited sample of high schools in my analysis of the GEAR UP 
Kentucky project, there were schools who were doing a better job of approaching instruction systematically than other schools were. It was evident in the work that all schools wanted to do better, but that school improvement was difficult. School leaders say all the time, they wish they had an example (or a model) of someone who is already doing this. We need to work diligently to support and cultivate those schools and leaders who are working to address the challenges I have presented here, and offering practicebased models for leaders is one important way to support this work.

In Kentucky, we have a designation that allows schools and districts to embrace innovation and in some cases get policy support to try new approaches. The Districts of Innovation designation should be supported and developed as a model to leverage system change across the state. The power of the designation is that schools have the freedom to outline a plan or program they will implement. It isn't a one-size fits all approach, but rather a process that formally identifies schools that are interested in pushing boundaries.

It is difficult for leaders to innovate in many settings, because stakeholders do not always understand that as new programs are implemented there may actually be an initial reduction in summative assessment scores. Eastwood and Louis (1992) identify many reasons why this dip occurs, but the district of innovation designation should be accompanied by supports for leaders to make sure they are able to inform stakeholders about the progress they are making toward their innovation/change goals.

In addition to the formal state designation as a 'district of innovation', there are other schools and leaders who are doing amazing things in their districts. It is important that all of the entities in Kentucky who are supporting schools are working together. 
Together institutes of higher education, Educational Cooperatives, and Non-profit entities need to work together to support the spread of these innovative approaches. All too often practices are not shared outside of regional affiliations because of lack of communication. If Kentucky is to embrace these system changes, we have to create networks across the state. The Kentucky Department of Education is one of the obvious choices, but other entities must heed the call to step up. As Berea College's Partners in Education has done with its Rural College and Access Summit, we need more opportunities for sharing the best practices we are learning. 


\section{CHAPTER 5}

This dissertation reviews education reform in Kentucky beginning in 1990. The history of reform in Kentucky education is strong and Kentucky has come a long way from the $48^{\text {th }}$ ranked state in education outcomes. It still has a long way to go, but if history tells us anything, it is that Kentucky is not afraid to take chances.

In the first article, we explored Kentucky's response to No Child Left Behind (NCLB) and the different approaches taken to achieve the reforms associated with that law. The high poverty and rural nature of Kentucky made some of the components obsolete. For instance in many rural counties, if the school was not performing adequately there was no other school for the students to go. Schools and districts performed inconsistently on the mandates of proficiency for all students. From this era, Kentucky can claim to have been a leader in developing career readiness alongside of college readiness, as well as, sending more students to college than ever before. Students performed again with mixed results. Kentucky students continue to aspire to go to college at a rate of about $86 \%$, and because of a $23 \%$ increase in students who were identified as college ready, a greater percent of them were able to go and avoid remediation (Bonilla \& Dee, 2017). The college ready label that was part of the NCLB accountability system did allow more students access. Unfortunately that label did not always reflect a student's true preparedness.

Even though the goal of NCLB was to close the achievement gap, the gap was not closed and in many settings the gaps increased. The focus on one imperfect measure of 
achievement forced schools to narrow their focus (and curriculum) on getting students to be able to pass a test. The irony of this focus is that the tests in Kentucky were not always aligned to the standards that Kentucky had adopted to better prepare their students for postsecondary success. This dichotomy played out in several settings including the focus on getting students prepared for college. If a student did not qualify as academic ready on the ACT, then they were forced to take senior classes that were focused on passing less rigorous tests. The classes did not contain the kinds of learning experiences that prepare students for college, but instead provided them the moniker of college-ready while teaching them that rote memorization was an important learning strategy.

The second article explored a group of 21 high-poverty high schools that participated in the states Gaining Early Awareness for Undergraduate Programming GEAR UP) State Grant. The schools were primarily rural with 16 of the schools qualifying for rural status and all having a free/reduced lunch status population of at least $50 \%$. The schools participated in a two part analysis of instruction in their building as part of the grant. The process included classroom observations of every core content course and teacher, and a self-analysis using the School Performance Guide for a College-going Culture.

The results of the process indicated that analysis of instruction through the identified framework at the school level correlated with college readiness and success outcomes. However, the analysis showed that high schools struggle to create a comprehensive vision for instruction across departments and even classrooms. Instruction in one department seldom correlated with instruction in another. In fact English Language Arts and Mathematics had a weak but negative correlation. This lack of 
consistency may be related to the rural status of the schools and the inability of some rural schools to recruit highly-qualified teachers. It may also connect to the issue that teachers struggle to implement whole school reform efforts. Regardless of the reason, the fact is that when a school has consistency in focus on rigor their students perform better on the important measures of college success.

The three components of rigorous instruction provide schools a map of how they can build a comprehensive approach to college-readiness if they are willing to look at their policies, practices, and classroom expectations. Standards-based instruction by itself is not enough, instructional practices must also engage the student in the learning process, and students must be expected to interact with the content through higher-order thinking processes. Leadership can support this focus by ensuring that policies and practices align to research that positively impacts opportunities for all students. Often policies are put in place that limit opportunities for less-advantaged students.

Data from the two processes correlated with both predictors of college readiness and college success providing a tool for measuring how much a school contributes to the college success of its students. Previously researchers have used alternative methods to determine the rigor a students' school contributes to their college readiness, including course selection and high school grade point average. Capturing how much a school contributes to student postsecondary success should not be used for accountability purposes as much as helping schools achieve their mission and vision for educating their students. One disturbing finding was that even in the GEAR UP project that was focused on first generation, high-poverty schools, schools with a higher percentage of free/reduced lunch population had lower rigor scores. It is not enough to just change 
instruction, the schools have to embed policies that provide all students the opportunity to be successful in an educational setting. The School Performance Guide forced schools to own policies that were not equitable including providing all students access to early advanced math classes or making the default enrollment that all students are enrolled in advanced classes. These policies have been shown to be productive for all students, especially high poverty and non-traditional students. Schools have to support students in being successful but must also take into account the supports necessary for adults to implement these kinds of policies

The final article uses what has been learned from the previous two articles to propose how Kentucky, as it moves into the new Every Student Succeeds Act (ESSA) accountability era, can learn from its past to make the system most effective. Kentucky's plan was approved by the United States Education Department in May of 2018 and the analysis provided in the first two articles helps frame areas where Kentucky schools have advantage as well as where they need to think creatively. Again, Kentucky showed in their plan that reform is something Kentucky can do well. The state crafted a response that built on its lessons learned from NCLB and gave schools some freedom to build responses to that fit their unique setting. The state established, as Jim Collins would say, Big Hairy Audacious Goals. These goals may seem impossible to some, but with a strong plan, focused efforts, and a lot of energy Kentucky can achieve its goals. Closing the achievement gaps on K-PREP will take more than a test centered approach. Kentucky has established programs that do more than prepare students for tests, and it will be up to the school districts to create the programs that make sense for them. There are many innovative programs across the state that schools can use as models. There are partners 
who are focused on supporting schools as they implement new programs. The example of Kentucky's focus on dual credit for the last decade established a framework, now schools need to explore how they can open those programs to more students, and provide them the additional supports they need to be successful. Again, these programs exist in Kentucky already for people who are willing to create the opportunity. In addition, Kentucky's career readiness parallel focus was also provided more flexibility for innovation. Schools and their community partners will embrace the push for apprenticeships and 'exceptional work experiences' for their students.

The ESSA plan is not perfect but Kentucky did respond with a plan that was designed to support the whole child. Kentucky included the arts and world language in its response, sending a clear message that all aspects of the curriculum are important. The plan also includes an extra component focused on making sure that not only the gap groups of students are supported in their learning but that gifted students are also provided exceptional experiences. This component will provide Kentucky an opportunity to show how far it has come by making sure that all of Kentucky's students are included in the gifted programming, yet another area where Kentucky schools can showcase innovative approaches to solving big educational issues.

The three articles paint the picture of a Kentucky educational landscape that is struggling to truly embrace college readiness for all, and to address the myriad of challenges students and school face in this effort. The state implemented more rigorous instructional standards with the 2011 adoption of the Common Core, but were hampered by a lack of alignment with assessments. Previously, alignment kept teachers from fully embracing the new standards. Schools want their students to succeed, but are not always 
sure the best way to support students in achieving their aspirations, while meeting the demand of a high-stakes testing system. Instruction in the schools did not align with student aspirations of college-going but did align with using the accountability system to get students identified as college-ready. In article 2 the weak correlations between the Kentucky Accountability College-Readiness Index and student progress toward graduation provided evidence that schools need help in understanding how to navigate the Now that the ESSA assessment system will be written to Kentucky's standards, then perhaps instruction will embrace the challenge of preparing students to be able to demonstrate what they know. As article 2 showed, rigorous instructional approaches have evidence that they support student development of college ready behaviors and skills.

As with NCLB, ESSA has a requirement of monitoring gap groups to make sure the gap in learning is closing. Unfortunately, article 2 continues the disturbing findings that free/reduced lunch status negatively correlated with rigorous instruction. In this new era, schools have data and experience and proven practices that can be implemented. Research-based practices continue to be a mandate as part of ESSA, and it is time schools implement proven interventions with fidelity. Case studies are referenced in article three of schools that are taking the lead in designing programming that provides all schools college ready experiences. These examples highlight the power moving forward that schools and districts can tap into for models of effective practice. 


\section{REFERENCES}

ACT (2004). On course for success. Retrieved June 1, 2018, from https://edtrust.org/resource/on-course-for-success/.

ACT. (2008). The forgotten middle: Ensuring that all students are on track for college and career readiness before high school. Iowa City, IA.

ACT. (2012). The condition of college \& career readiness. Iowa City, IA.

ACT (2017). The condition of college \& career readiness 2017 Kentucky key findings. retrieved February 25, 2018, from https://www.act.org/content/dam/act/unsecured/documents/cccr2017/KentuckyCCCR-2017-Final.pdf.

ACT. (2018). ACT college and career readiness standards. Retrieved July 15, 2018 from http://www.act.org/content/act/en/college-and-career-readiness/standards.html.

AdvanceKentucky. (2015). Elements of Success. Retrieved June 1, 2018, from http://www.advancekentucky.com/our-program/ap-program/elements-ofsuccess/13-our-program/mission/elements-of-success.

AdvanceKentucky. (2013). Five-year review: 2008-2013. Retrieved June 1, 2018, from http://www.advancekentucky.com/our-program/ap-program/elements-ofsuccess/78-our-program/mission/proven-results.

AdvanceKentucky. (2017). 2017 year in review AP college readiness program. Retrieved June 1, 2018 from https://www.advancekentucky.com/sites/default/files/inlinefiles/AdvanceKY_YIR-2017_Dec5.pdf.

Adelman, C. (1999). Answers in the tool box. academic intensity, attendance patterns, and bachelor's degree attainment. US Department of Education.

Adelman, C. (2006). The toolbox revisited: Paths to degree completion from high school through college. US Department of Education.

Akey, T. M. (2006). School context, student attitudes and behavior, and academic achievement: An exploratory analysis. $M D R C$. 
Alan, S., Boneva, T., \& Ertac, S. (2016). Ever failed, try again, succeed better: Results from a randomized educational intervention on grit. HCEO Working Paper No. 2015-009.

Alexander, K., \& Entwisle, D. (1996). Educational tracking in the early years: First grade placements and middle school constraints. Generating social stratification:

Toward a new research agenda, 83-113.

Allen, J. (2013). Updating the ACT college readiness benchmarks. ACT research report series 2013 (6). ACT, Inc. Iowa City, IA.

Amadio, M. (2013). A rapid assessment of curricula for general education focusing on cross-curricular themes and generic competences or skills. Background paper for EFA Global Monitoring Report 14.

Anderson, L. and M. Fulton (2015). Multiple measures for college readiness. Education Commission of the States. Retrieved July 13, 2018 from https://files.eric.ed.gov/fulltext/ED561931.pdf

Angrist, J. D. (2003). Randomized trials and quasi-experiments in education research. NBER Reporter Online (Summer 2003), 11-14.

Arshavsky, N., Edmunds, J. A., Miller, L. C., Corritore, M., Arshavsky, N., Edmunds, J., Corritore, M. (2014). Success in the college preparatory mathematics pipeline: Impact of policies and practices employed by three high school reform models. International Journal of Research, Policy and Practice, 25(4), 531-554.

Bailey, T. R., \& Zumeta, R. (2015). How states can help rural LEAs meet the needs of special populations. Uncovering the productivity promise of rural education. The SEA of the Future, 4, 40-54.

Barnes, W., et al. (2010). College-readiness and academic preparedness: The same concepts? Current Issues in Education 13(4).

Bauer, P. W., et al. (2006). State growth empirics: the long-run determinants of state income growth. Federal Reserve Bank of Cleveland Working Paper 06-06. Retrieved July 13, 2018 from https://core.ac.uk/download/pdf/6986909.pdf

Beegle, D. M. (2003). Overcoming the silence of generational poverty. Talking Points 15(1): 11-20.

Bettinger, E. P. and B. T. Long (2009). Addressing the needs of underprepared students in higher education does college remediation work? Journal of Human resources 44(3): 736-771. 
Bilazs, S. (2015). Education: Where does Kentucky rank \& why does it matter? Retrieved: November 29, 2017, https://cedikentucky.wordpress.com/2015/09/08/education-where-does-kentuckyrank-why-does-it-matter/.

Bishaw, A. \& Benson, C. (2017). Poverty: 2015 and 2016 American community survey briefs. Retrieved November 15, 2017 from http://census.gov.

Bissell, K. A. (2017). College and career readiness: An interview study of high school graduates and their description of postsecondary life (Unpublished doctoral dissertation). University of Pittsburgh, Pittsburgh, PA.

Blackburn, B. R. (2013). Rigor made easy: Getting started. New York, NY: Routledge.

Blazar, D., Litke, E., \& Barmore, J. (2016) What Does It Mean to Be Ranked a "High" or "Low" Value-Added Teacher? Observing Differences in Instructional Quality Across Districts. American Educational Research Journal, 53(2), 324-359.

Bloom, B. S. (1956). Taxonomy of educational objectives: The classification of educational goals: Handbook I, cognitive domain (B. S. Bloom, Ed.). Longmans.

Blum, W. \& Niss, M. (1991). "Applied mathematical problem solving, modelling, applications, and links to other subjects - State, trends and issues in mathematics instruction." Educational studies in mathematics 22(1): 37-68.

Bonilla, S. \& Dee, T. (2017). The effects of school reform under nclb waivers: Evidence from focus schools in Kentucky, National Bureau of Economic Research.

Borsato, G. N., et al. (2013). College Readiness Indicator Systems Framework. Voices in Urban Education 38: 28-35.

Bowles, S. \& Gintis, H. (2002). The inheritance of inequality. The Journal of Economic Perspectives 16(3): 3-30.

Boser, U., Wilhelm, M., and Hanna, R. (2014). The power of the Pygmalion effect: Teachers expectations strongly predict college completion. Washington, DC: Center for American Progress.

Brewer, C., Knoeppel, R. C., \& Lindle, J. C. (2015). Consequential validity of accountability policy: Public understanding of assessments. Educational Policy, 29(5), 711-745.

Bridgstock, R. (2009). The graduate attributes we've overlooked: enhancing graduate employability through career management skills. Higher Education Research \& Development 28(1): 31-44. 
Bureau of Labor Statistics. (2017). May 2017 State Occupational Employment and Wage Estimates Kentucky. Retrieved June 1, 2018, from https://www.bls.gov/oes/current/oes_ky.htm

Burney, V. H. \& Beilke, J. R. (2008). The constraints of poverty on high achievement. Journal for the Education of the Gifted 31(3): 295-321.

Burns, S. L. (2011). Competition among Public Schools: An Analysis of Kentucky Public Elementary Schools (Graduate Capstone). Retrieved Novermber 15, 2017 from https://uknowledge.uky.edu/cgi/viewcontent.cgi?article=1079\&context=mpampp _etds

Bush, G. W. (2001). No Child Left Behind. Washington, DC: U.S. Department of Education.

Camburn, E. M. \& Han, S. W. (2015). Infrastructure for teacher reflection and instructional change: An exploratory study. Journal of Educational Change 16(4): 511-533.

Carlyle, E. (2014). America's 20 fastest growing cities. Retrieved November 15, 2018 from https://www.forbes.com/sites/erincarlyle/2014/02/14/americas-20-fastestgrowing-cities/\#31bb9862461b.

Carnevale, A., Rose, S., \& Cheah, B. (2013). The College Payoff: Education, Occupations, Lifetime Earnings. Georgetown University Center on Education and the Workforce.

Carnevale, A. P. \& N. Smith (2013). A Decade Behind: Breaking Out of the Low-Skill Trap in the Southern Economy. Retrieved November 19, 2017 from https://repository.library.georgetown.edu/bitstream/handle/10822/559302/Decade Behind.FullReport.073112.pdf?sequence=1,

Carr, P. J., \& Kefalas, M. J. (2009). Hollowing out the middle: The rural brain drain and what it means for America. Boston, MA: Beacon Press.

Catterall, J., et al. (1998). Kentucky instructional results information system: A technical review. Kentucky Office of Education Accountability, Kentucky General Assembly, Frankfort, Kentucky.

Census Bureau (2010). Poverty: 2008 and 2009 American community survey briefs (Publication No. ACSBR/09-1). Retrieved November 15, 2017 from http://www.census.gov/prod/2010pubs/acsbr09-1.pdf

Clearinghouse, W. (2014). Procedures and standards handbook (Version 3.0). Washington, DC: US Department of Education. 
College Board (2014). The 10th annual AP report to the nation. Retrieved June 1, 2018 from http://media.collegeboard.com/digitalServices/pdf/ap/rtn/10th-annual/10thannual-ap-report-to-the-nation-single-page.pdf.

College Board (2017). Benchmarks. Retrieved November 15, 2017 from https://collegereadiness.collegeboard.org/about/scores/benchmarks.

Commonwealth of Kentucky (1997). Kentucky Postsecondary Education Improvement Act of 1997. Retrieved November 15, 2017 from http://www.lrc.state.ky.us/recarch/97ss/HB1/bill.doc.

Commonwealth of Kentucky (2009). Senate Bill 1. Retrieved November 15, 2017, from http://www.lrc.ky.gov/record/09rs/SB1.htm.

Commonwealth of Kentucky (2009). General fund budet reduction order 10-01.

Retrieved November 15, 2017, from

https://osbd.ky.gov/Archives/Documents/Budget\%20Period\%202008-2010/20082010\%20Budget\%20of\%20the\%20Commonwealth/General\%20Fund\%20Budget $\% 20$ Reduction\%20Order\%2010-01.pdf.

Conger, D., Long, M. C., \& Iatarola, P. (2009). Explaining race, poverty, and gender disparities in advanced course-taking. Journal of Policy Analysis and Management, 28, 555-576. doi:10.1002/pam.20455

Conley, D. T. (2007). Toward a comprehensive conception of college readiness. Retrieved July 13, 2018 from https://docs.gatesfoundation.org/documents/collegereadinesspaper.pdf.

Conley, D. T., Hiatt, E., McGaughy, C., Seburn, M., \& Venezia, A. (2010). Improving alignment between secondary and postsecondary education: The Texas college and career readiness initiative. Paper presented at the 2010 annual conference of the American Educational Research Association, Denver, CO. Retrieved November 15, 2017 from https://eric.ed.gov/?id=ED509644.

Conley, D. T. (2014). New conceptions of college and career ready: A profile approach to admission. Journal of College Admission (223).

Contreras, F. E. (2005). Access, achievement, and social capital: Standardized exams and the Latino college-bound population. Journal of Hispanics in Higher Education 4, 197-214.

Corwin, Z. B., \& Tierney, W. G. (2007). Getting there-and beyond: Building a culture of college-going in high schools. Los Angeles: USC Center for Higher Education Policy Analysis. 
Counsell, C. (2000). Historical knowledge and historical skills. Issues in history teaching: 54-70. London: Routledge.

Crocco, M.S. \& Costigan, A.T. (2007). The narrowing of curriculum and pedagogy in the age of accountability: Urban educators speak out. Urban Education 42 (6), 512535

Croft, A., et al. (2010). Job-embedded professional development: What it is, who is responsible, and how to get it done well. issue brief. Washington, DC: National Comprehensive Center for Teacher Quality.

Cronbach, L. J. (1951). Coefficient alpha and the internal structure of tests. Psychometrika, Ift, 297-334.

Cunningham, B. C. (2017). Appalachia's stem occupation forecast. Alexandria, VA: CNA,

Daggett, W. (2014). Rigor/relevance framework: A guide to focusing resources to increase student performance. International Center for Leadership in Education. Retrieved from http://www. leadered. com/pdf/rigor_relevance_ framework_2014. pdf.

Daggett, W. R. (2005). Achieving academic excellence through rigor and relevance. Rexford, NY: International Center for Leadership in Education.

Danielson, C. (2017). Kentucky framework for teaching. Retrieved January 2018, from https://education.ky.gov/teachers/PGES/TPGES/Documents/Kentucky\%20Frame work\%20for\%20Teaching.pdf.

Darling-Hammond, L. (2000). Teacher quality and student achievement. Education policy analysis archives $8: 1$.

Darling-Hammond, L. (2004). Inequality and the right to learn: Access to qualified teachers in California's public schools. Teachers College Record, 106(10), 19361966.

Darling-Hammond, L. \& Youngs, P. (2002). Defining "highly qualified teachers": What does "scientifically-based research" actually tell us? Educational Researcher 31(9): 13-25.

Darling-Hammond, L., Noguera, P., Cobb, V. L., \& Meier, D. (2007). Evaluating" no child left behind". NATION-NEW YORK-, 284(20), 11.

Davis, A. F. (2009). Kentucky's Urban/Rural Landscape: What is driving the differences in wealth across Kentucky? Center for Business and Economic Research. 
Day, R. E. and J. A. G. Ewalt (2013). Education reform in Kentucky: Just what the court ordered. Retrieved June 1, 2018 from https://encompass.eku.edu/cgi/viewcontent.cgi?article=1034\&context=ci_fsresear ch

Deal, T. E. and K. D. Peterson (2016). Shaping school culture. San Francisco, CA: John Wiley \& Sons.

Deci, E. L., Nezlek, J., \& Sheinman, L. (1981). Characteristics of the rewarder and intrinsic motivation of the rewardee. Journal of Personality and Social Psychology, 40, 1-40.

Dede, C. (2010b). Comparing frameworks for 21st century skills. In J. Bellanca and R. Brandt (eds), 21st century skills (Bloomington, IN: Solution Tree Press), 51-76.

Dee, T. \& Dizon-Ross, E. (2017). School performance, accountability and waiver reforms: Evidence from Louisiana, National Bureau of Economic Research.

Dee, T. S. \& Jacob, B. A. (2010). The impact of no child left behind on students, teachers, and schools. Brookings papers on economic activity 2010(2): 149-194.

Demi, M., A. Coleman-Jensen, and A. Snyder. 2010. The rural context and secondary school enrollment: An ecological systems approach. Journal of Research in Rural Education 25(7).

Desilver, D. (2017). U.S. students' academic achievement still lags that of their peers in many other countries. Pew Research Center. Retrieved March 31, 2018 from http://www.pewresearch.org/fact-tank/2017/02/15/u-s-students-internationallymath-science/

Desimone, L. M., et al. (2002). Effects of professional development on teachers' instruction: Results from a three-year longitudinal study. Educational Evaluation and Policy Analysis 24(2): 81-112.

Douglas, R., Klentschy, M. P., Worth, K., \& Binder, W. (Eds.). (2006). Linking science and literacy in the K-8 classroom. Arlington, VA: National Science Teachers Association.

Education in Kentucky (N.D.). In Wikipedia. Retrieved June 1, 2018, from https://en.wikipedia.org/wiki/Education_in_Kentucky

Education Professional Standards Board (2016). Annual report. Retrieved January 29, 2018, from http://www.epsb.ky.gov/pluginfile.php/133/mod_data/content/1669/201516\%20Annual\%20Report.pdf. 
Education Week (2015). The every student succeeds act: Explained. Retrieved June 1, 2018, from https://www.edweek.org/ew/articles/2015/12/07/the-every-studentsucceeds-act-explained.html.

Ehrenberg, R. G. \& Brewer, D. J. (1994). Do school and teacher characteristics matter? Evidence from high school and beyond. Economics of Education Review 13(1): 117.

Elementary and Secondary Education Act (1965). Retrieved June 1, 2018, from http://acsc.lib.udel.edu/exhibits/show/legislation/esea.

Ellison, M. S. (2015). Ninth Grade Student Responses to Authentic Science Instruction. Retrieved from PDXScholar.

Eppley, K. (2009). Rural schools and the highly qualified teacher provision of no child left behind: A critical policy analysis. Journal of Research in Rural Education (Online) 24(4): 1.

Every Student Succeeds Act (2015). Retrieved June 1, 2018, from https://www.congress.gov/bill/114th-congress/senate-bill/1177.

Faulkner, S. A. and C. M. Cook (2006). Testing vs. teaching: The perceived impact of assessment demands on middle grades instructional practices. RMLE Online 29(7): 1-13.

Felton, E. (2016). A state embraces the idea that not everyone needs to go to college. Retrieved June 1, 2018, from http://hechingerreport.org/state-embraces-idea-noteveryone-needs-go-college/.

Forward, L., Killion, J., \& Crow, T. L. (2011). Standards for professional learning: Learning Forward. Retrieved November 15, 2018 from https://learningforward.org/standards

Freedom Kentucky. (2018). Kentucky educational reform act. Retrieved June 1, 2018, from http://www.freedomkentucky.org/Kentucky_Education_Reform_Act

Freeman, S., Eddy, S.L., McDonough, M., Smith, M.K., Okoroafor, N., Jordt, H., and Wenderoth, M.P. (2014). "Active learning increases student performance in science, engineering, and mathematics." Proceedings of the National Academy of Sciences, 111(23), 8410-8415.

Gaertner, M. N., \& McClarty, K. L. (2015). Performance, perseverance, and the full picture of college readiness. Educational Measurement: Issues and Practice, 34(2), 20-33. 
Gay, G. (2007). The rhetoric and reality of NCLB. Race Ethnicity and Education, 10(3), 279-293.

Gilboy, M. B., Heinerichs, S., \& Pazzaglia, G. (2015). Enhancing student engagement using the flipped classroom. Journal of nutrition education and behavior, 47(1), 109-114.

Glancy, E., Fulton, M., Anderson, L., Zinth, J. D., \& Millard, M. (2014). Blueprint for College Readiness: A 50-State Policy Analysis. Education Commission of the States. Retrieved November 15, 2017 from https://files.eric.ed.gov/fulltext/ED556058.pdf.

Goetz, S. \& Debertin, D. (1996). Local Economic Conditions and Kentucky's Education Reform Act (KERA). Kentucky Annual Economic Report. Frankfort. Retrieved November 15, 2017 from http://www.uky.edu/ deberti/test/kera.htm.

Gofen, A. (2009). Family capital: How first-generation higher education students break the intergenerational cycle. Family Relations 58(1): 104-120.

Goldstein, H. \& Blatchford, P. (1998). Class size and educational achievement: a review of methodology with particular reference to study design. British Educational Research Journal 24(3): 255-268.

Gowing, A. M. (2017). "Only Connect": exploring student and staff understandings of connectedness to school and factors associated with this process. Retrieved from Minerva.

Great Schools (2016). What the no child left behind law means for your child. Retrieved January 30, 2018 from https://www.greatschools.org/gk/articles/no-child-leftbehind/

Griffith, Kelly L. (2015) High School Graduates' Perceptions of College Readiness. Retrieved from ProQuest.

Han, S., Capraro R., \& Capraro, M. M. (2014). How science, technology, engineering, and mathematics (stem) project-based learning (pbl) affects high, middle, and low achievers differently: the impact of student factors on achievement. International Journal of Science and Mathematics Education 13(5), 1089-1113.

Hardman, M. \& Mulder, M. (2003). Federal education reform: Critical issues in public education and the impact on students with disabilities. Eagle Summit on Personnel Preparation in Behavior and Emotional Disorders. Dallas: University of North Texas. 
Harmon, H. (2001). Education issues in rural schools in America. Paper presented at Appalachian Rural Systemic Initiatives Conference, Lexington, Kentucky. Retrieved from ERIC database. (ED455987)

Hemelt, S. W. and B. Jacob (2017). differentiated accountability and education production: Evidence from nclb waivers, National Bureau of Economic Research.

Hodara, M. \& Lewis, K. (2017). How well does high school grade point average predict college performance by student urbanicity and timing of college entry?. (REL 2017-250). Washington, DC: U.S. Department of Education, Institute of Education Sciences, National Center for Education Evaluation and Regional Assistance, Regional Educational Laboratory Northwest. Retrieved May 2017; https://ies.ed.gov/ncee/edlabs/regions/northwest/pdf/REL_2017250.pdf.

Holmes, N. (2015). Student perceptions of their learning and engagement in response to the use of a continuous e-assessment in an undergraduate module. Assessment \& Evaluation in Higher Education, 40(1), 1-14.

Howley, C. B., et al. (2006). Saving the children of the poor in rural schools. Annual Meeting of the American Educational Research Association, San Francisco, California.

$\mathrm{Hu}$, S. (2003). Educational aspirations and postsecondary access and choice: Students in urban, suburban, and rural schools compared. Education Policy Analysis Archives, 11(14). Retrieved July 15, 2018 from http://epaa.asu.edu/epaa/v11n14/.

Husband, T. \& Hunt, C. (2015). A review of the empirical literature on no child left behind from 2001 to 2010. Planning and Changing 46(1/2): 212.

Imazeki, J. \& Reschovsky, A. (2004). Is no child left behind an un (or under) funded federal mandate? Evidence from Texas. National Tax Journal: 571-588.

indeed.com (2018). Retrieved June 1, 2018, from https://www.indeed.com/q-Welding-1Kentucky-jobs.html?vjk=fa66b4f153aff21e.

Jacob, R., Hill, H., \& Corey, D. (2017). The impact of a professional development program on teachers' mathematical knowledge for teaching, instruction, and student achievement. Journal of Research on Educational Effectiveness, 10(2), 379-407.

Jennings, J. \& Rentner, D. S. (2006). Ten big effects of the no child left behind act on public schools. Phi Delta Kappan 88(2): 110-113.

Johnson, J., Showalter, D., Klein, R., \& Lester, C. (2014). Why rural matters 2013-14:

The condition of rural education in the 50 states. Retrieved from Rural School and 
Community Trust website: http://www.ruraledu. org/user_uploads/fi le/2013-14Why-Rural-Matters.pdf

Ishitani, T. T. (2006). Studying attrition and degree completion behavior among firstgeneration college students in the United States. Journal of Higher Education: 861-885.

Johnson, C. C. (2009). An examination of effective practice: Moving toward elimination of achievement gaps in science. Journal of Science Teacher Education 20(3): 287-306.

Kautz, T., et al. (2014). Fostering and measuring skills: Improving cognitive and noncognitive skills to promote lifetime success. National Bureau of Economic Research.

Kautz, T. \& Zanoni, W. (2014). Measuring and fostering non-cognitive skills in adolescence: Evidence from Chicago public schools and the onegoal program. University of Chicago. Retrieved November 15, 2017 from https://www.onegoalgraduation.org/wp-content/uploads/2018/04/Measuring-andFostering-Non-Cognitive-Skills-in-Adolescence-Evidence-from-Chicago-PublicSchools-and-the-OneGoal-Program.pdf

Kavanagh, M. H. \& Drennan,L. (2008). What skills and attributes does an accounting graduate need? Evidence from student perceptions and employer expectations. Accounting \& Finance 48(2): 279-300.

Kentucky Center for Workforce Statistics (2016a). "Kentucky Occupational Outlook to 2024." Retrieved November 15, 2017 from https://kcews.ky.gov/Content/Reports/20142024\%20KY\%20Occupational\%20Outlook.pdf.

Kentucky Center for Workforce Statistics (2016b). 2014 Kentucky High School Feedback College Going Public Access Data File. Retrieved November 15, 2017 from https://kcews.ky.gov/Reports/Files.

Kentucky Department of Education (2012, May 5). ACT Data. Retrieved May 5, 2012, from http://education.ky.gov/AA/Reports/Documents/ACT_CPE_Benchmarks_201112 .xls

Kentucky Department of Education (2014). The facts about kentucky's core academic standards in english language arts and mathematics. Retrieved November 15, 2017 from https://education.ky.gov/comm/UL/Documents/Facts\%20about\%20the\%20KCAS $\% 202014 . p d f$. 
Kentucky Department of Education (2015, September 25). Kentucky academic standards. Retrieved November 15, 2017 from http://education.ky.gov/comm/ul/pages/kentucky-core-academic-standards.aspx.

Kentucky Department of Education. (2017). Kentucky's plan to implement federal Every Student Succeeds Act takes a step forward. Retrieved January 12, 2018, from https://education.ky.gov/comm/news/Documents/R17-176 Consolidated plan feedback.pdf

Kentucky Department of Education (2017, January 29). School Report Card. Retrieved January 29, 2018 from https://education.ky.gov/AA/distsupp/Pages/SRC.aspx

Kentucky Department of Education (2017, November 15). Transitional Interventions. Retrieved November 15, 2017 from https://education.ky.gov/educational/int/hscf/Pages/default.aspx.

Kentucky Department of Education. (2018a). Assessments: end of course. Retrieved June 15, 2018, from https://education.ky.gov/AA/Assessments/Pages/EOC.aspx.

Kentucky Department of Education. (2018b). Kentucky Performance Rating for Educational Progress (K-PREP) tests. Retrieved June 15, 2018, from https://education.ky.gov/AA/Assessments/Pages/K-PREP.aspx.

Kentucky Department of Education. (2018c). Science Assessment System. Retrieved June 15, 2018, from https://education.ky.gov/curriculum/conpro/science/Pages/ScienceAssessment.aspx.

Kentucky Department of Education. (2018d). State Systemic Improvement Plan (SSIP). Retrieved June 1, 2018, from https://education.ky.gov/specialed/excep/instresources/Pages/State-SystemicImprovement-Plan-(SSIP).aspx.

Kentucky Department of Education. (2018e). Transition Readiness: Under Kentucky Accountability System. Retrieved June 1, 2018, from https://education.ky.gov/curriculum/modcurrframe/Documents/Transition_Readin ess_Academic_Readiness_KDE_Approved_Dual_Credit_Guidance_Document.p df.

Kim, M. J. (2011). States rights at heart of new 'no child left behind' debate. US News and World Report. Retrieved from http://usnews.com

Kintz, T. M. (2015). Principal leadership for quality intellectual work: Professional development related to authentic instruction and student cognitive engagement. Retrieved from ProQuest. 
Klopfenstein, K. and K. Lively (2012). Dual enrollment in the broader context of collegelevel high school programs. New Directions for Higher Education 2012(158): 5968.

Kolmar, Z. (2018). Fastest growing jobs in Kentucky in 2017. Retrieved June 1, 2018, from https://www.zippia.com/advice/fastest-growing-jobs-in-kentucky/.

Kozak, M. (2009). What is strong correlation? Teaching Statistics 31(3): 85-86.

Kuh, G.D., Kinzie, J., Schuh, J.H., Whitt, E.J., \& Associates (2005). Student success in college: Creating conditions that matter. San Francisco: Jossey-Bass.

Ladd, H. F. (2017). No child left behind: A deeply flawed federal policy. Journal of policy analysis and management, 36(2), 461-469.

Lamborn, S., Newmann, F., \& Wehlage, G. (1992). The significance and sources of student engagement. Student engagement and achievement in American secondary schools.Retrieved from ProQuest.

Lind, J. (2017). Instructional Strategies to Promote Engagement for Students Of Poverty In A Mathematics Classroom. Retrieved from Digital Commons.

Lombardi, A., Seburn, M., \& Conley, D. (2011). Development and initial validation of a measure of academic behaviors associated with college and career readiness. Journal of Career Assessment, 19(4), 375-391.

Maietta, H. (2016). Unfamiliar Territory: Meeting the Career Development Needs of First-Generation College Students. NACE Journal, 19-25.

Marks, H. M. (2000). Student Engagement in Instructional Activity: Patterns in the Elementary, Middle, and High School Years. American Educational Research Journal 37(1): 153-184.

Martinez, M., \& Klopott, S. (2003). Improving college access for minority, low-income, and first-generation students. Washington, DC: Pathways to College Network Clearinghouse.

Martinez, R. R., Baker, S. B., \& Young, T. (2017). Promoting career and college readiness, aspirations, and self-efficacy: Curriculum field test. The Career Development Quarterly, 65(2), 173-188.

Mastrorilli, T. M. (2016). Understanding the high school dropout process through student engagement and school processes: Evidence from the educational longitudinal study of 2002. New York, NY: City University of New York. 
Matusevich, M. N., et al. (2009). The nonnegotiables of academic rigor. Gifted Child Today 32(4): 44-52.

Mattern, K., Burrus, J., Camara, W., O'Connor, R., Hansen, M. A., Gambrell, J., ... \& Bobek, B. (2014). Broadening the Definition of College and Career Readiness: A Holistic Approach. ACT Research Report Series, 2014 (5). ACT, Inc.

Mattern, K. D. \& Wyatt, J. N. (2012). "The validity of the academic rigor index (ARI) for predicting FYGPA."

Maxwell, L. A. (2017). Kentucky lawmakers approve charter school law. Education Week. Retrieved May 12, 2017 http://blogs.edweek.org/edweek/charterschoice/2017/03/kentucky.html.

McClenney, K., Marti, C. N., \& Adkins, C. (2012). Student engagement and student outcomes: Key findings from. Community College Survey of Student Engagement. Retrieved July 21, 2018 from https://files.eric.ed.gov/fulltext/ED529076.pdf.

McGuinn, P. J. (2006). No child left behind and the transformation of federal education policy, 1965-2005, Univ Pr of Kansas.

McNeish, D. M., Radunzel, J., \& Sanchez, E. (2015). A Multidimensional Perspective of College Readiness: Relating Student and School Characteristics to Performance on the ACT®. ACT Research Report Series 2015 (6). ACT, Inc.

MET Project. (2010). Learning about teaching: Initial findings from the Measures of Effective Teaching Project. Retrieved from http://www.metproject.org/downloads/Preliminary_Findings-Research_Paper.pdf

MET Project. (2012). Gathering feedback for teaching: Combining high-quality observations with student surveys and achievement gains. Retrieved from http://www.metproject.org/downloads/MET_Gathering_Feedback_Research_Pap er.pdf.

Moore, G., Slate, J. R., Edmonson, S., Bustamante, R., \& Onwuegbuzie, A. J. (2010). High school students and their lack of preparedness for college: A statewide study. Education and Urban Society 42(7), 817-838.

Morrison, K. (2001). Randomised controlled trials for evidence-based education: some problems in judging'what works'. Evaluation \& Research in Education 15(2): 6983.

Moss, B., \& Bordelon, S. (2007). Preparing students for college-level reading and writing: Implementing a rhetoric and writing class in the senior year. Reading Research and Instruction, 46(3), 197-221. 
Mudd, A. (2018). WKU to tighten admission standards, expects enrollment dip. Retrieved July 31, 2018 from https://www.bgdailynews.com/news/wku-to-tightenadmission-standards-expects-enrollment-dip/article_91b2d59c-3fca-5387-8a3609629eee76ae.html.

Munoz, C. (2015). Q\&A: what you need to know about the fix to no child left behind. Retrieved June 1, 2018, from https://obamawhitehouse.archives.gov/blog/2015/12/07/qa-what-you-need-knowabout-fix-no-child-left-behind.

Nagaoka, J., et al. (2013). Readiness for College: The Role of Noncognitive Factors and Context. Voices in Urban Education 38: 45-52.

National Center for Education Statistics. (2018). National Assessment of Educational Progress: Mathematics Report Card. Washington, D.C.: National Center for Education Statistics, Institute of Education Sciences, U.S. Dept. of Education.

National Center for Education Statistics. (2018). National Assessment of Educational Progress: Reading Report Card. Washington, D.C.: National Center for Education Statistics, Institute of Education Sciences, U.S. Dept. of Education.

National Center for Fair and Open Testing (2018). What's Wrong with No Child Left Behind (NCLB), and What You Can Do to Change It. Retrieved November 15, 2017, from http://www.fairtest.org/national/fairtest\%20on\%20national.

National Charter School Resource Center (2018). What is a Charter School? Charterschoolcenter.ed.gov. Retrieved 12 February 2018, from https://charterschoolcenter.ed.gov/what-is-a-charter-school

National Governors Association Center for Best Practices, \& Council of Chief State School Officers. (2010). Common Core State Standards Initiative. Retrieved from http://www.corestandards.org/read-the-standards/.

National Research Council. (2002). Learning and understanding: Improving advanced study of mathematics and science in US high schools. Washington, DC: National Academies Press.

National Research Council. (2013a). Education for life and work: Developing transferable knowledge and skills in the 21st century. Washington, DC: National Academies Press.

National Research Council. (2013b). Next generation science standards: For states, by states. Retrieved April 15, 2018 from https://www.nextgenscience.org/sites/default/files/resource/files/Appendix \%20F 
$\% 20 \% 20$ Science $\% 20$ and $\% 20$ Engineering $\% 20$ Practices $\% 20$ in $\% 20$ the $\% 20$ NGSS \%20-\%20FINAL\%20060513.pdf.

Newmann, F. M. (1996). Authentic achievement: Restructuring schools for intellectual quality. San Francisco, CA: Jossey-Bass.

Newmann, F. M., Bryk, A. S., \& Nagaoka, J. K. (2001). Authentic intellectual work and standardized tests: Conflict or coexistence? Improving Chicago's schools. Chicago, IL: Consortium on Chicago School Research.

Newmann, F. M., Lopez, G., \& Bryk, A. S. (1998). The quality of intellectual work in Chicago schools: A baseline report. Chicago, IL: Consortium on Chicago School Research.

Northern Kentucky Tribune. (2018). Kentucky's plan to implement federal every student succeeds act takes a step forward. Retrieved June 1, 2018, from http://www.nkytribune.com/2017/12/kentuckys-plan-to-implement-federal-everystudent-succeeds-act-takes-a-step-forward/.

Oakes, J. (2003). Critical conditions for equity and diversity in college access: Informing policy and monitoring results. UC Accord. Retrieved November 15, 2017 from https://cloudfront.escholarship.org/dist/prd/content/qt427737xt/qt427737xt.pdf

O'Donnell, C. L. (2008). Defining, conceptualizing, and measuring fidelity of implementation and its relationship to outcomes in $\mathrm{K}-12$ curriculum intervention research. Review of educational research 78(1): 33-84.

Paige, D. D., Smith, G. S., \& Sizemore, J. M. (2015). Conceptualizing rigor and its implications for education in the era of the Common Core. Cogent Education, 2(1), 1048084.

Pascarella, E. T., et al. (2004). First-generation college students: Additional evidence on college experiences and outcomes. The Journal of Higher Education 75(3): 249284.

Payne, R. K. (2005). A framework for understanding poverty. Highlands, TX: aha! Process, Incorporated.

Pearson, P. D. and J. A. Dole (1987). Explicit comprehension instruction: A review of research and a new conceptualization of instruction. The Elementary School Journal 88(2): 151-165.

Penuel, W. R., Fishman, B. J., Yamaguchi, R., \& Gallagher, L. P. (2007). What makes professional development effective? Strategies that foster curriculum implementation. American educational research journal, 44(4), 921-958. 
Phillips, A. (2015). I had to learn that on my own: successful first-generation, lowincome college students from rural areas at an urban institution (Doctoral Dissertation). Retrieved November 1, 2017 from https://ir.library.louisville.edu/cgi/viewcontent.cgi?referer=https://scholar.google. $\underline{\text { com } / \& \text { httpsredir }=1 \& \text { article }=3002 \& \text { context=etd. }}$

Plasman, J. S. (2018). Career/Education Plans and Student Engagement in Secondary School. American Journal of Education, 124(2), 000-000.

Pondiscio, R. (2016). New York's reading standards rewrite should alarm parents. Retrieved June 1, 2018, from https://edexcellence.net/articles/new-yorks-readingstandards-rewrite-should-alarm-parents.

Powell, T. (2017). CPE Roles and Responsibilities. Retrieved November 15, 2017 from http://cpe.ky.gov/aboutus/documents/cpe-role-responsibilities.pdf.

Prichard Committee (2012). Kentucky school updates- professional development. Retrieved November 15, 2017, from http://www.prichardcommittee.org/wpcontent/uploads/2012/09/2012-Professional-Development-KSU-Chapter.pdf.

Project Lead the Way Kentucky. (2018). Retrieved June 1, 2018, from http://www.pltwky.org/.

Ravitch, D. (2016). The death and life of the great American school system: How testing and choice are undermining education. New York, NY: Basic Books.

Reid, M. J. and J. L. Moore (2008). College readiness and academic preparation for postsecondary education oral histories of first-generation urban college students. Urban Education 43(2): 240-261.

Rudalevige, A. (2005). Adequacy, accountability, and the impact of "no child left behind.". Adequacy Lawsuits: Their Growing Impact on American Education. Harvard University.

Reid, M. J. \& Moore, J. L. (2008). College readiness and academic preparation for postsecondary education oral histories of first-generation urban college students. Urban Education 43(2): 240-261.

Rich, M. (2013). Holding states and schools accountable. New York Times. Retrieved from http://www.nytimes.com.

Rowe, M. \& Oltmann, C. (2016). Randomised controlled trials in educational research: Ontological and epistemological limitations. African Journal of Health Professions Education 8(1): 6-8. 
Sadler, P. M., et al. (2016). AP: A Critical Examination of the Advanced Placement Program."NCSSS Journal 21(1): 26-27.

Sanford, K. \& Troske, K. (2007). Why is Kentucky so poor? A look at the factors affecting cross-state differences in income. Kentucky Annual Economic Report. Retrieved November 15, 2017 from https://uknowledge.uky.edu/cber_kentuckyannualreports/6/.

Schmitt, N. (1996). Uses and abuses of coefficient alpha. Psychological Assessment, 8(4), 350.

Schoenfeld, A. H. (2014). Mathematical problem solving. Elsevier.

Shernoff, D. J., Csikszentmihalyi, M., Schneider, B., \& Shernoff, E. S. (2014). Student engagement in high school classrooms from the perspective of flow theory. In Applications of Flow in Human Development and Education (pp. 475-494): Springer.

Shields, K. A. \& O’Dwyer, L. M. (2017). Remedial education and completing college: Exploring differences by credential and institutional level. The Journal of Higher Education 88(1): 85-109.

Shkolnik, J., Song, M., Mitchell, K., Uekawa, K., Knudson, J., \& Murphy, R. (2007). Changes in rigor, relevance, and student learning in redesigned high schools: An evaluation for the Bill \& Melinda Gates Foundation. Washington, DC: American Institutes for Research.

Silver, H. F., Strong, R. W., \& Perini, M. J. (2001). Teaching What Matters Most: Standards and Strategies for Raising Student Achievement. Alexandria: VA: ASCD.

Simon, N. S. \& Johnson, S. M. (2015). Teacher turnover in high-poverty schools: What we know and can do. Teachers College Record 117(3): 1-36.

Simpson, R. L., Lacava, P. G., \& Sampson Graner, P. (2004). The no child left behind act: Challenges and implications for educators. Intervention in school and clinic, 40(2), 67-75.

Siskar, J., \& Theobald, P. (2008). The meaning of place and community in contemporary educational discourse. Journal of Inquiry and Action in Education, 1(2), 58-78.

Slavin, R. E. (1987). Ability grouping and student achievement in elementary schools: A best-evidence synthesis. Review of Educational Research 57(3): 293-336.

Slavin, R. E. (1990). Achievement effects of ability grouping in secondary schools: A best-evidence synthesis. Review of Educational Research 60(3): 471-499. 
Smeyers, P. (2006). The relevance of irrelevant research; the irrelevance of relevant research. Educational research: Why 'what works' doesn't work. Dordrecht: Springer.

Smith, J., Pender, M., \& Howell, J. (2013). The full extent of student-college academic undermatch. Economics of Education Review, 32, 247-261.

Soria, K. M. \& Stebleton, M. J. (2012). First-generation students' academic engagement and retention. Teaching in Higher Education 17(6): 673-685.

Southern Regional Education Board (2000). Learning-centered leadership program. Atlanta, GA. Retrieved November 15, 2017 from https://www.sreb.org/learningcentered-leadership-program .

Spitzer, T. M. (2000). Predictors of college success: A comparison of traditional and nontraditional age students. NASPA Journal 38(1): 82-98.

Sternberg, R. J. \& Davidson, J. E. (2005). Conceptions of giftedness, Cambridge University Press.

Strange, M., Johnson, J., Showalter, D., \& Klein, R. (2012). Why Rural Matters 2011-12: The Condition of Rural Education in the 50 States. A Report of the Rural School and Community Trust Policy Program. Rural School and Community Trust.

Sunderman, G. \& Orfield, G. (2006). Domesticating a revolution: No child left behind reforms and state administrative response. Harvard Educational Review 76(4): 526-556.

Tierney, W. G. \& Duncheon, J. C. (2015). The problem of college readiness, New York, NY: SUNY Press.

Tierney, W. G., \& Garcia, L. D. (2008). Preparing underprepared students for college: Remedial education and early assessment programs. Journal of At-Risk Issues, 14(2), 1-7.

Timmel, K.M., Hoppmann, G. W., Nelson, D., Alexander, A., Landy, B. \& Olds, S. (2014). A Look Inside Kentucky's College And Career Readiness Data. (Research Report No. 410). Frankfort, KY: Legislative Research Commission.

U.S. Department of Education (2005a). 10 Facts About K-12 Education Funding, Washington, D.C. 
U.S. Department of Education. (2005b, March 8). No child left behind: Expanding the promise. Retrieved February 12, 2018, from

https://www2.ed.gov/about/overview/budget/budget06/nclb/index.html

U.S. Department of Education. (2010, December 6). No Child Left Behind. Retrieved February 12, 2018, from https://www2.ed.gov/policy/elsec/leg/esea02/index.html

U.S. Department of Education. (2012, October 12). Flexibility and Waivers. Retrieved February 12, 2018, from https://www2.ed.gov/nclb/freedom/local/flexibility/index.html

U.S. Department of Education (2015, September 26). Laws and guidance frequently asked questions. Retrieved November 15, 2017 from https://www2.ed.gov/policy/gen/guid/fpco/faq.html\#q5.

U.S. Department of Education. (2015). Every Student Succeeds Act Assessments Under Title I, Part A \& Title I, Part B: Summary of Final Regulations. Retrieved June 1, 2018, from https://www2.ed.gov/policy/elsec/leg/essa/essaassessmentfactsheet1207.pdf

U.S. Department of Education (2017). Rural and Low-Income School Program, Who is Eligible. Retrieved November 5, 2017, from https://www2.ed.gov/programs/reaprlisp/eligibility.html.

University of Kentucky (2018). Center for Innovation in Education. Retrieved July 15, 2018 from https://education.uky.edu/cie/.

Valli, L. \& Buese, D. (2007). The changing roles of teachers in an era of high-stakes accountability. American Educational Research Journal 44(3), 519-558.

Van Driel, J. H., et al. (1998). Developing science teachers' pedagogical content knowledge. Journal of research in Science Teaching 35(6): 673-695.

Walker, D, \& O'Daniel, R. (2013). Gear up Kentucky 3.0 Guidance document: Eliminating tracking and ability grouping. Louisville, KY: CTL.

Wilbur, T. G. and V. J. Roscigno (2016). First-generation disadvantage and college enrollment/completion. Socius 2: 2378023116664351.

Willingham, D. T. (2008). Critical thinking: Why is it so hard to teach?. Arts Education Policy Review, 109(4), 21-32.

Wimberly, G. L., \& Noeth, R. J. (2005). College Readiness Begins in Middle School. ACT Policy Report. American College Testing ACT Inc. 
Young, J. L., Young, J. R., \& Ford, D. Y. (2017). Standing in the gaps: Examining the effects of early gifted education on Black girl achievement in STEM. Journal of Advanced Academics, 28(4), 290-312.

Yu, R., \& Singh, K. (2016). Teacher support, instructional practices, student motivation, and mathematics achievement in high school. The Journal of Educational Research, 1-14.

Zimmer, R., \& Gill, B. (2007). State and Local Implementation of the "No Child Left Behind Act." Volume I--Title I School Choice, Supplemental Educational Services, and Student Achievement. A Report from the National Longitudinal Study of "No Child Left Behind" (NLS-" NCLB"). Washington, DC: US Department of Education. 


\title{
APPENDIX A
}

\section{CTL High School Walkthrough Observation}

\author{
ACT College Readiness Standards
}

\begin{tabular}{|l|l|l}
\hline $\mathbf{0}=$ not observed & $\mathbf{1}=$ observed \\
\hline
\end{tabular}

\section{College Readiness Standards: ENGLISH - Writing}

Topic Development: Purpose and Focus

1. Read various genres and experiment with a variety of writing styles

2. Identify central idea of main topic of straightforward piece of writing

3. Revise writing to ensure sentences are relevant to purpose and that no important information is left out

4. Identify basic purpose or role of specified phrase or sentence

5. Delete clause or sentence that is irrelevant to essay

6. Decide appropriate verb tense based on sentence meaning

7. Revise writing to sharpen focus and coherence

8. Determine whether a simple essay has met a straightforward goal

Organization, Unity and Coherence

1. Use conjunctive adverbs or phrases to show logical relationships in simple narrative essays (e.g., then, this time, first, in response)

2. Introduce paragraphs with language that creates transitions

3. Add a sentence that introduces a paragraph and builds interest

4. Select most logical place to add sentence or specific information in an essay

5. Recognize/experiment with more sophisticated organizational structures (compare-contrast, causeeffect)

6. Provide a simple conclusion to a paragraph or essay (e.g., expressing one of the essay's main ideas)

Word Choice: Style, Tone, Clarity and Economy

1. Revise sentences to correct awkward or confusing wording

2. Revise vague nouns or pronouns that create logic problems

3. Delete synonymous and wordy material, for concise, precise writing that eliminates redundancy

4. Revise expressions not consistent with essay style

5. Determine clearest, most logical conjunction to link clauses

Sentence Structure and Formation

1. Use conjunctions or punctuation to join simple clauses and avoid awkward sounding fragments

2. Revise shifts in verb tenses; ensure tense used is appropriate for meaning

3. Experiment with writing more sophisticated sentences

4. Recognize and correct disturbances of sentence flow (misplaced modifiers, participial phrase fragments, incorrect relative pronouns)

Conventions of Usage

1. Solve basic grammatical problems at how to:

a. form the past and past participle of irregular verbs and how to form comparative and superlative adjectives e.g., better, best)

b. use adverb or adjective, ensure subject-verb or pronoun-antecedent agreement, use correct preposition 
c. recognize appropriate word in pairs (there and their, led and lead)

2. Use idiomatically appropriate prepositions, in combination with verbs (long for, appeal to)

3. Ensure verb-subject agreement when there is text between the two

4. Use the appropriate word in frequently confused pairs (e.g., there and their, past and passed, led and lead)

Conventions of Punctuation

1. Delete commas that create basic sense problems (e.g., between verb and direct object) or disturb sentence flow

2. Provide appropriate punctuation in straightforward situations (items in a series)

3. Use commas to set off simple parenthetical phrases

4. Recognize inappropriate use of commas

\section{College Readiness Standards: SOCIAL STUDIES \& ENGLISH - Reading}

Main Ideas and Author's Approach

1. Identify or infer the main idea or purpose of straightforward paragraphs in a range of literary narratives or passages, from uncomplicated to challenging

2. Understand the overall approach taken by an author or narrator (point of view, kinds of evidence used) in both uncomplicated and challenging passages

3. Summarize basic events and ideas in more challenging passages

4. Develop a reasonable interpretation of the central themes or main points of challenging text

5. Summarize key supporting ideas and details in somewhat challenging passages

Supporting Details

1. Locate important details in both uncomplicated and challenging passages

2. Locate details that are minor or subtly stated

3. Make inferences about how details are used in passages

4. Discern details that support important points in challenging passages

5. Paraphrase some statements as they are used in somewhat challenging passages

Sequential, Comparative and Cause-Effect Relationships

1. Order sequences of events in uncomplicated passages

2. Understand how the order of events or altering events might change outcomes

3. Understand relationships between people/characters and ideas in a range of passages or literary narratives, from uncomplicated to challenging

4. Understand implied or subtly stated cause-effect relationships in passages ranging from uncomplicated to challenging

5. Read conflicting viewpoints of an event and use text evidence to identify most reasonable explanation of cause and effect

Meanings of Words

1. Clarify meaning of words or phrases by searching for text clues (sentence structure, context, prefixes and suffixes,spelling patterns)

2. Use context to determine the appropriate meaning of virtually any word, phrase of statement in uncomplicated passages

3. Use context to determine appropriate meaning of figurative and non-figurative words, phrases and statements in more challenging passages

4. Investigate the meaning of words and their possible effect on perceptions and behavior of people

Generalizations and Conclusions 
1. Draw generalizations and conclusions about people and ideas from uncomplicated passages and literary narratives

2. Draw simple generalizations and conclusions using details that support main points of challenging passages

3. Synthesize information in challenging texts, making valid generalizations about people and situations

Purpose and Point of View (PPV)

1. Identify a clear purpose of somewhat challenging passages and how that purpose shapes content and style

2. Understand point of view in somewhat challenging passages

Arguments ARG)

1. Analyze how one or more sentences in somewhat challenging passages offer reasons for or support a claim

2. Identify a clear central claim in somewhat challenging passages

Multiple Texts (SYN)

1. Draw logical conclusions using information from two literary narratives

Text Structure (TST)

1. Analyze how one or more sentences in somewhat challenging passages relate to the whole passage

2. Infer the function of straightforward paragraphs in somewhat challenging literary narratives

3. Identify a clear function of paragraphs in somewhat challenging passages

4. Analyze the overall structure of somewhat challenging passages

\section{College Readiness Standards: MATHEMATICS}

Basic Operations and Applications

1. Solve one-step arithmetic problems (using whole numbers, fractions, decimals) such as single-step percent

2. Solve two-step arithmetic problems

3. Solve multi-step arithmetic problems involving concepts such as rate and proportion, tax added, percentage off, and computing with a given average

4. Solve multi-step arithmetic problems that involve planning, or converting units of measure (e.g. feet per second to miles per hour)

5. Relate a graph to a situation described in terms of a starting value and an additional amount per unit (e.g., unit cost, weekly growth)

Probability, Statistics and Data Analysis 
1. Calculate the average given a list of numbers, data values and sums, or frequency counts of all the data values

2. Read tables and graphs

3. Perform computations on data from tables and graphs

4. Use the relationship between the probability of an event and the probability of its complement

5. Calculate the missing data value, given the average and all data values but one

6. Translate from one representation of data to another

7. Determine the probability of a simple event

8. Exhibit knowledge of simple counting techniques

9. Manipulate data from tables and graphs

10. Compute probabilities

11. Use Venn diagrams in counting

12. Describe events as combinations of other events (e.g., using and, or, and not)

Numbers: Concepts and Properties

1. Exhibit knowledge of number concepts including place value, rounding, the ordering of decimals, pattern identification, absolute value, primes, and factors/greatest common factor

2. Find and use the least common multiple

3. Order fractions

4. Work with numerical factors

5. Work with scientific notation

6. Work with squares/cubes and square/cube roots of numbers

7. Work problems involving positive integer exponents

8. Determine when an expression is undefined

9. Exhibit knowledge of complex numbers

10. Write positive powers of 10 by using exponents

11. Understand absolute value in terms of distance

12. Find the distance in the coordinate plane between two points with the samex-coordinate or y-coordinate

13. Add and subtract matrices that have integer entries

Graphical Representations

1. Locate points on the number line

2. Locate points in the coordinate plane

3. Comprehend the concept of length on the number line

4. Exhibit knowledge of slope

5. Identify the graph of a linear inequality on the number line

6. Determine the slope of a line from points or equations

7. Match linear graphs with their equations

8. Find the midpoint of a line segment

Expressions, Equations and Inequalities 


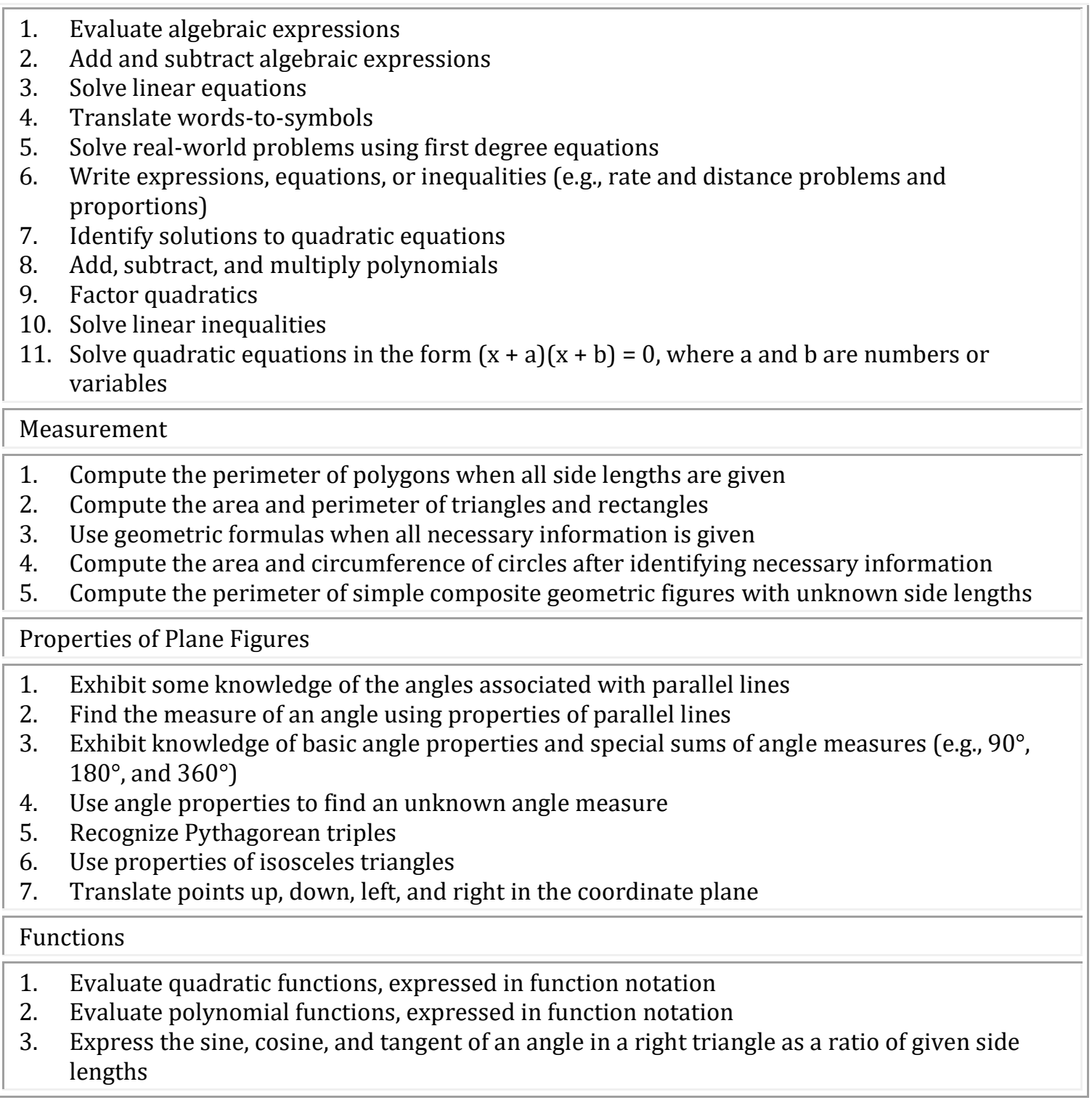

\begin{tabular}{|l||}
\hline \multicolumn{2}{|l|}{ College Readiness Standards: SCIENCE } \\
\hline Interpretation of Data \\
\hline 1. Interpolate and/or extrapolate between data points in a table or graph \\
2. Compare or contrast data from two or more data presentations ranging from simple to \\
complex \\
3. Determine how the value of one variable changes as the value of another changes in complex \\
data presentations \\
4. Identify and/or use a simple/complex (e.g., linear/non-linear) mathematical relationship \\
5. Setween data \\
6. Translate information into a table, graph, or diagram \\
\hline Scientific Investigations \\
\hline
\end{tabular}


1. Understand the methods and tools used in a complex experiment

2. Understand a complex experimental design

3. Predict the results of an additional trial or measurement in an experiment

4. Identify similarities and differences between experiments

5. Determine the experimental conditions that would produce specified results

6. Determine the hypothesis for an experiment

7. Identify an alternate method for testing a hypothesis

8. Carry out scientific investigations paying attention to accuracy and precision

9. Identify a control in an experiment

10. Determine which experiments utilized a given tool, method, or aspect of design

Evaluation of Models, Inferences, and Experimental Results

1. Determine whether given information supports or contradicts a simple/complex hypothesis or conclusion, and why

2. Identify strengths and weaknesses in one or more models

3. Identify similarities and differences between models

4. Select a data presentation or a model that supports or contradicts a hypothesis, prediction, or conclusion

5. Determine whether new information supports or weakens a model, hypothesis, conclusion or story, and why

6. Use new information to make a prediction based on a model

7. identify key assumptions in a model 


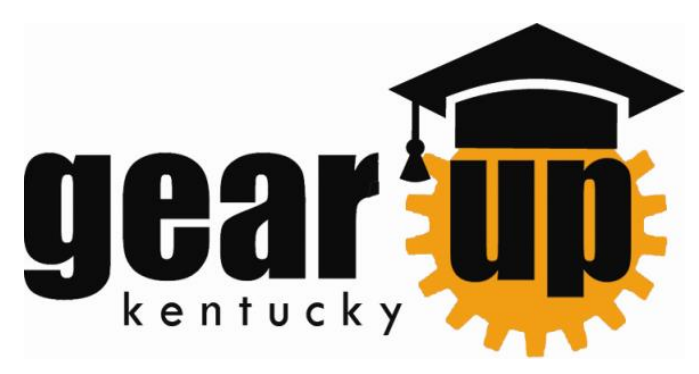

\section{GEAR UP Kentucky Performance Guide for a College-Going Culture}

2012 


\section{GEAR UP Kentucky Performance Guide for A College-Going Culture}

\section{Introduction and Use}

GEAR UP provides support for creating a college-going culture where all students are prepared for postsecondary education. Creation of a college-going culture is paramount for participating GEAR UP schools. This School Performance Guide is designed to help schools assess the extent to which such a culture exists, pinpoint strengths, and target areas for improvement. As part of the walkthrough data collection process, leadership teams are asked to highlight in advance of the visit the rubric descriptors that apply to their site and also indicate sources of evidence from those given or in addition to those provided.

The School Performance Guide is organized as follows:

1. A rubric with a three-part set of indicators for each of the GEAR UP attributes: aspiration, rigor, expectation, accountability and sustainability. The rubric for each attribute is followed by sources of evidence to support a school's assessment of its college-going culture. Reading through the sources of evidence allows school leaders to begin to develop a clear picture of their school. Finally, the rubric and sources of evidence are followed by suggested critical actions that teachers and school leaders can take and corresponding GEAR UP strategies to support a college-going culture.

2. The rubric itself starts with each of the attributes, offering a brief description and intended student outcome. The indicators are organized into categories: Square One, Transition to a College-Going Culture, and Achieving a College-Going Culture. Each is defined below:

- Square One: The school is at the beginning stage of addressing the need to prepare all students for postsecondary education. It most resembles older conceptions of schooling, that only some students will achieve and that the school is not organized or charged with making sure all students graduate from high school ready for college.

- Transition to a College-Going Culture: The school has already begun to address the learning needs of all students and to work toward providing rigorous instruction and insisting on high expectations for student accomplishment. Faculty has made positive steps and is on the way to ensuring that students are college-ready.

- Achieving a College-Going Culture: The school expects much of itself and has committed to ensuring that each student graduates high school college-ready. There are systems in place that connect and support all instructional improvement efforts and that promote direct support of individual students in preparing and applying for college.

3. Additional tools that are part of the School Performance Guide and accompany the rubric, sources of evidence and critical actions are: a planning template for schools to set CSIP goals to strengthen their school culture; and a set of district standards that describe conditions at the district level necessary for student achievement and college readiness 


\section{KY SCHOOL PERFORMANCE GUIDE FOR A COLLEGE-GOING CULTURE -}

\section{ASPIRATION}

The School Performance Guide for a College-Going

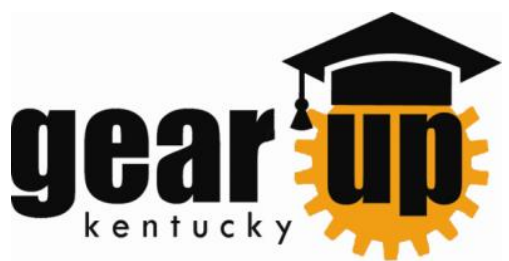

Culture (2011 version) addresses the five GEAR UP KY attributes - aspiration, rigor, expectation, accountability and sustainability - in rubric form, for purposes of school self-assessment.

\begin{tabular}{|c|c|c|c|}
\hline ATTRIBUTE & SQUARE ONE & $\begin{array}{c}\text { TRANSITION TO A } \\
\text { COLLEGE-GOING } \\
\text { CULTURE }\end{array}$ & $\begin{array}{c}\text { ACHIEVING A } \\
\text { COLLEGE-GOING } \\
\text { CULTURE }\end{array}$ \\
\hline $\begin{array}{l}\text { ASPIRATION } \\
\text { Students, } \\
\text { dreams for their } \\
\text { future, } \\
\text { including } \\
\text { college and } \\
\text { career that } \\
\text { reflect a sense } \\
\text { of possibility } \\
\text { and potential }\end{array}$ & $\begin{array}{l}\text { 3. There are some efforts } \\
\text { to transition students to } \\
\text { middle and high school } \\
\text { for social development } \\
\text { and feeling comfortable } \\
\text { in a new setting but } \\
\text { lacking in emphasis on } \\
\text { academics and college } \\
\text { preparation. } \\
\text { 4tudent organizational } \\
\text { and related skills for } \\
\text { learning are not } \\
\text { explicitly taught; } \\
\text { moreover, traditional } \\
\text { style of teaching does } \\
\text { not develop } \\
\text { independent and self- } \\
\text { sufficient learning in } \\
\text { students. } \\
\text { The school offers no or } \\
\text { very few AP, dual } \\
\text { credit or IB courses. } \\
\text { There are not } \\
\text { accelerated learning } \\
\text { options for most or any } \\
\text { students. }\end{array}$ & $\begin{array}{l}\text { 1. The school surveys } \\
\text { students on their } \\
\text { aspirations, and } \\
\text { counselors check to } \\
\text { see that students who } \\
\text { indicate an interest in } \\
\text { college are taking a } \\
\text { pre-college } \\
\text { curriculum. School } \\
\text { newsletters and web- } \\
\text { site post the pre- } \\
\text { college curriculum. } \\
\text { On a limited basis the } \\
\text { school uses the ILP to } \\
\text { have students monitor } \\
\text { their progress toward } \\
\text { college and career, } \\
\text { most specifically when } \\
\text { selecting courses for } \\
\text { the following year. } \\
\text { The school does not } \\
\text { yet capitalize on } \\
\text { students' aspirations } \\
\text { for college and career. } \\
\text { The school offers } \\
\text { middle and high } \\
\text { school transition } \\
\text { activities to acquaint } \\
\text { students with the } \\
\text { campus, rules and } \\
\text { procedures, and } \\
\text { academic } \\
\text { expectations. } \\
\text { Some classes provide } \\
\text { guidance on } \\
\text { organization and note } \\
\text { taking but there is not } \\
\text { yet an intentional or } \\
\text { consistent approach to } \\
\text { those skills and } \\
\text { behaviors referred to } \\
\text { as college knowledge. }\end{array}$ & $\begin{array}{l}\text { 1. The school encourages } \\
\text { students to dream big } \\
\text { dreams, including college } \\
\text { and meaningful careers } \\
\text { that build on student } \\
\text { strengths. Counselors and } \\
\text { teachers encourage } \\
\text { students to articulate their } \\
\text { dreams and choose } \\
\text { courses/programs } \\
\text { accordingly. } \\
\text { The school provides } \\
\text { students with } \\
\text { opportunities to identify } \\
\text { their interests and talents } \\
\text { and match them to college } \\
\text { and career, including use } \\
\text { of the ILP throughout } \\
\text { middle and high school } \\
\text { and resources like } \\
\text { KnowHow2Go. } \\
\text { School programs, } \\
\text { structures, classroom } \\
\text { instruction and activities } \\
\text { address students' } \\
\text { academic and } \\
\text { developmental needs as } \\
\text { they transition to middle } \\
\text { or high school. } \\
\text { Classroom instruction } \\
\text { emphasizes college } \\
\text { knowledge-skill building } \\
\text { that includes organization, } \\
\text { time management, note } \\
\text { taking and studying, test } \\
\text { taking and self- } \\
\text { assessment. } \\
\text { 3. }\end{array}$ \\
\hline
\end{tabular}


6. Courses are organized in a traditional manner, by department. The pre-college curriculum is posted on the school and district website.
5. The school has increased the number of AP, dual credit and/or IB courses offered, and it makes them available to a wider range of students.

6. The school has organized some courses into clusters aligned with college majors and careers, a positive step forward but still needs to provide guidance to students in how clusters connect with their aspirations. garner college credit as appropriate.

6. Courses are aligned with career topics and teachers make intentional connections between what students are learning and how it will serve them in college and career. Internships are available within career clusters.

\section{ASPIRATION: Sources of data for student aspirations could include:}

$\checkmark$ Number and types of transition activities and structures.

$\checkmark$ Number and percentage of students who have up-to-date ILP's.

$\checkmark$ Inclusion of college knowledge in regular classroom instruction based on course syllabi and classroom observation data.

Presence of career clusters in organization of courses.

\section{ASPIRATION: Examples of actions to foster student aspirations for college:} \begin{tabular}{l|l} 
CLASSROOM ACTIONS & SCHOOL ACTIONS
\end{tabular}

- Students are scheduled into

AP courses as a rule and exceptions made only when parents and students request an alternate placement.

- Teachers incorporate college knowledge - organization, time management, note taking and study skills, test strategies and selfassessment - into regular classroom instruction to help students become independent, self-sufficient learners.

- Teachers cooperate across disciplines to design and implement interdisciplinary units, to develop student intellectual abilities and to make connections

- English and social studies courses in particular incorporate stories about
- Counselors make a systematic effort to help students identify dreams and specific goals, and to guide them to take courses that will prepare them for postsecondary study.

- The School engages parents in supporting their students' aspirations and providing them information they need to help them realize those aspirations.

- The ILP and other resources are regularly used to help students solidify goals, select courses, evaluate EPAS scores, and plan accordingly.

- The school implements a Freshman Academy or other structure to ensure students GEAR-UP STRATEGIES

- Incorporate GEAR UP 2 College and Career strategy (grades 9-12) into school curriculum/services to help students clarify their aspirations and make them a reality.

- Encourage students in grades 10-12 to participate in Summer Enrichment academy to gain experience on a college campus and confidence in their own ability to realize their college dreams.

- For incoming ninth graders, as part of the transition effort, use the GEAR UP 2 Learn

Freshman institute to strengthen students' academic and social development.

- Send a school team to the annual GEAR UP Alliance Institute for a College-Going Culture to provide support for college aspirations. 


\begin{tabular}{|l|l|l|}
\hline $\begin{array}{l}\text { students who worked against } \\
\text { odds to realize college and } \\
\text { career dreams. }\end{array}$ & $\begin{array}{l}\text { are supported academically } \\
\text { and socially as they enter } \\
\text { high school. }\end{array}$ & \\
$\begin{array}{l}\text { Across disciplines students } \\
\text { compose research projects } \\
\text { that focus on careers and } \\
\text { necessary postsecondary } \\
\text { preparation. }\end{array}$ & $\begin{array}{l}\text { The school implements } \\
\text { career clusters or other } \\
\text { structures so that students } \\
\text { focus their coursework on } \\
\text { areas of interest that prepare } \\
\text { them for postsecondary } \\
\text { education and eventual } \\
\text { careers. }\end{array}$ & \\
\hline
\end{tabular}




\section{KY SCHOOL PERFORMANCE GUIDE FOR A COLLEGE-GOING CULTURE - RIGOR}

The School Performance Guide for a College-Going Culture (2011 version) addresses the five GEAR UP KY

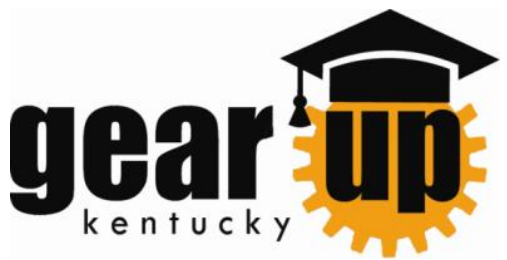
attributes - aspiration, rigor, expectation, accountability and sustainability - in rubric form, for purposes of school self-assessment.

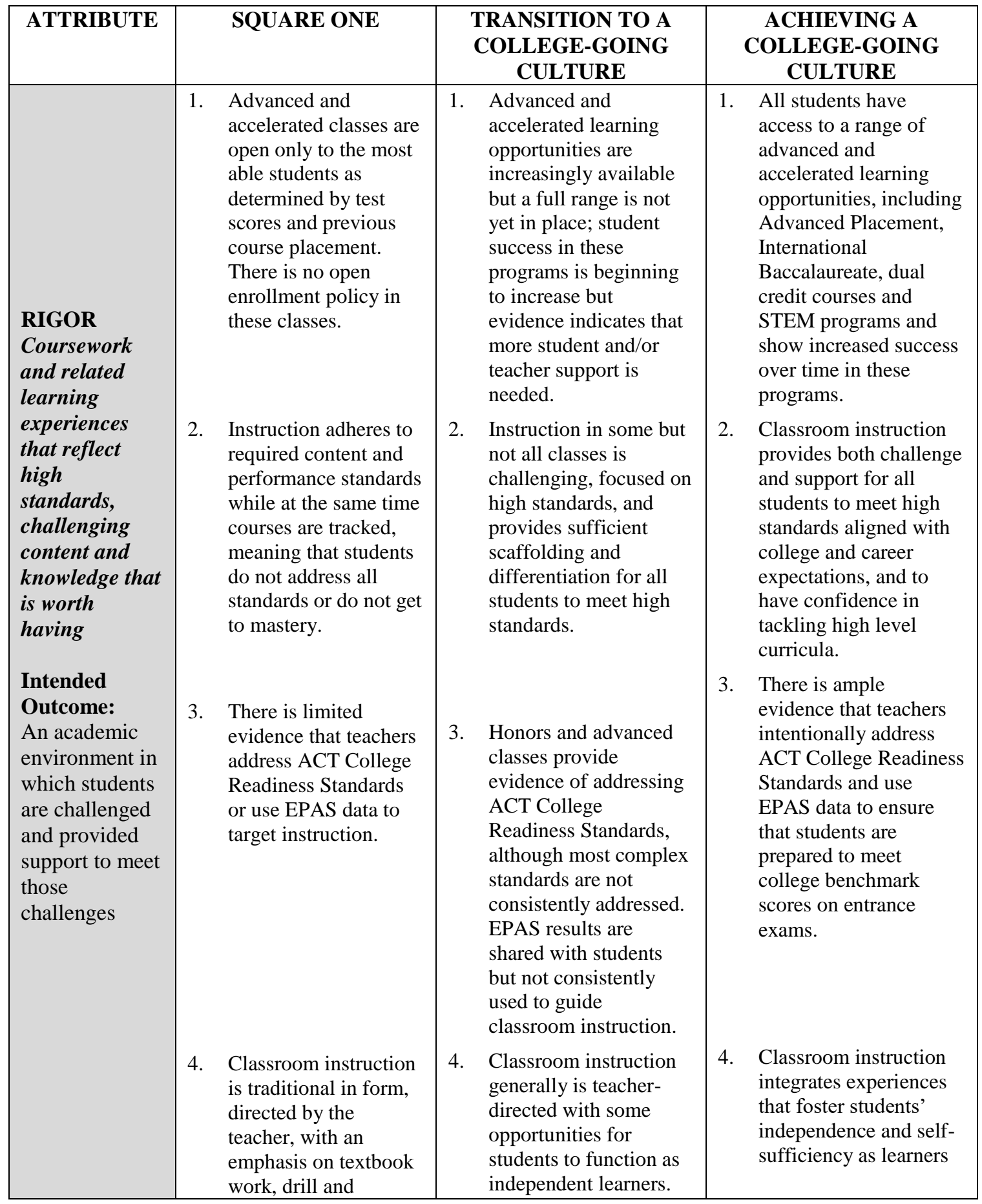




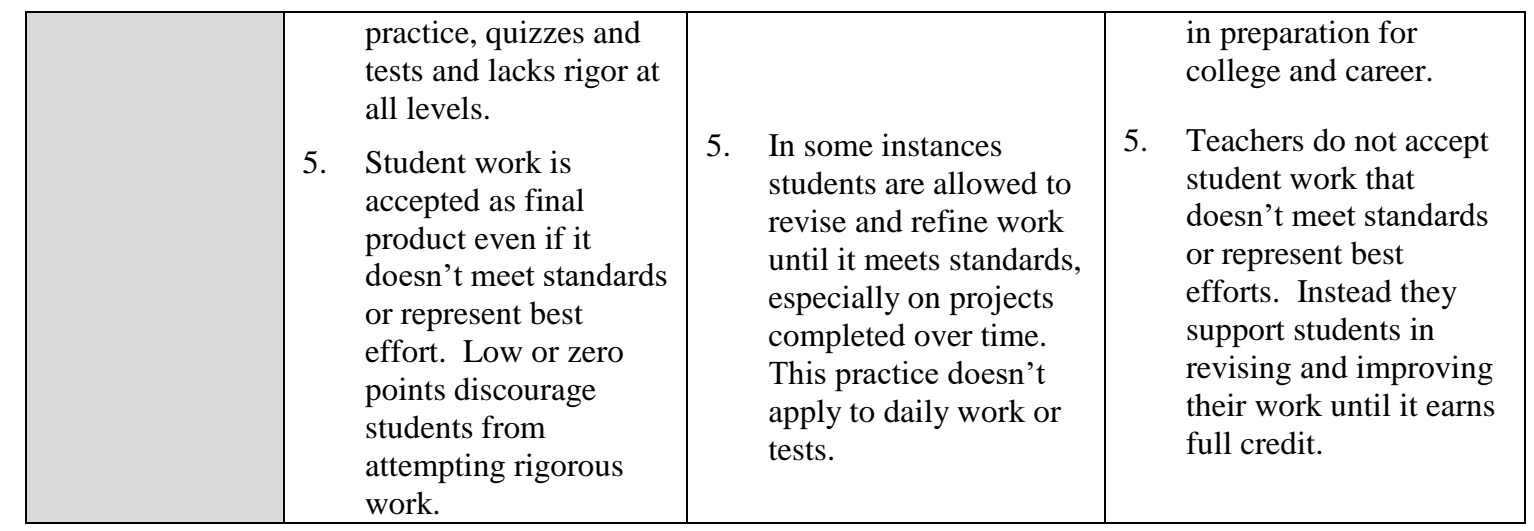

\section{Rigor: Sources of data for rigor could include:}

$\checkmark$ Number of AP, dual credit and IB courses, whether these classes are open to all students, and what number and percentage of students participate. For AP and IB, how many students pass the required qualifying tests.

$\checkmark$ Number and percentage of classes in Reading, English/Language Arts, Mathematics and Science addressing the ACT College Readiness Standards.

$\checkmark$ Score on Rigor, Relevance and Differentiation scales on CTL Walkthrough protocol. Survey data from Core Practice Inventory on classroom rigor.

\section{RIGOR: Examples of actions to increase the challenge and complexity of classroom}

\section{learning:}

\begin{tabular}{|c|c|c|}
\hline CLASSROOM ACTIONS & SCHOOL ACTIONS & GEAR-UP STRATEGIES \\
\hline $\begin{array}{l}\text { Teachers ensure that all } \\
\text { courses address adopted } \\
\text { standards and are focused on } \\
\text { student mastery. } \\
\text { Teachers scaffold learning so } \\
\text { that students not previously } \\
\text { in advanced courses develop } \\
\text { necessary skills and } \\
\text { background knowledge. } \\
\text { Students are tutored for AP, } \\
\text { dual credit or IB courses for } \\
\text { students not previously } \\
\text { taking advanced coursework, } \\
\text { during an additional period, } \\
\text { when students have open } \\
\text { time from dual credit courses, } \\
\text { before or after school so they } \\
\text { don't fall behind. } \\
\text { Teachers differentiate } \\
\text { instruction on dimensions of } \\
\text { reading level of materials, } \\
\text { complexity of task, time } \\
\text { allotted, opportunities to } \\
\text { work cooperatively with } \\
\text { other students, and formats } \\
\text { for assessments of student } \\
\text { learning. }\end{array}$ & $\begin{array}{l}\text { The school eliminates } \\
\text { comprehensive or other low } \\
\text { level/remedial courses. } \\
\text { The school makes AP, dual } \\
\text { credit and IB courses open to } \\
\text { all students } \\
\text { The principal uses teacher } \\
\text { evaluation and supervision } \\
\text { processes to foster rigor. } \\
\text { The school uses intensive and } \\
\text { ongoing professional } \\
\text { development to promote rigor } \\
\text { in instruction, including } \\
\text { modeling in the classroom, } \\
\text { support for teacher planning } \\
\text { and ongoing examination of } \\
\text { student work as an indication } \\
\text { of rigorous assignments. } \\
\text { The school encourages the use } \\
\text { of teacher networks, } \\
\text { professional learning } \\
\text { communities and other forms } \\
\text { of collaboration focused on } \\
\text { increasing rigor. } \\
\text { The principal engages in } \\
\text { regular communication and } \\
\text { collaboration with college }\end{array}$ & $\begin{array}{l}\text { Use GEAR UP } 2 \text { Learn } \\
\text { (grades 7-9) to prepare } \\
\text { students for more advanced } \\
\text { learning in high school and to } \\
\text { set a foundation for college. } \\
\text { Use GEAR UP Summer } \\
\text { Enrichment (grades 10-12) to } \\
\text { engage students in rigorous } \\
\text { learning on college } \\
\text { campuses, with benefits for } \\
\text { both high school and } \\
\text { eventual college } \\
\text { achievement. } \\
\text { Participate in Core } \\
\text { Framework school audit } \\
\text { process and in CTL } \\
\text { Walkthrough, to help set } \\
\text { targets for improving } \\
\text { classroom and school level } \\
\text { practices and ensure closer } \\
\text { alignment with ACT College } \\
\text { Readiness Standards. } \\
\text { Send a school team to the } \\
\text { annual GEAR UP Alliance } \\
\text { Institute for a College-Going } \\
\text { Culture to help increase rigor. }\end{array}$ \\
\hline
\end{tabular}




\begin{tabular}{|l|l|l|}
\hline $\begin{array}{l}\text { Teachers vary their } \\
\text { instructional style so that } \\
\text { students take a more active } \\
\text { role in their own learning, } \\
\text { have responsibility for }\end{array}$ & $\begin{array}{l}\text { faculty to ensure articulation } \\
\text { and rigor. }\end{array}$ \\
investigations and extended \\
study, and engage in learning \\
with peers to deepen \\
knowledge and consider \\
other perspectives.
\end{tabular}




\section{KY SCHOOL PERFORMANCE GUIDE FOR A COLLEGE-GOING CULTURE - EXPECTATION}

The School Performance Guide for a College-Going Culture (2011 version) addresses the five GEAR UP KY

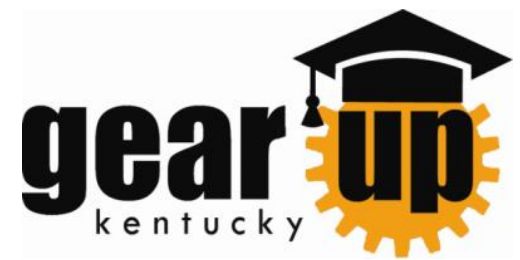
attributes - aspiration, rigor, expectation, accountability and sustainability - in rubric form, for purposes of school self-assessment.

\begin{tabular}{|c|c|c|c|}
\hline ATTRIBUTE & SQUARE ONE & $\begin{array}{c}\text { TRANSITION TO A } \\
\text { COLLEGE-GOING } \\
\text { CULTURE }\end{array}$ & $\begin{array}{c}\text { ACHIEVING A } \\
\text { COLLEGE-GOING } \\
\text { CULTURE }\end{array}$ \\
\hline $\begin{array}{l}\text { EXPECTATION } \\
\text { School and } \\
\text { classroom } \\
\text { structures that } \\
\text { reflect } \\
\text { commitment to } \\
\text { all students } \\
\text { graduating from } \\
\text { high school } \\
\text { college-ready } \\
\text { Intended } \\
\text { Outcome: } \\
\text { The school } \\
\text { demonstrates in } \\
\text { its policies and } \\
\text { practices } \\
\text { confidence that } \\
\text { all students can } \\
\text { succeed }\end{array}$ & $\begin{array}{l}\text { 1. Counselors advise } \\
\text { groups of students, } \\
\text { usually in classroom } \\
\text { settings, about course } \\
\text { selection, and } \\
\text { requirements for } \\
\text { graduation and college. } \\
\text { Students in advanced } \\
\text { courses may receive } \\
\text { additional information } \\
\text { or support. } \\
\text { The school issues } \\
\text { progress reports at } \\
\text { regular intervals, in } \\
\text { addition to report } \\
\text { cards, so that students } \\
\text { and parents can } \\
\text { monitor progress. } \\
\text { Summer school or } \\
\text { repeating courses the } \\
\text { next year is available } \\
\text { for students who fail } \\
\text { courses. } \\
\text { Information about } \\
\text { college application and } \\
\text { financial aid is } \\
\text { available on the school } \\
\text { website and in the } \\
\text { career center. }\end{array}$ & $\begin{array}{l}\text { 3. The school offers both } \\
\text { student and parent } \\
\text { workshops in completing } \\
\text { the college application, } \\
\text { applying for financial aid } \\
\text { and in hearing from } \\
\text { admissions officers what } \\
\text { colleges are looking for } \\
\text { in terms of student } \\
\text { preparation. } \\
\text { The school includes } \\
\text { regular features and } \\
\text { information about } \\
\text { college going in its } \\
\text { publications, written and } \\
\text { online; and uses PTA and } \\
\text { other outreach activities } \\
\text { to communicate } \\
\text { expectations about } \\
\text { college. } \\
\text { There are increasing } \\
\text { opportunities for college }\end{array}$ & $\begin{array}{l}\text { 1. There is a comprehensive } \\
\text { and systematic student } \\
\text { advisement, providing } \\
\text { personalized attention to } \\
\text { each student and ensures } \\
\text { that all students are } \\
\text { supported in planning for } \\
\text { and applying to college or } \\
\text { other postsecondary } \\
\text { education. } \\
\text { 2. Counselors and other } \\
\text { personnel monitor student } \\
\text { progress and provide } \\
\text { additional support, } \\
\text { including tutoring, } \\
\text { transition courses and } \\
\text { credit recovery options, } \\
\text { for students who struggle } \\
\text { or fall behind. }\end{array}$ \\
\hline
\end{tabular}




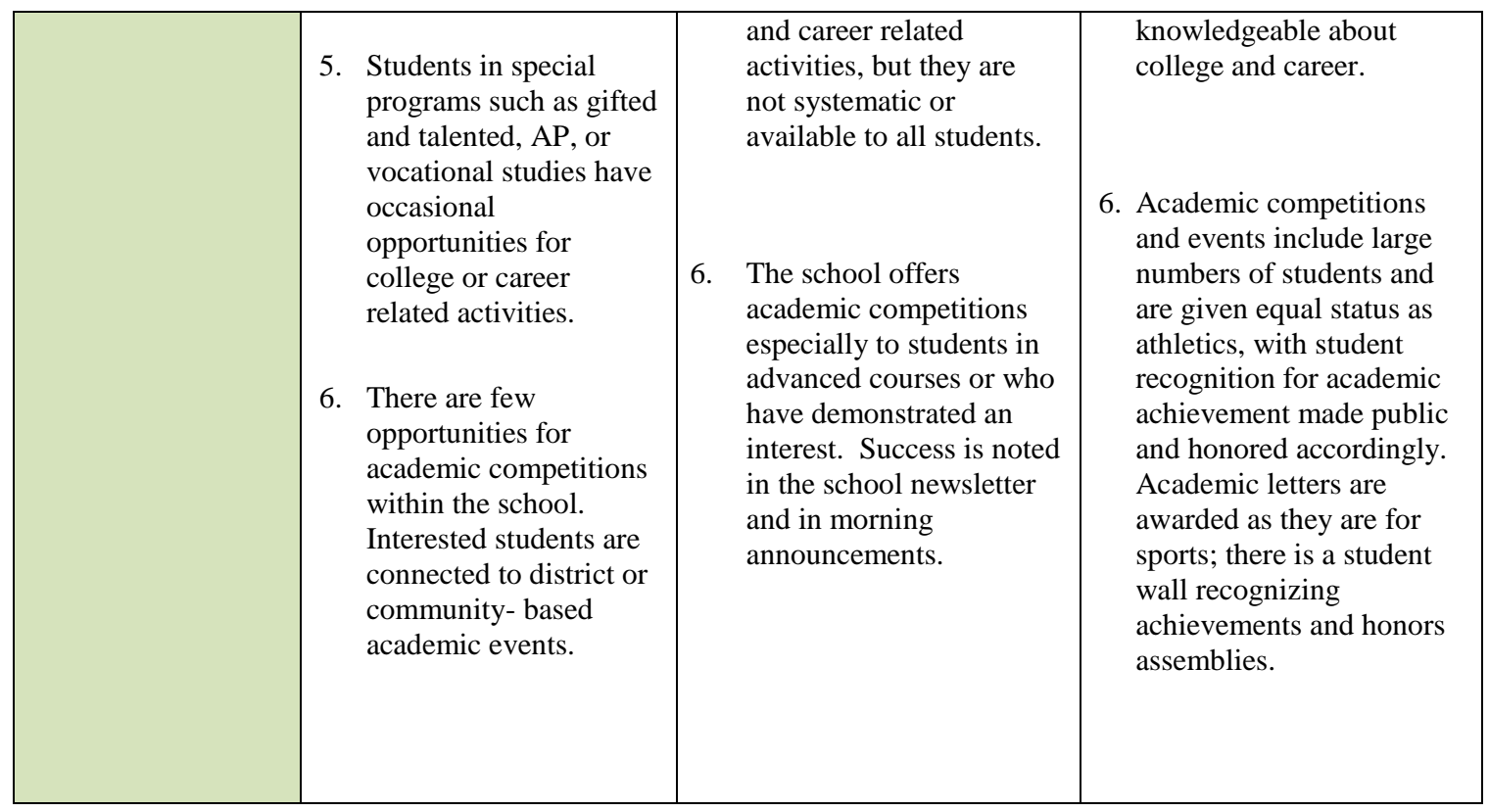

\section{EXPECTATION: Sources of data for aspirations could include:}

Number of counselors and teacher advisors participating in student advisement training and total number of training hours.

$\checkmark \quad$ Number and percentage of juniors and seniors completing at least one college application.

$\checkmark \quad$ Number of available transition courses and online credit recovery options, and number and percentage of students taking advantage of these options.

$\checkmark$ Number and percentage of students participating in college visits, job shadowing, internships and other college and career-related activities.

$\checkmark$ Number and percentage of courses requiring substantial research papers or field studies.

\section{EXPECTATION: Examples of teachers and schools holding high expectations for} student achievement and college going:

\begin{tabular}{|c|c|c|c|c|c|}
\hline \multicolumn{2}{|r|}{ CLASSROOM ACTIONS } & \multicolumn{2}{|c|}{ SCHOOL ACTIONS } & \multicolumn{2}{|r|}{ GEAR-UP } \\
\hline O & $\begin{array}{l}\text { Teachers engage in a } \\
\text { systematic review of the } \\
\text { kinds of experiences focused } \\
\text { on college readiness that } \\
\text { each course and department } \\
\text { provides its students. }\end{array}$ & ○ & $\begin{array}{l}\text { The school evaluates current } \\
\text { advisement efforts, including } \\
\text { data showing how many } \\
\text { students receive counseling } \\
\text { services about college } \\
\text { planning and application. }\end{array}$ & & $\begin{array}{l}\text { Incorporate GEAR UP's } \\
\text { College Readiness Advising } \\
\text { Model to strengthen school } \\
\text { efforts to implement a } \\
\text { comprehensive advising } \\
\text { program. }\end{array}$ \\
\hline O & $\begin{array}{l}\text { Teachers work together, } \\
\text { during collaborative } \\
\text { planning time, to design such } \\
\text { classroom experiences and to } \\
\text { evaluate their effectiveness. }\end{array}$ & ○ & $\begin{array}{l}\text { The school sets targets to } \\
\text { increase systematic, } \\
\text { individualized services to all } \\
\text { students. }\end{array}$ & & $\begin{array}{l}\text { Use GEAR UP's Mentoring } 4 \\
\text { A Focus to help students who } \\
\text { are at risk stay on track, and } \\
\text { gain the knowledge they need }\end{array}$ \\
\hline
\end{tabular}




\begin{tabular}{|c|c|c|c|c|c|}
\hline O & $\begin{array}{l}\text { English teachers assign } \\
\text { college application essays in } \\
11^{\text {th }} \text { and } 12^{\text {th }} \text { grade, } \\
\text { providing teacher and peer } \\
\text { feedback to refine student } \\
\text { writing. }\end{array}$ & O & $\begin{array}{l}\text { The school provides ongoing } \\
\text { professional development for } \\
\text { counselors and teacher } \\
\text { advisors to increase the } \\
\text { efficacy of student advisement } \\
\text { services. } \\
\text { The school arranges for } \\
\text { college visits tied to students' } \\
\text { goals and dreams, match } \\
\text { students with mentors in their } \\
\text { future career, and connect } \\
\text { them with summer academies } \\
\text { and internships. } \\
\text { The school ensures there is } \\
\text { support for all } 11^{\text {th }} \text { and } 12^{\text {th }} \\
\text { grade students in completing } \\
\text { the college application } \\
\text { process. } \\
\text { The school reviews all } \\
\text { communications with parents } \\
\text { and students regarding college } \\
\text { going, for message, } \\
\text { inclusivity, and opportunities } \\
\text { to engage students and parents } \\
\text { in extended discussions about } \\
\text { college. }\end{array}$ & 0 & $\begin{array}{l}\text { to prepare and apply for } \\
\text { college. } \\
\text { Engage students in GEAR } \\
\text { UP's Summer Enrichment } \\
\text { academies to give them the } \\
\text { confidence that they can } \\
\text { succeed in a college setting. } \\
\text { Send a school team to the } \\
\text { annual GEAR UP Alliance } \\
\text { Institute for a College-Going } \\
\text { Culture to address } \\
\text { expectations. }\end{array}$ \\
\hline
\end{tabular}




\section{KY SCHOOL PERFORMANCE GUIDE FOR A COLLEGE-GOING CULTURE - ACCOUNTABILITY}

The School Performance Guide for a College-Going Culture (2011 version) addresses the five GEAR UP KY

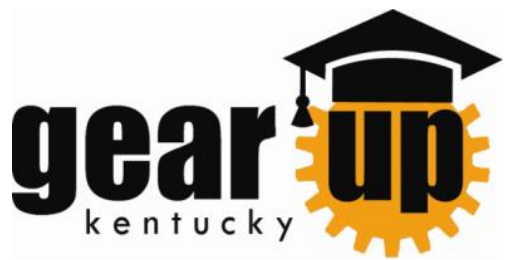

attributes - aspiration, rigor, expectation, accountability and sustainability - in rubric form, for purposes of school self-assessment.

\begin{tabular}{|c|c|c|c|}
\hline ATTRIBUTE & SQUARE ONE & $\begin{array}{c}\text { TRANSITION TO A } \\
\text { COLLEGE-GOING } \\
\text { CULTURE }\end{array}$ & $\begin{array}{c}\text { ACHIEVING A } \\
\text { COLLEGE-GOING } \\
\text { CULTURE }\end{array}$ \\
\hline $\begin{array}{l}\text { ACCOUNTABILITY } \\
\text { School leadership and } \\
\text { faculty taking } \\
\text { responsibility for the } \\
\text { achievement and } \\
\text { college readiness of all } \\
\text { students } \\
\text { Intended } \\
\text { Outcome: } \\
\text { An environment in } \\
\text { which decision-making } \\
\text { is informed by a } \\
\text { consistent analysis of a } \\
\text { variety of data points } \\
\text { that support student } \\
\text { achievement and } \\
\text { college going }\end{array}$ & $\begin{array}{l}\text { 3. Faculty reviews school- } \\
\text { level data as part of the } \\
\text { school improvement } \\
\text { planning process but not } \\
\text { in a targeted way to } \\
\text { improve classroom } \\
\text { instruction or respond to } \\
\text { individual learning } \\
\text { needs. } \\
\text { The school assigns } \\
\text { students who are failing } \\
\text { classes to lower track } \\
\text { courses, opting out of a } \\
\text { pre-college curriculum. }\end{array}$ & $\begin{array}{l}\text { 2. School faculty reviews } \\
\text { EPAS and state } \\
\text { assessment data as a } \\
\text { group and with their } \\
\text { students, with a focus } \\
\text { on how to improve } \\
\text { scores including the } \\
\text { number of students } \\
\text { meeting ACT } \\
\text { benchmarks. } \\
\text { 3. Faculty makes } \\
\text { programmatic } \\
\text { decisions based on } \\
\text { school-level trend data, } \\
\text { including interventions } \\
\text { for students not on } \\
\text { track for graduation. } \\
\text { Student-level data are } \\
\text { not used in a consistent } \\
\text { or intentional way. } \\
\text { 4he school provides } \\
\text { options for students } \\
\text { who fail classes to } \\
\text { recover credit while } \\
\text { remaining in a pre- } \\
\text { college curriculum. }\end{array}$ & $\begin{array}{l}\text { 1. The school uses state } \\
\text { assessment and EPAS } \\
\text { data as well as the high } \\
\text { school follow-up } \\
\text { report, at the building, } \\
\text { classroom and } \\
\text { individual student } \\
\text { levels to determine } \\
\text { student readiness for } \\
\text { college and career. } \\
\text { 2. Faculty is committed to } \\
\text { increasing annually the } \\
\text { number of students } \\
\text { meeting ACT College } \\
\text { Readiness benchmarks } \\
\text { on the PLAN } \\
\text { EXPLORE and ACT } \\
\text { tests and demonstrating } \\
\text { proficiency on the state } \\
\text { assessment. } \\
\text { Faculty uses student- } \\
\text { level data to develop } \\
\text { comprehensive student } \\
\text { profiles so that } \\
\text { interventions and } \\
\text { instruction is targeted } \\
\text { appropriately. }\end{array}$ \\
\hline
\end{tabular}




\begin{tabular}{|c|c|c|c|}
\hline & $\begin{array}{l}\text { 6. Both school and district } \\
\text { websites offer links to } \\
\text { information about } \\
\text { financial aid. }\end{array}$ & $\begin{array}{l}\text { financial literacy } \\
\text { through print and } \\
\text { online sources and } \\
\text { through home room or } \\
\text { advisory periods to } \\
\text { reach all students. } \\
\\
\text { 6. The school holds } \\
\text { parent and student } \\
\text { workshops several } \\
\text { times during the school } \\
\text { year for those seeking } \\
\text { assistance with } \\
\text { financial aid paperwork } \\
\text { or needing information } \\
\text { about college } \\
\text { admissions. Materials } \\
\text { from the workshops are } \\
\text { posted on the school } \\
\text { website. }\end{array}$ & $\begin{array}{l}\text { parents have necessary } \\
\text { information to reduce } \\
\text { barriers related to } \\
\text { family finances. } \\
\text { 6. The school provides } \\
\text { individual assistance in } \\
\text { completing FAFSA } \\
\text { paperwork, applying } \\
\text { for scholarships, } \\
\text { learning about } \\
\text { work/study options } \\
\text { while in college, and } \\
\text { understanding the } \\
\text { importance of } \\
\text { maintaining a high } \\
\text { grade point for college } \\
\text { admissions and KEES } \\
\text { scholarships. }\end{array}$ \\
\hline
\end{tabular}

\section{ACCOUNTABILITY: Sources of data for accountability could include:}

$\checkmark$ Documentation of analysis of student data at the student level and numbers and percentages of students on track for college

$\checkmark$ Number and percentage increase over the prior year of students meeting ACT benchmarks on EPAS suite of tests

$\checkmark$ Number and percentage of students participating in interventions to increase achievement

$\checkmark$ Number and percentage of high school students enrolled in and passing a precollege curriculum

$\checkmark$ A "no failure" policy where students continue to refine their work products until they meet performance standards

$\checkmark$ Materials, training agendas, completed ILP's and other evidence of students engaged in college planning and financial literacy learning

$\checkmark$ Number and percentage of $11^{\text {th }}$ and $12^{\text {th }}$ grade students receiving individualized help with completing financial aid paperwork, developing a college budget, and completing scholarship applications

\section{ACCOUNTABILITY: Examples of actions schools can take to hold themselves} accountable for achievement and college readiness:

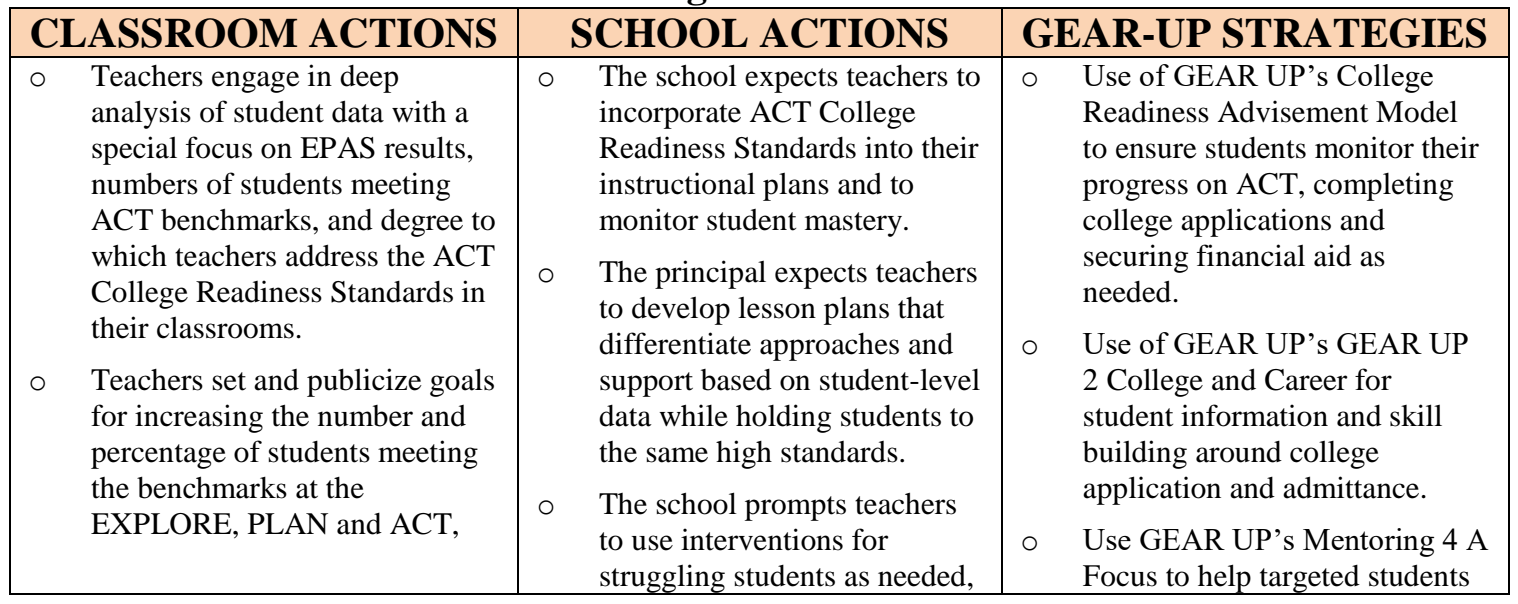




\begin{tabular}{|c|c|c|c|c|c|}
\hline . & $\begin{array}{l}\text { and make results available to all } \\
\text { stakeholders. } \\
\text { Teachers enlist parents in } \\
\text { developing and supporting } \\
\text { individualized student plans to } \\
\text { help students meet ACT } \\
\text { benchmarks. } \\
\text { Teachers are trained to use } \\
\text { student-level data to develop } \\
\text { individual plans to help students } \\
\text { meet benchmarks and other } \\
\text { instructional goals. } \\
\text { Teachers communicate with all } \\
\text { audiences about the skills and } \\
\text { knowledge required to be } \\
\text { college and career ready, and } \\
\text { what can be done to help } \\
\text { students acquire the knowledge } \\
\text { and skills. } \\
\text { Teachers come together to } \\
\text { discuss issues of academic } \\
\text { readiness, college application } \\
\text { and admittance, and financial } \\
\text { literacy, in terms of paying for } \\
\text { college and related expenses. }\end{array}$ & . & $\begin{array}{l}\text { and to make connections for } \\
\text { students between the } \\
\text { intervention program and } \\
\text { regular classroom instruction. } \\
\text { The school requires teachers } \\
\text { to incorporate information on } \\
\text { college planning, application } \\
\text { and financial literacy as } \\
\text { appropriate. For example, } \\
\text { English teachers can help } \\
\text { students develop and refine } \\
\text { their application essay. } \\
\text { Practical living courses can } \\
\text { build financial literacy skills. }\end{array}$ & O & $\begin{array}{l}\text { with college preparation and } \\
\text { financial aid knowledge } \\
\text { Use NCEA's Core Practice } \\
\text { Framework to strengthen the } \\
\text { school's overall instructional } \\
\text { program, and in particular to } \\
\text { address Theme } 4 \text { Monitoring: } \\
\text { Compilation, Analysis and Use } \\
\text { of Data, and theme } 5 \\
\text { Recognition, Intervention and } \\
\text { Adjustment. } \\
\text { Send a school team to the } \\
\text { annual GEAR UP Alliance } \\
\text { Institute for a College-Going } \\
\text { Culture to address } \\
\text { expectations. }\end{array}$ \\
\hline
\end{tabular}

2011 KY SCHOOL PERFORMANCE GUIDE FOR A COLLEGE-GOING CULTURE -

\section{SUSTAINABILITY}

The School Performance Guide for a College-Going Culture (2011 version) addresses the five GEAR UP KY attributes - aspiration, rigor, expectation, accountability and sustainability - in rubric form, for purposes of school self-assessment.

\begin{tabular}{|c|c|c|c|}
\hline ATTRIBUTE & SQUARE ONE & $\begin{array}{c}\text { TRANSITION TO A } \\
\text { COLLEGE-GOING } \\
\text { CULTURE }\end{array}$ & $\begin{array}{c}\text { ACHIEVING A } \\
\text { COLLEGE-GOING } \\
\text { CULTURE }\end{array}$ \\
\hline $\begin{array}{l}\text { SUSTAINABILITY } \\
\text { Able to implement } \\
\text { and maintain } \\
\text { long-term } \\
\text { improvements to } \\
\text { school culture and } \\
\text { classroom } \\
\text { instruction beyond } \\
\text { the life of the GEAR } \\
\text { UP grant } \\
\text { Intended Outcome: } \\
\text { Through } \\
\text { participation in } \\
\text { GEAR UP the } \\
\text { school attains a } \\
\text { college-going culture } \\
\text { and transforms } \\
\text { expectations and } \\
\text { learning for students }\end{array}$ & $\begin{array}{l}\text { 1. The school adopts } \\
\text { and implements a } \\
\text { variety of initiatives } \\
\text { aimed at increasing } \\
\text { student achievement } \\
\text { and readiness for } \\
\text { college and career; } \\
\text { however, these are } \\
\text { not coordinated or } \\
\text { evaluated for } \\
\text { efficacy, and } \\
\text { sometimes individual } \\
\text { initiatives are at cross } \\
\text { purposes. }\end{array}$ & $\begin{array}{l}\text { The school begins in } \\
\text { an intentional manner } \\
\text { to coordinate } \\
\text { resources and } \\
\text { initiatives in support } \\
\text { of student readiness } \\
\text { for college and } \\
\text { career, including } \\
\text { addressing college- } \\
\text { going goals in its } \\
\text { CSIP. The school } \\
\text { increases its } \\
\text { engagement in } \\
\text { professional } \\
\text { development but not } \\
\text { necessarily tied to } \\
\text { making sustainable } \\
\text { improvements in } \\
\text { culture, rigor and } \\
\text { commitment to } \\
\text { continuous } \\
\text { improvement. }\end{array}$ & $\begin{array}{l}\text { 1. The school uses } \\
\text { resources, including } \\
\text { GEAR UP, to put in } \\
\text { place sustainable } \\
\text { improvements to } \\
\text { school culture, } \\
\text { instructional rigor, } \\
\text { and capacity for } \\
\text { ongoing } \\
\text { improvement, } \\
\text { reflected in its CSIP } \\
\text { and GEAR UP plan: } \\
\text { 1) ongoing } \\
\text { professional } \\
\text { development to } \\
\text { improve classroom } \\
\text { practice, 2) } \\
\text { establishment of a } \\
\text { school leadership } \\
\text { team focused on } \\
\text { raising standards and } \\
\text { expectations, and 3) }\end{array}$ \\
\hline
\end{tabular}




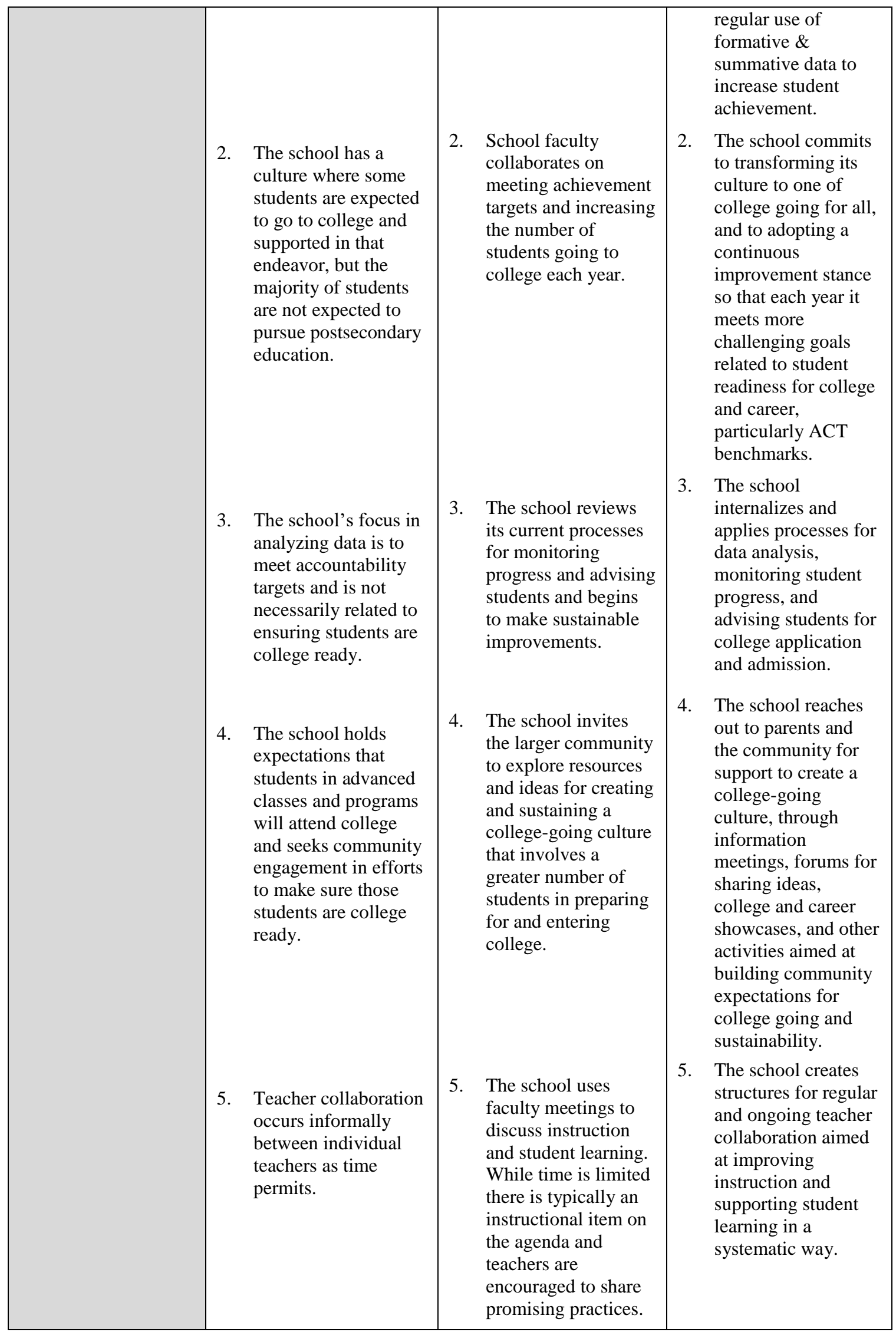


6. Each teacher is responsible for communicating his/her expectations in terms of homework completion, note taking, binder organization and grading procedures.

7. Classroom instruction is mostly teacherdirected and teachercentered, with few opportunities for students to work collaboratively or to study topics in depth. Lower track classes provide the fewest opportunities for engaging learning.
6. At the sixth and ninth grades there is a unit implemented in all core content classes emphasizing organization and study skills as well as support for students to take greater responsibility for their learning, appropriate to either middle or high school.

7. Classroom teachers frequently use cooperative learning arrangements to provide opportunities for students to learn from and with each other and to pursue areas of interest.
6. Classroom teachers incorporate "college knowledge" skills and behaviors into their regular instruction so that students become effective, independent learners: organization, notetaking, study skills, self-assessment and application of learning to new situations are emphasized.

7. Teachers transform their instruction so that it engages students in high level independent and collaborative work requiring extended investigations and synthesis of knowledge; and also scaffold learning so all students regardless of previous experiences can achieve at high levels.

\section{SUSTAINABILITY: Sources of data for sustainability could include:}

$\checkmark$ The school's comprehensive improvement plan provides for sustainability of efforts to increase rigor and create a college-going culture

$\checkmark$ The school sets annual targets for increasing student achievement with a goal of increasing each year the number of students meeting ACT benchmarks

$\checkmark$ Data analysis documents evidencing monitoring of student progress correlated with the number and percentage of students applying to college each year

$\checkmark$ Community engagement in creating and sustaining a college-going culture as evidenced by number of parents and community members involved and documentation of activities and results

$\checkmark$ Master schedule, agendas and notes from teacher collaboration meetings, number and percentage of teaching staff involved in co-planning, co-teaching and analysis of student work

$\checkmark$ Syllabi and lesson plans showing intentional teaching of college knowledge by course and teacher

$\checkmark$ Lesson plans, classroom observation data and student work products demonstrating high level work and appropriate scaffolding 


\section{SUSTAINABILITY: Examples of actions designed to sustain a college-going}

culture:

\begin{tabular}{|c|c|c|c|c|}
\hline & $\begin{array}{c}\text { CLASSROOM } \\
\text { ACTIONS }\end{array}$ & \multicolumn{2}{|r|}{ SCHOOL ACTIONS } & $\begin{array}{c}\text { GEAR-UP } \\
\text { STRATEGIES }\end{array}$ \\
\hline O & $\begin{array}{l}\text { Teachers use the school } \\
\text { planning process to put in } \\
\text { place structures and practices } \\
\text { that will support and sustain a } \\
\text { college-going culture. }\end{array}$ & O & $\begin{array}{l}\text { The school ensures that } \\
\text { teachers address ACT } \\
\text { College Readiness standards } \\
\text { in their instructional planning } \\
\text { and informal assessments. }\end{array}$ & $\begin{array}{l}\text { O Use GEAR UP's GEAR UP } 2 \\
\text { Learn Freshman institute to } \\
\text { ready students for high school } \\
\text { and impart college } \\
\text { knowledge. }\end{array}$ \\
\hline 0 & $\begin{array}{l}\text { Teachers track and make } \\
\text { public to the school and } \\
\text { community progress in } \\
\text { increasing the number of } \\
\text { students meeting ACT }\end{array}$ & O & $\begin{array}{l}\text { The school creates } \\
\text { opportunities for teachers to } \\
\text { co-teach or observe each } \\
\text { other and then work together } \\
\text { to refine lessons. }\end{array}$ & $\begin{array}{l}\text { Use GEAR UP's GEAR UP } 2 \\
\text { College and Career for } \\
\text { preparing students for } \\
\text { college. }\end{array}$ \\
\hline 0 & $\begin{array}{l}\text { benchmarks each year. } \\
\text { Teachers monitor student } \\
\text { progress at the individual } \\
\text { student level and keep records } \\
\text { of efforts to prepare students } \\
\text { for college study and }\end{array}$ & O & $\begin{array}{l}\text { The school supports teachers } \\
\text { in embedding college } \\
\text { knowledge in their classroom } \\
\text { teaching, and in producing } \\
\text { evidence of increasing } \\
\text { student preparedness. }\end{array}$ & $\begin{array}{l}\text { Use ACT/NCEA's Core } \\
\text { Practice Framework, Themes } \\
\text { 1-5 to ensure sustainability in } \\
\text { terms of rigor, teacher } \\
\text { effectiveness and school } \\
\text { culture. }\end{array}$ \\
\hline 0 & $\begin{array}{l}\text { completing college } \\
\text { applications. } \\
\text { Teachers engage community } \\
\text { partners to create a college- } \\
\text { going culture within/beyond } \\
\text { the school, through task } \\
\text { forces, forums and } \\
\text { showcases. }\end{array}$ & O & $\begin{array}{l}\text { The school has teachers vary } \\
\text { their instructional practice to } \\
\text { allow increasing opportunities } \\
\text { for student collaboration, } \\
\text { investigations and extended, } \\
\text { in-depth projects that prepare } \\
\text { them for advanced study in } \\
\text { college. }\end{array}$ & $\begin{array}{l}\text { Send a school team to the } \\
\text { annual GEAR UP Alliance } \\
\text { Institute for a College-Going } \\
\text { Culture to help create } \\
\text { sustainability of efforts. }\end{array}$ \\
\hline 0 & $\begin{array}{l}\text { Teachers use common } \\
\text { planning time to collaborate } \\
\text { on a regular basis, supported } \\
\text { through face-to-face and/or } \\
\text { online communities of } \\
\text { practice. }\end{array}$ & O & $\begin{array}{l}\text { Teacher participation in } \\
\text { professional development and } \\
\text { follow-up implementation of } \\
\text { new professional learning is } \\
\text { monitored and supported by } \\
\text { school administrators. }\end{array}$ & \\
\hline 0 & $\begin{array}{l}\text { Teachers participate in } \\
\text { faculty work groups to } \\
\text { develop a college knowledge } \\
\text { curriculum that is } \\
\text { implemented across content } \\
\text { areas and referenced in course } \\
\text { syllabi. }\end{array}$ & & & \\
\hline 0 & $\begin{array}{l}\text { Teachers participate in } \\
\text { professional development to } \\
\text { improve classroom practice, } \\
\text { increasing student } \\
\text { engagement and rigor. }\end{array}$ & & & \\
\hline
\end{tabular}




\section{APPENDIX C}

\section{Table C1}

Walkthrough Content Scores with Normalized Scores for each subsection (ACT Standards, Common Core Instructional Shifts, and Rigor, Relevance, and Differentiation)

\begin{tabular}{|c|c|c|c|c|c|c|c|c|c|c|c|c|}
\hline & \multicolumn{4}{|c|}{ Social Studies } & \multicolumn{4}{|c|}{ Math } & \multicolumn{4}{|c|}{ Science } \\
\hline & Act & Lit & Rrd & Total & Act & Lit & Rrd & Total & Act & Lit & Rrd & Total \\
\hline S1 & 1.3 & 0.2 & 1.8 & 3.35 & 1.1 & 0.0 & 0.8 & 1.89 & 0.0 & 0.2 & 1.5 & 1.69 \\
\hline $\mathrm{S} 2$ & 0.0 & 0.9 & 2.3 & 3.19 & 2.0 & 1.5 & 4.8 & 8.28 & 0.5 & 0.8 & 2.1 & 3.34 \\
\hline S3 & 1.1 & 1.3 & 1.9 & 4.30 & 0.2 & 0.2 & 1.0 & 1.39 & 0.5 & 1.6 & 3.0 & 5.08 \\
\hline S4 & 1.8 & 1.2 & 4.3 & 7.27 & 0.3 & 0.5 & 2.0 & 2.89 & 0.5 & 1.1 & 2.6 & 4.19 \\
\hline S5 & 0.6 & 1.5 & 3.6 & 5.66 & 1.7 & 1.0 & 4.3 & 6.95 & 0.6 & 1.3 & 4.7 & 6.61 \\
\hline S6 & 0.0 & 0.6 & 1.1 & 1.70 & 0.3 & 0.6 & 1.8 & 2.70 & 0.5 & 1.4 & 2.8 & 4.59 \\
\hline S7 & 0.0 & 1.0 & 1.1 & 2.07 & 1.7 & 1.1 & 4.2 & 6.93 & 0.5 & 1.3 & 2.9 & 4.80 \\
\hline S8 & 0.9 & 1.3 & 1.9 & 4.09 & 0.4 & 0.9 & 2.3 & 3.58 & 0.9 & 0.8 & 2.5 & 4.27 \\
\hline S9 & 0.6 & 0.6 & 2.0 & 3.15 & 1.0 & 0.0 & 1.3 & 2.38 & 0.4 & 0.8 & 3.6 & 4.83 \\
\hline $\mathrm{S} 10$ & 0.0 & 1.0 & 0.6 & 1.58 & 0.3 & 0.3 & 0.8 & 1.36 & 0.3 & 0.8 & 2.6 & 3.76 \\
\hline S11 & 0.0 & 2.9 & 3.4 & 6.34 & 0.3 & 0.4 & 1.1 & 1.88 & 0.3 & 0.9 & 2.8 & 3.94 \\
\hline $\mathrm{S} 12$ & 0.0 & 1.0 & 1.3 & 2.36 & 0.9 & 0.4 & 2.5 & 3.77 & 0.9 & 2.1 & 4.5 & 7.56 \\
\hline $\mathrm{S} 13$ & 1.5 & 2.6 & 4.2 & 8.32 & 0.9 & 0.2 & 1.2 & 2.34 & 0.5 & 1.1 & 2.5 & 4.07 \\
\hline S14 & 0.7 & 2.1 & 2.9 & 5.73 & 0.2 & 0.3 & 1.3 & 1.79 & 0.2 & 0.4 & 1.3 & 1.95 \\
\hline S15 & 0.6 & 0.9 & 3.3 & 4.75 & 0.9 & 0.9 & 3.1 & 4.95 & 0.0 & 0.5 & 1.3 & 1.83 \\
\hline S16 & 1.3 & 1.3 & 4.7 & 7.31 & 1.5 & 1.0 & 3.5 & 5.96 & 0.2 & 0.7 & 4.2 & 5.15 \\
\hline S17 & 1.4 & 1.2 & 3.8 & 6.50 & 1.1 & 0.8 & 2.5 & 4.46 & 0.5 & 1.0 & 2.5 & 3.96 \\
\hline S18 & 0.1 & 0.1 & 0.2 & 0.49 & 1.3 & 0.0 & 2.7 & 3.97 & 0.3 & 0.4 & 3.1 & 3.83 \\
\hline S19 & 0.0 & 0.7 & 1.4 & 7.50 & 1.1 & 0.6 & 1.8 & 20.00 & 0.2 & 1.0 & 3.7 & 4.93 \\
\hline S20 & 1.2 & 1.6 & 1.8 & 17.33 & 0.6 & 0.9 & 2.3 & 19.00 & 0.6 & 1.4 & 2.2 & 4.18 \\
\hline S21 & 0.0 & 1.8 & 2.4 & 15.50 & 1.0 & 0.5 & 2.3 & 20.29 & 0.1 & 0.9 & 3.5 & 4.53 \\
\hline
\end{tabular}


Walkthrough Content Scores with Normalized Scores for each subsection (continued)

\begin{tabular}{|c|c|c|c|c|c|c|c|}
\hline \multicolumn{9}{|c|}{ English/Language Arts } & \multicolumn{4}{c|}{ Total Walkthrough Scores } \\
\hline Act & Lit & Rrd & Total & Total ACT & Total Lit & Total Rrd & W_Total \\
\hline 0.8 & 0.8 & 2.8 & 4.4 & 3.2 & 1.2 & 6.9 & 11.3 \\
\hline 1.2 & 1.5 & 4.1 & 6.8 & 3.7 & 4.7 & 13.3 & 21.7 \\
\hline 0.6 & 0.7 & 2.4 & 3.6 & 2.4 & 3.8 & 8.3 & 14.5 \\
\hline 1.3 & 1.1 & 2.8 & 5.3 & 3.9 & 3.9 & 11.7 & 19.5 \\
\hline 0.8 & 1.0 & 2.0 & 3.8 & 3.7 & 4.8 & 14.6 & 23.1 \\
\hline 1.3 & 1.3 & 2.4 & 5.0 & 2.1 & 3.9 & 8.1 & 14.1 \\
\hline 0.9 & 1.1 & 2.5 & 4.5 & 3.1 & 4.5 & 10.7 & 18.3 \\
\hline 1.2 & 0.8 & 2.0 & 3.9 & 3.4 & 3.8 & 8.7 & 15.9 \\
\hline 0.4 & 1.0 & 1.5 & 2.9 & 2.4 & 2.4 & 8.4 & 13.2 \\
\hline 0.7 & 0.6 & 2.1 & 3.5 & 1.3 & 2.7 & 6.1 & 10.1 \\
\hline 0.7 & 0.9 & 3.1 & 4.7 & 1.3 & 5.1 & 10.4 & 16.8 \\
\hline 0.5 & 1.1 & 2.9 & 4.6 & 2.3 & 4.6 & 11.2 & 18.1 \\
\hline 1.5 & 1.5 & 2.9 & 5.9 & 4.4 & 5.4 & 10.8 & 20.6 \\
\hline 1.3 & 1.5 & 3.0 & 5.9 & 2.4 & 4.3 & 8.5 & 15.2 \\
\hline 1.3 & 1.0 & 3.3 & 5.6 & 2.8 & 3.3 & 11.0 & 17.1 \\
\hline 0.2 & 0.3 & 1.7 & 2.2 & 3.2 & 3.3 & 14.1 & 20.6 \\
\hline 1.0 & 1.3 & 3.5 & 5.8 & 4.0 & 4.3 & 12.3 & 20.6 \\
\hline 0.3 & 0.6 & 0.7 & 1.6 & 2.0 & 1.1 & 6.7 & 9.8 \\
\hline 1.5 & 1.6 & 4.3 & 7.4 & 2.8 & 3.9 & 11.2 & 17.9 \\
\hline 1.6 & 1.4 & 4.1 & 7.1 & 4.0 & 5.3 & 10.4 & 19.7 \\
\hline 1.2 & 1.7 & 2.7 & 5.6 & 2.3 & 4.9 & 10.9 & 18.1 \\
\hline
\end{tabular}




\section{Table C2}

Walkthrough Content Scores with Scores for each Analysis (TOT_**_All-All Items, TOT_**_10-Below 10\%/Above 90\%

$\underline{\text { Removed, TOT_**_Norm-Subscale Normed from Reduced Item List) }}$

\begin{tabular}{|c|c|c|c|c|c|c|c|c|c|}
\hline \multirow[t]{2}{*}{ Schools } & \multicolumn{3}{|c|}{ English } & \multicolumn{3}{|c|}{ Social Studies } & \multicolumn{3}{|c|}{ Science } \\
\hline & TOT_E_all & TOT_E_10 & TOT_E_norm & TOT_SS_all & TOT_SS_10 & TOT_SS_norm & TOT_SCI_all & TOT_SCI_10 & TOT_SC_norm \\
\hline $\mathrm{S} 1$ & 24.2 & 17.2 & 4.4 & 12.5 & 10.0 & 3.4 & 5.4 & 5.4 & 1.7 \\
\hline $\mathrm{S} 2$ & 32.8 & 27.8 & 6.8 & 11.0 & 11.0 & 3.2 & 11.7 & 11.1 & 3.3 \\
\hline S3 & 19.3 & 14.1 & 3.6 & 18.7 & 14.4 & 4.3 & 19.1 & 17.6 & 5.1 \\
\hline S4 & 26.3 & 22.3 & 5.3 & 27.6 & 23.0 & 7.3 & 15.2 & 14.2 & 4.2 \\
\hline S5 & 18.3 & 16.0 & 3.8 & 20.2 & 19.0 & 5.7 & 22.3 & 21.7 & 6.6 \\
\hline S6 & 24.6 & 21.4 & 5.0 & 6.1 & 6.1 & 1.7 & 17.2 & 15.8 & 4.6 \\
\hline S7 & 22.9 & 18.7 & 4.5 & 7.6 & 7.6 & 2.1 & 16.5 & 16.3 & 4.8 \\
\hline S8 & 19.1 & 16.7 & 3.9 & 15.5 & 14.0 & 4.1 & 17.8 & 14.0 & 4.3 \\
\hline S9 & 15.0 & 11.6 & 2.9 & 11.1 & 10.1 & 3.2 & 16.7 & 15.7 & 4.8 \\
\hline $\mathrm{S} 10$ & 16.8 & 13.8 & 3.5 & 6.2 & 6.2 & 1.6 & 13.1 & 12.4 & 3.8 \\
\hline S11 & 20.5 & 17.9 & 4.7 & 24.2 & 23.4 & 6.3 & 13.4 & 13.1 & 3.9 \\
\hline $\mathrm{S} 12$ & 23.0 & 18.0 & 4.6 & 8.6 & 8.6 & 2.4 & 27.0 & 25.8 & 7.6 \\
\hline S13 & 31.8 & 25.6 & 5.9 & 34.2 & 28.3 & 8.3 & 16.2 & 13.8 & 4.1 \\
\hline S14 & 28.3 & 24.4 & 5.9 & 23.0 & 20.2 & 5.7 & 7.0 & 6.5 & 2.0 \\
\hline S15 & 26.0 & 23.5 & 5.6 & 15.7 & 15.3 & 4.7 & 6.3 & 6.2 & 1.8 \\
\hline S16 & 10.6 & 7.6 & 2.2 & 26.7 & 23.5 & 7.3 & 16.4 & 16.4 & 5.2 \\
\hline S17 & 26.1 & 22.6 & 5.8 & 22.2 & 20.9 & 6.5 & 14.1 & 13.4 & 4.0 \\
\hline S18 & 8.0 & 7.3 & 1.6 & 1.7 & 1.7 & 0.5 & 13.7 & 12.0 & 3.8 \\
\hline S19 & 35.3 & 30.3 & 7.4 & 7.5 & 7.5 & 2.1 & 18.3 & 16.3 & 4.9 \\
\hline S20 & 32.8 & 28.8 & 7.0 & 17.3 & 16.0 & 4.6 & 15.8 & 14.5 & 4.2 \\
\hline S21 & 27.7 & 23.4 & 5.6 & 15.5 & 15.3 & 4.2 & 15.0 & 15.0 & 4.5 \\
\hline
\end{tabular}


Walkthrough Content Scores with Scores for each analysis (continued)

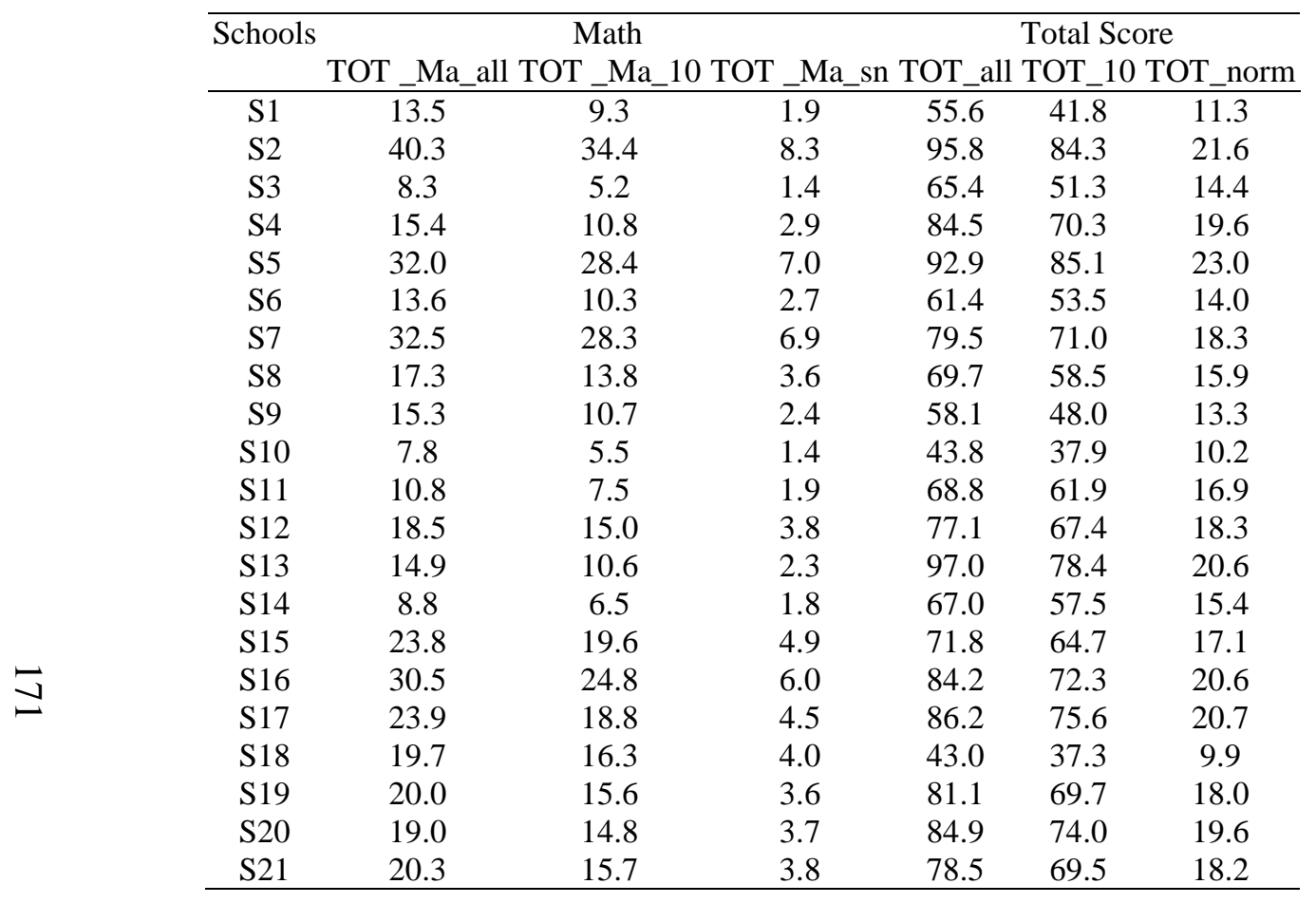




\section{Table C3}

\section{Variable Abbreviations, Names, Descriptions}

\begin{tabular}{|c|c|c|}
\hline \multicolumn{3}{|c|}{ Variable } \\
\hline Abbreviation & Name & Description \\
\hline \multicolumn{3}{|c|}{ Moderator Variable } \\
\hline$\% \mathrm{FRL}$ & Percent of Free/Reduced Lunch Status & $\begin{array}{l}\text { Percent of students qualifying for free/reduced } \\
\text { lunch status }\end{array}$ \\
\hline \multicolumn{3}{|c|}{ College Readiness - internal } \\
\hline HSGPA & High School Grade Point Average & Mean High School GPA \\
\hline \multicolumn{3}{|c|}{ College Readiness - external } \\
\hline ACT_ela & ACT Mean Score for English & \\
\hline ACT_math & ACT Mean Score for Mathematics & \\
\hline ACT_read & ACT Mean Score for Reading & \\
\hline ACT_sci & ACT Mean Score for Science & \\
\hline ACT_comp & ACT Mean Composite Score & \\
\hline CGRate & Percent of students going to college & \\
\hline KYCollR & $\begin{array}{l}\text { Percent of students determined to be } \\
\text { college-ready by Kentucky's } \\
\text { Accountability System }\end{array}$ & \\
\hline \multicolumn{3}{|c|}{ College Success } \\
\hline Earn30 & \multirow{2}{*}{\multicolumn{2}{|c|}{$\begin{array}{l}\text { Earn } 30 \text { hours during college freshman year } \\
\text { Return for the beginning of sophomore year }\end{array}$}} \\
\hline Soph & & \\
\hline \multicolumn{3}{|c|}{$\begin{array}{c}\text { Walkthrough Input Data } \\
\text { Content Subscores }\end{array}$} \\
\hline E_act_n & ELA ACT Standards Normed Score & \\
\hline E_cc_n & ELA Common Core Normed Score & \\
\hline E_rrd_n & $\begin{array}{l}\text { ELA Rigor/Relevance/Differentiation } \\
\text { Normed Score }\end{array}$ & \\
\hline TOT_E_norm & Total ELA Normed Score & $\begin{array}{l}\text { All three section scores added together ( } 30 \\
\text { point scale) }\end{array}$ \\
\hline SS_act_n & \multicolumn{2}{|c|}{ Social Studies ACT Standards Normed Score } \\
\hline SS_cc_n & \multicolumn{2}{|c|}{ Social Studies Common Core Normed Score } \\
\hline SS_rrd_n & \multicolumn{2}{|c|}{ Social Studies Rigor/Relevance/Differentiation Normed Score } \\
\hline TOT_SS_norm & Total Social Studies Normed Score & $\begin{array}{l}\text { All three section scores added together ( } 30 \\
\text { point scale) }\end{array}$ \\
\hline SC_act_n & Science ACT Standards Normed Score & \\
\hline SC_cc_n & Science Common Core Normed Score & \\
\hline SC_rrd_n & Science Rigor/Relevance/Differentiatio & ormed Score \\
\hline TOT_SC_norm & Total Science Normed Score & $\begin{array}{l}\text { All three section scores added together ( } 30 \\
\text { point scale) }\end{array}$ \\
\hline M_act_n & Math ACT Standards Normed Score & \\
\hline M_cc_n & Math Common Core Normed Score & \\
\hline & Math Rigor/Relevance/Differentiation I & med Score \\
\hline
\end{tabular}




\begin{tabular}{|c|c|c|}
\hline TOT_M_norm & Total Math Normed Score & $\begin{array}{l}\text { All three section scores added together ( } 30 \\
\text { point scale) }\end{array}$ \\
\hline \multicolumn{3}{|c|}{ Section Subscores } \\
\hline TOT_ACT_n & Total ACT Standards Normed Score & $\begin{array}{l}\text { All four content area normed ACT scores } \\
\text { added together ( } 40 \text { point scale) }\end{array}$ \\
\hline TOT_CC_n & $\begin{array}{l}\text { Total Common Core Instructional Shift } \\
\text { Normed Score }\end{array}$ & $\begin{array}{l}\text { All four content area normed ACT scores } \\
\text { added together ( } 40 \text { point scale) }\end{array}$ \\
\hline TOT_RRD_n & $\begin{array}{l}\text { Total Rigor/Relevance/Differentiation } \\
\text { Normed Score }\end{array}$ & $\begin{array}{l}\text { All four content area normed ACT scores } \\
\text { added together ( } 40 \text { point scale) }\end{array}$ \\
\hline \multicolumn{3}{|c|}{ Total Walkthrough Input Scores } \\
\hline & Total Normed Score & $\begin{array}{l}\text { This score is calculated from the reduced set } \\
\text { of items, normed for each section of each } \\
\text { content. The total scores can by calculated by } \\
\text { adding each content score together or by } \\
\text { adding the three section total scores together } \\
\text { (120 point scale) }\end{array}$ \\
\hline TOT_all & Total score using all items & $\begin{array}{l}\text { This score was calculated by adding together } \\
\text { all items for each school and the score is } \\
\text { unnormed. }\end{array}$ \\
\hline TOT_10 & Total Reduced Items & $\begin{array}{l}\text { Items that appeared in less than } 10 \% \text { of } \\
\text { observations and more than } 90 \% \text { of } \\
\text { observations were removed. The remaining } \\
\text { items were added together for each school and } \\
\text { the score is unnormed. }\end{array}$ \\
\hline \multicolumn{3}{|c|}{$\begin{array}{l}\text { School Performance Guide } \\
\text { Attribute Scores }\end{array}$} \\
\hline Asp_n & Normed Aspiration Score & \\
\hline Rigor_n & Normed Rigor Score & \\
\hline Exp_n & Normed Expectations Score & \\
\hline Acc_n & Normed Accountability Score & \\
\hline Sus_n & Normed Sustainability Score & \\
\hline SPG_n & Normed Total SPG Score & $\begin{array}{l}\text { The five attribute scores were added to create } \\
\text { the overall SPG score ( } 80 \text { point scale) }\end{array}$ \\
\hline SPG-Acct_n & $\begin{array}{l}\text { Normed SPG Score with Accountability } \\
\text { Attribute Removed }\end{array}$ & $\begin{array}{l}\text { The Accountability Attribute Score was } \\
\text { removed from the SPG_n score ( } 64 \text { point } \\
\text { scale) }\end{array}$ \\
\hline \multicolumn{3}{|c|}{ Combined Walkthrough and School Performance Guide Score } \\
\hline TOT\&SPG & Combined Walkthrough and SPG Score & $\begin{array}{l}\text { Calculated by adding the two process scores } \\
\text { together ( } 184 \text { point scale) }\end{array}$ \\
\hline
\end{tabular}




\section{APPENDIX D}

\section{Dictionary of Terms}

Academic Intensity- a composite measure of the academic content and performance the student brings forward from secondary school into higher education, dominated by the intensity and quality of secondary school curriculum (Adelman, 1999)

Authentic work- work that intellectually involves the student in meaningful inquiry to solve real life problems that may extend beyond the classroom (Newmann, Wehledge, \& Lamborn, 1992)

Career readiness- high school graduates who possess both the necessary knowledge and technical skills needed for employment in their desired career field

College readiness- high school graduates who are academically prepared, ready for postsecondary education or training without the need for remedial courseworkStudentcentered instruction- a teaching style that places the focus of teaching on students actively engaging in learning activities than on the instructor led activities

Common Core State Standards (CCSS)- a set of high-quality academic standards in mathematics and English language arts/literacy (ELA)

(http://www.corestandards.org/about-the-standards/)

Daggett's Rigor/Relevance Framework is an approach to looking at college- and career-ready standards and assessment. It is based on traditional elements of education, yet encourages movement from acquisition of knowledge to application of knowledge (Daggett, 2017)

Quadrant A- Acquisition: simple recall and basic understanding of knowledge Quadrant B- Application: use acquired knowledge to solve problems, design solutions, and complete work

Quadrant C- Assimilation: extend and refine their acquired knowledge to automatically and routinely analyze and solve problems as well as create unique solutions Quadrant D - Adaptation: think in complex ways and apply knowledge and skills they have acquired to unique situations

Educational aspirations- student expectations they will go on to postsecondary education $(\mathrm{Hu}, 2003)$

Engagement- the intensity and emotional quality of children's involvement in learning activities (McClenney, Marti, and Adkins, 2012)

Every Student Succeeds Act (ESSA)- US law passed in December 2015 that governs the United States K-12 public education policy. The law replaced its predecessor, the No Child Left Behind Act (NCLB), and modified but did not eliminate provisions relating to the periodic standardized tests given to students. 
First generation- someone whose parents did not attend college. You can be a firstgen if you are the first person from your family to attend college, or if your sibling went and you are going, too.

Free/Reduced Lunch Status- A student from a household with an income at or below 130 percent of the poverty income threshold is eligible for free lunch. A student from a household with an income between 130 percent and up to 185 percent of the poverty threshold is eligible for reduced price lunch. FRL is often used as a proxy for poverty. (NCES, 2015)

GEAR UP- Gaining Early Awareness and Readiness for Undergraduate Programs: A discretionary federal grant program is designed to increase the number of low-income students who are prepared to enter and succeed in postsecondary education (U.S. Department of Education, 2018)

Generational poverty- a person or family having lived in poverty for at least two generations (Bowles and Gintis 2002)

High-stakes Accountability- use of tests to make important decisions about students, educators, schools, or districts

Highly qualified teachers- to be deemed highly qualified, teachers must have: 1) a bachelor's degree, 2) full state certification or licensure, and 3) prove that they know each subject they teach (NCLB, 2001)

National Assessment of Educational Progress (NAEP)- the largest nationally representative and continuing assessment of what America's students know and can do in various subject areas. (https://nces.ed.gov/nationsreportcard/)

No Child Left Behind (NCLB)- An Act passed by Congress in 2001 and signed into law by President George W. Bush on Jan. 8, 2002. It is the 2001 update to the Elementary and Secondary Education Act of 1965.

Non-cognitive skills, success skills, or postsecondary success skills- skills associated with positive outcomes for young people, correlated with academic outcomes.

Programme for International Student Assessment (PISA)- a triennial international survey which aims to evaluate education systems worldwide by testing the skills and knowledge of 15-year-old students.( http://www.oecd.org/pisa/aboutpisa/)

Research-based instruction- research that involves the application of rigorous, systematic, and objective procedures to obtain reliable and valid knowledge relevant to education activities and programs (Zucker, 2004)

Rigor 
SREB- the expectation that students will be able to perform at levels of cognitive complexity necessary for proficiency at each grade level, and readiness for postsecondary education and the workplace (including advanced training) (SREB, 2000)

Strong, Silver, \& Perini- the goal of helping ALL students develop the capacity to understand content that is complex, ambiguous, provocative, and personally or emotionally challenging (Strong, Silver, \& Perini, 2001)

Barbara Blackburn- creating an environment in which each student is expected to learn at high levels, each student is supported so he or she can learn at high levels, and each student demonstrates learning at high levels (Blackburn, 2013)

Situational poverty- poverty caused by an event (Payne, 2005)

Standards-based- systems of instruction, assessment, grading, and academic reporting based on students demonstrating mastery of the knowledge and skills they are expected to learn as they progress through their education. (Great Schools Partnership, https://www.edglossary.org/standards-based/)

Teacher-centered instruction- a teaching style that places the focus of teaching on teacher actions with students being recipients of knowledge

Through Course Tasks- periodic, common, formative assessments given at least twice annually and part of a comprehensive system of assessment in science in Kentucky.

Transition readiness- the attainment of the necessary knowledge, skills and dispositions for a student to successfully transition to the next level of his or her educational career" (KDE, 2018).

Webb's Depth of Knowledge- employed to analyze the cognitive expectation demanded by standards, curricular activities and assessment tasks (Webb, 2002)

Level 1- recall: ability to recall facts

Level 2- application: conceptual knowledge, or the ability to put facts into context Level 3- strategic thinking: employing strategic thinking through the use of reasoning or decision making

Level 4- create: using extended thinking to synthesize information or apply it to realworld applications 


\section{CURRICULUM VITA}

NAME: $\quad$ Roland Lawrence O’Daniel

ADDRESS: 3209 Chickadee Road

Louisville, KY 40213

DOB: $\quad$ Louisville, KY - August 5, 1965

EDUCATION \& TRAINING:

BA, Mathematics and History

University of Louisville, Louisville KY

$1983-1989$

M.A.T., Teaching, Secondary Education with Middle School Endorsement Spalding University, Louisville KY

$1992-1997$

Ph.D., Curriculum and Instruction

University of Louisville, Louisville KY

2005-2018

AWARDS: Mathematics Education Service and Achievement Award, Kentucky Council of Teachers of Mathematics

2013

Leonard E. Gibbs Award, Campbell Collaboration

Awarded for "rigorous systematic reviews that can inform social work policy welfare and practice."

2013

AEGON Teacher Award

2005

Kentucky Middle Grades Mathematics Teachers Network

Grant for Mathematics Professional Development 1995

PROFESSIONAL SOCIETIES:

National Council of Teachers of Mathematics 
Association for Supervision and Curriculum Development

American Educational Research Association

PUBLICATIONS:

Gear up Kentucky 3.0 Guidance document: Eliminating tracking andability grouping. Louisville, KY: CTL. 2013

Co-Author, "Systematic Review: Cognitive-behavioural interventions for children who have been sexually abused" CDPLPG 2011

Research Committee Issue Brief: Quality and Effectiveness in K-12 Online Learning, NACOL 2010

\section{NATIONAL MEETING PRESENTATIONS:}

"GEAR UP Kentucky: Using Data-Driven Decision Making to Align School Improvement Services with Classroom Walkthrough Data" NCCEP National Conference 2015

"Creating College Ready Graduates: Sustainability Summit" GEAR UP West Conference 2014

"GEAR UP Kentucky: School Improvement Services for Supporting Leadership" GEAR UP West Conference 2014

"An Evaluation of a Hybrid Online Instructional Program for Algebra 1" National Council of Teachers of Mathematics 2011

"Developing a Social Media Presence for ISTE SIGs" ISTE Leadership Development Institute 2011

"So You're a Literacy Coach; How about the Math Department?" International Reading Association Conference 2008 